UNIVERSIDADE DE SÃO PAULO

ESCOLA DE ENFERMAGEM DE RIBEIRÃO PRETO

PROGRAMA INTERUNIDADES DE DOUTORAMENTO EM ENFERMAGEM

\title{
Toxicidade ao tratamento quimioterápico em mulheres com câncer de mama
}

Thais de Oliveira Gozzo

Ribeirão Preto

2008 


\section{Toxicidade ao tratamento quimioterápico em mulheres com câncer de mama}

Tese apresentada ao Programa
Interunidades de Doutoramento em
Enfermagem da Escola de Enfermagem e
Escola de Enfermagem de Ribeirão Preto
da Universidade de São Paulo para
obtenção do título de Doutor em
Enfermagem

Área de concentração: Enfermagem

Linha de Pesquisa: Sociedade, Saúde e Enfermagem

Orientadora: Profa. Dra. Ana Maria de Almeida

Ribeirão Preto 


\section{FICHA CATALOGRÁFICA}

Gozzo, Thais de Oliveira

Toxicidade ao tratamento quimioterápico em mulheres com câncer de mama. Ribeirão Preto, 2008.

113 p. il. ; $30 \mathrm{~cm}$.

Tese de Doutorado apresentada à Escola de Enfermagem de Ribeirão Preto/USP Programa Interunidades de Doutoramento em Enfermagem.

Área de Concentração - Enfermagem.

Orientadora: Almeida, Ana Maria

1. Enfermagem. 2. Neoplasias mamárias. 3. Protocolo de quimioterapia combinada antineoplásica. 4. Efeitos adversos. 


\section{FOLHA DE APROVAÇÃO}

\section{Thais de Oliveira Gozzo}

Toxicidade ao tratamento quimioterápico em mulheres com câncer de mama.

Tese apresentada ao Programa Interunidades de Doutoramento em Enfermagem da Escola de Enfermagem e Escola de Enfermagem de Ribeirão Preto da Universidade de São Paulo para obtenção do título de Doutor em Enfermagem

Área de Concentração: Enfermagem

Aprovada em de 2008

\section{BANCA EXAMINADORA}

Prof. Dr. :

Instituição:

Assinatura:

Prof. Dr. :

Instituição:

Assinatura:

Prof. Dr. :

Instituição:

Assinatura:

Prof. Dr. :

Instituição:

Assinatura:

Prof. Dr. :

Instituição:

Assinatura: 
Dedico este trabalho a todas as mulheres, que com muita coragem recebem o diagnóstico, enfrentam as etapas do tratamento do câncer de mama. E apesar de tudo não desistem de sua luta, de seus sonhos e ainda conseguem nos ensinar tanto... 


\section{AGRADECIMENTOS}

Aos meus pais, Edson e Tereza, por estarem sempre presentes na minha vida e que nunca deixaram de acreditar em mim.

Aos meus irmãos, Letícia e Diego, esta é mais uma etapa que passamos juntos.

À minhas amigas Lizandra Ohata, Elizabeth Barichelo e Simone Optz, pela amizade, paciência, pela compreensão e com minha ausência durante este estudo.

Ao Prof. Dr. Helio Carrara e Profa. Dra. Marislei Panobianco, pela amizade e pelo incentivo constante na realização deste estudo.

À Profa. Dra. Gelici Perdoná e Lucilia, pela cuidadosa análise estatística dos dados deste estudo.

À Rita Barbieri, pela compreensão, incentivo e muita ajuda em conciliar o trabalho no hospital com a realização deste estudo.

As funcionárias e colegas de trabalho na Enfermaria de Ginecologia e Obstetrícia, pelo incentivo e pelas palavras amigas nas horas difíceis.

Às "meninas" do Balcão Verde Claro pela paciência e auxilio durante a realização deste trabalho, principalmente na coleta de dados. Vocês me ajudaram muito...

A Sra. Vera do Arquivo semi-ativo e os funcionários do SAME, pela disponibilidade e presteza durante a coleta dos dados deste estudo.

Agradecer por cada sorriso e cada lágrima, afinal fazem parte desta jornada.

Gostaria de agradecer especialmente à $\operatorname{Prof}^{\mathrm{a}} \operatorname{Dr}^{\mathrm{a}}$ Ana Maria de Almeida, por sua orientação, pela paciência, pelo incentivo na realização deste trabalho.

Meu muito obrigado! 


\section{SUMÁRIO}

\section{LISTA DE FIGURAS}

LISTA DE TABELAS

LISTA DE TURAS

RESUMO

ABSTRACT

RESUMÉN

\section{I . INTRODUÇÃO}

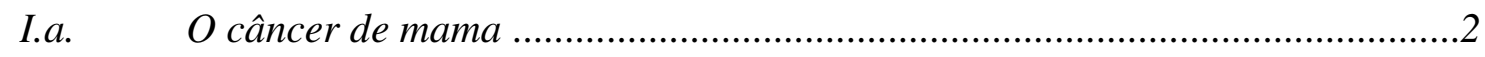

I.b. O tratamento para o câncer de mama....................................................................

I.c. A quimioterapia e o câncer de mama.....................................................................

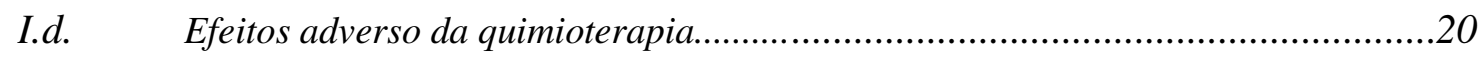

\section{II . PROCEDIMENTOS METODOLÓGICOS}

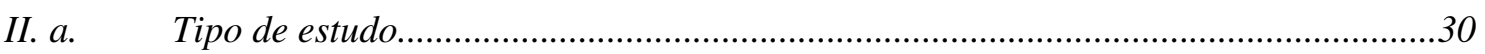

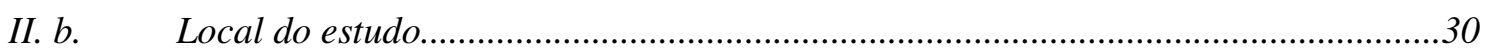

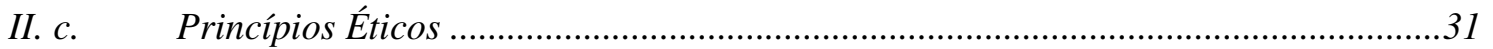

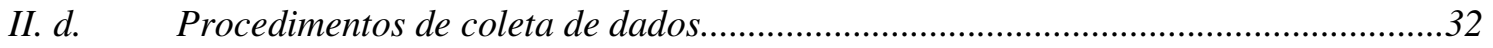

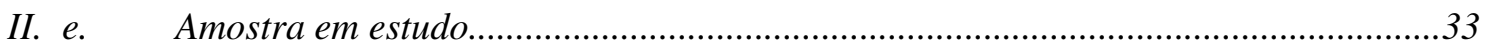

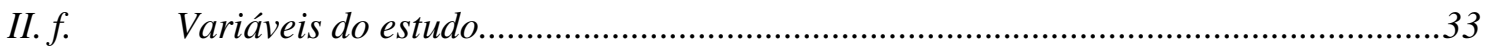

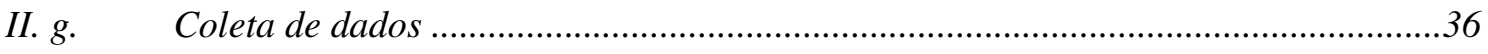

II. g. 1 Instrumentos para a coleta de dados..................................................36

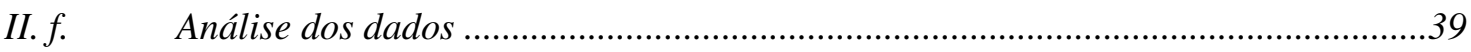

\section{III . RESULTADOS E DISCUSSÃO}

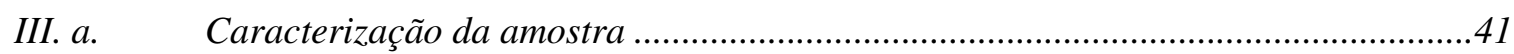

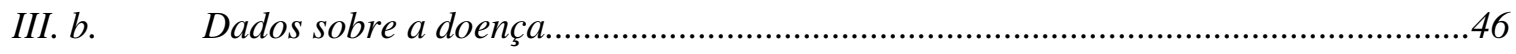

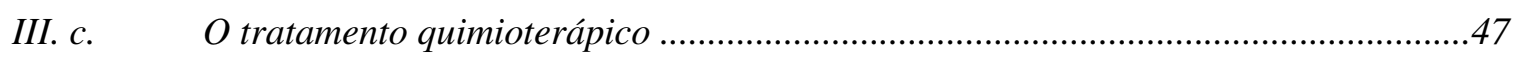

III. d. Complicações e intercorrências durante o tratamento para câncer de

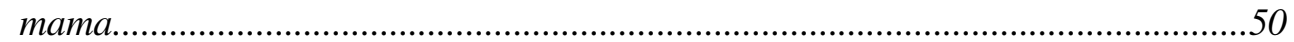

III.d.1. Hospitalizações durante o tratamento quimioterápico..................................50

III.d.2. Complicações e intercorrências no pós- operatório.......................................51

III.d.3. Complicações e intercorrências nos ciclos de quimioterapia......................53

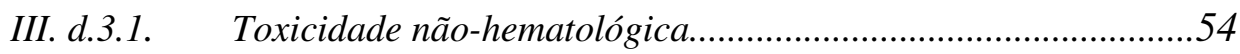

III. d. 3.2. Toxicidade hematológica...........................................................60 
III.d.3.2.1. Neutropenia...........................................................61

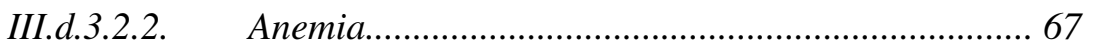

III.d.3.2.3. $\quad$ Atrasos e reduções de dose.........................................71

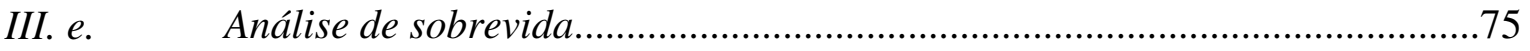

III. e. $1 . \quad$ Tempo total de tratamento..................................................................75

III. e. 2. Análise de sobrevida das mulheres acometidas pelo câncer de

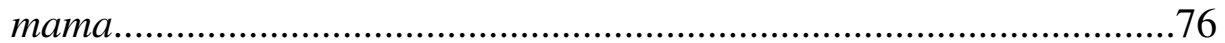

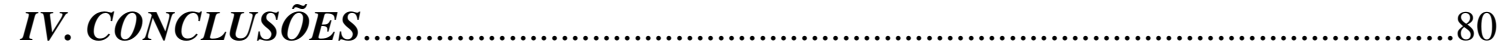

V. REFERÊ

\section{ANEXOS}

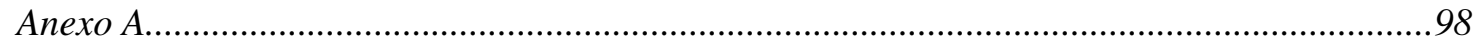

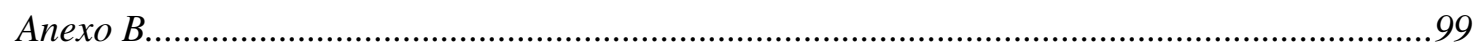

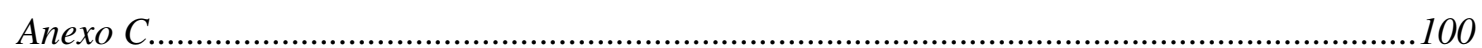

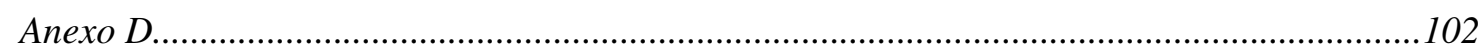

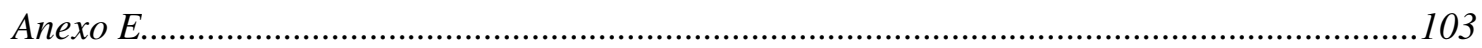

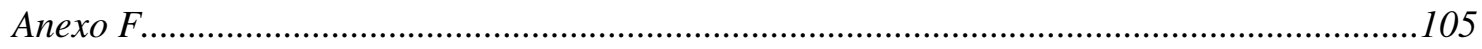

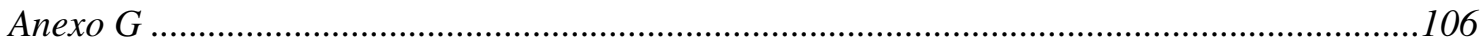

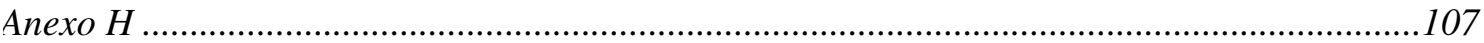

\section{APÊNDICES}

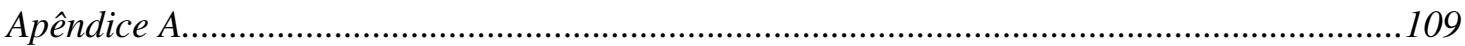

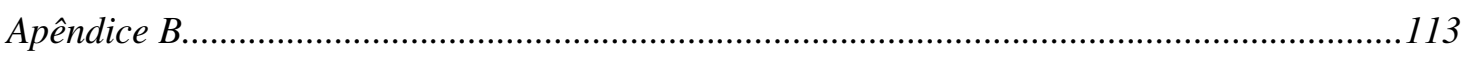




\section{LISTA DE FIGURAS}

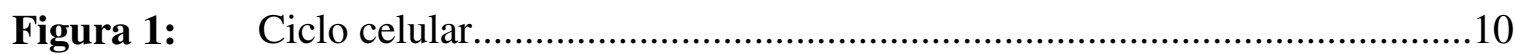

Figura 2: Curva de crescimento gompertziano dos tumores....................................11

Figura 3: Distribuição das mulheres submetidas à quimioterapia para câncer de mama, segundo o tipo de cirurgia. Ribeirão Preto, 2008.

Figura 4: Distribuição das mulheres submetidas à quimioterapia para câncer de mama segundo a superfície corporal e dosagem de docetaxel para o tratamento neoadjuvante. Ribeirão Preto, 2008.

Figura 5: Distribuição das mulheres submetidas à quimioterapia para câncer de mama segundo a superfície corporal e dosagem de epirrubicina para o tratamento neoadjuvante. Ribeirão Preto, 2008 47

Figura 6: Distribuição das mulheres submetidas à quimioterapia para câncer de mama segundo a superfície corporal e dosagem de epirrubicina para o tratamento adjuvante. Ribeirão Preto, 2008. .48

Figura 7: Distribuição das mulheres submetidas à quimioterapia para câncer de mama segundo a superfície corporal e dosagem de ciclofosfamida para o tratamento adjuvante. Ribeirão Preto, 2008. .48

Figura 8: Distribuição das mulheres submetidas à quimioterapia para câncer de mama, segundo o período do tratamento e o número de ciclos. Ribeirão Preto, 2008.

Figura 9: Distribuição da freqüência de toxicidade não-hematológica nas mulheres submetidas à quimioterapia neoadjuvante, Ribeirão Preto, 2008.

Figura 10: Distribuição da frequiência de toxicidade não-hematológica nas mulheres submetidas à quimioterapia adjuvante, Ribeirão Preto, 2008 .56

Figura 11: Distribuição da freqüência de toxicidade hematológica nas mulheres submetidas à quimioterapia neoadjuvante, Ribeirão Preto, 2008.

Figura 12: Distribuição da frequiência de toxicidade hematológica nas mulheres submetidas à quimioterapia adjuvante, Ribeirão Preto, 2008 .61

Figura 13: Tempo de tratamento das mulheres submetidas à quimioterapia para câncer de mama que apresentaram ou não neutropenia. Ribeirão Preto, 2008.......76

Figura 14: Tempo de sobrevida das mulheres submetidas à quimioterapia para câncer de mama que apresentaram ou não neutropenia. Ribeirão Preto, 200........77 


\section{LISTA DE TABELAS}

Tabela 1: Distribuição das mulheres submetidas à quimioterapia para câncer de mama, segundo idade, cor, lateralidade do tumor e status menopausal. Ribeirão Preto, 2008 $(\mathrm{N}=72)$.

Tabela 2: $\quad$ Distribuição das mulheres submetidas à quimioterapia para câncer de mama, segundo o tipo de neoplasia, biópsia e estádio da doença. Ribeirão Preto, 2008 $(\mathrm{N}=72)$..

Tabela 3: Distribuição das mulheres submetidas à quimioterapia para câncer de mama, segundo o tipo de cirurgia. Ribeirão Preto, 2008 (N=72).

Tabela 4: Distribuição das mulheres submetidas à quimioterapia para câncer de mama, segundo o tempo de tratamento. Ribeirão Preto, 2008 (N=72)......

Tabela 5: Distribuição das mulheres submetidas à quimioterapia para câncer de mama, segundo o motivo da internação durante o tratamento. Ribeirão Preto, 2008 ( $\mathrm{N=22}$ )..................50

Tabela 6: Distribuição das mulheres submetidas à quimioterapia para câncer de mama, segundo o sítio de infecção durante a internação. Ribeirão Preto, 2008(N=22).

Tabela7: Distribuição das mulheres submetidas à quimioterapia para câncer de mama, segundo complicações e intercorrências cirúrgicas. Ribeirão Preto, 2008 ( N=20).......................52

Tabela 8: Distribuição das mulheres submetidas à quimioterapia para câncer de mama, segundo intercorrências entre os ciclos. Ribeirão Preto, 2008 (558)...

Tabela 9: Distribuição das mulheres submetidas à quimioterapia para câncer de mama, segundo o motivo do atraso entre os ciclos. Ribeirão Preto, 2008 .54

Tabela 10: Distribuição da frequiência de toxicidade não-hematológica nas mulheres submetidas à quimioterapia, Ribeirão Preto, 2008 (153)

Tabela 11: Distribuição das mulheres submetidas à quimioterapia para câncer de mama, segundo a ocorrência de extravasamento. Ribeirão Preto, 2008 (109).

Tabela 12: Distribuição das mulheres submetidas à quimioterapia para câncer de mama, segundo a aplicação do protocolo de extravasamento. Ribeirão Preto, 2008 (20). .59

Tabela 13: Estatística descritiva da variável idade entre as mulheres que apresentaram ou não neutropenia durante a quimioterapia. Ribeirão Preto, 2008 (72).

Tabela 14: Estatísticas descritivas da variável GB entre as mulheres que apresentaram ou não neutropenia durante a quimioterapia neoadjuvante. Ribeirão Preto, 2008 (72)............65

Tabela 15: Estatísticas descritivas da variável GB entre as mulheres que apresentaram ou não neutropenia durante a quimioterapia adjuvante. Ribeirão Preto, 2008 (70). .66

Tabela 16: Estatísticas descritivas da variável HB entre as mulheres que apresentaram ou não neutropenia durante a quimioterapia neoadjuvante. Ribeirão Preto, 2008 (72). 
Tabela 17: Estatísticas descritivas da variável HB entre as mulheres que apresentaram ou não neutropenia durante a quimioterapia adjuvante. Ribeirão Preto, 2008 (N=70).............70

Tabela 18: Estatísticas descritivas da variável tempo de atraso entre os ciclos, para as mulheres que apresentaram ou não neutropenia durante a quimioterapia neoadjuvante. Ribeirão

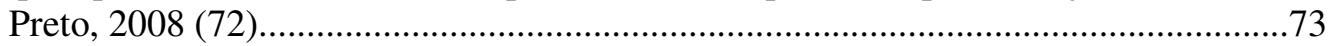

Tabela 19: Estatísticas descritivas da variável tempo de atraso entre os ciclos, para as mulheres que apresentaram ou não neutropenia durante a quimioterapia adjuvante. Ribeirão

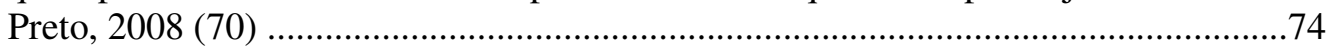

Tabela 20: Impacto do atraso entre os ciclos na dose total planejada de

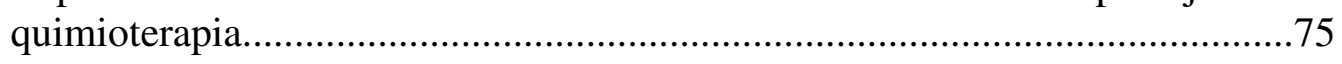


LISTA DE ABREVIATURAS

INCA Instituto Nacional do Câncer

MS

Ministério da Saúde

NSABP

National Surgical Adjuvant Breast and Bowel Project

$\mathrm{AC}$

Doxorrubicina e Ciclofosfamida

FAC

5-fluorouracil, Doxorrubicina e Ciclofosfamida

FEC

5-fluorouracil, Epirrubicina e Ciclofosfamida

$\mathrm{CMF}$

Ciclofosfamida, Metotrexate e 5-fluorouracil

TC

Docetaxel e Ciclofosfamida

EC

Epirrubicina e Ciclofosfamida

HCFMRP-USP Hospital das Clínicas da Faculdade de Medicina de Ribeirão Preto

da Universidade de São Paulo

GB

Glóbulos Brancos

HB

Hemoglobina

SAE

Evento Adverso Sério 


\section{ERRATA}

Página 47, primeiro parágrafo: onde se lê (...) de 100 a $140 \mathrm{mg}$ para ciclofosfamida (CICLO), lê-se (...) de 800 a 1100mg para para ciclofosfamida (CICLO).

Página 53, Tabela 8: onde se lê Número de hospitalizações para Neoadjuvante 14, lê-se 13.

Página 73, segundo parágrafo: onde se lê Entre as mulheres que não apresentaram (...) tempo médio de atraso entre os ciclos um a quatro vario de 4,4 a 14,5 (...) com duração de 28 dias, lê-se Entre as mulheres que apresentaram (...) tempo médio de atraso entre os ciclos um a quatro vario de 6,0 a 14 (...) com duração de 67 dias. 


\section{RESUMO}

GOZZO, T.O. Toxicidade ao tratamento quimioterápico em mulheres com câncer

de mama. 2008. 113 p. Tese (Doutorado)- Escola de Enfermagem de Ribeirão Preto da Universidade de São Paulo, Ribeirão Preto, 2008

Foi realizado um estudo retrospectivo, por meio da revisão de 72 prontuários de mulheres com diagnóstico de câncer de mama, submetidas ao tratamento quimioterápico neoadjuvante com epirrubicina e docetaxel e no adjuvante, epirrubicina e ciclofosfamida. Os prontuários revisados foram de mulheres na faixa de 30 a 60 , acompanhadas no Ambulatório de Mastologia do Departamento de Ginecologia e Obstetrícia do Hospital das Clínicas da Faculdade de Medicina de Ribeirão Preto da Universidade de São Paulo (HCFMRP-USP) e que receberam o tratamento quimioterápico entre os anos de 2003 e 2006. Resultados: As participantes foram divididas em dois grupos, sendo um das 31 mulheres que apresentaram neutropenia e o outro das 41 que não apresentaram. A média de idade das participantes foi de 47,8 anos. Entre as toxicidades gastrointestinais durante a neoadjuvância e a adjuvância observouse a mucosite $(8,4 \%$ e $2 \%)$, náusea $(18,6 \%$ e $18 \%)$ e vômito $(3,3 \%$ e $18 \%)$. Outra intercorrência observada foi o extravasamento durante o tratamento quimioterápico que ocorreu em $17(23,6 \%)$ mulheres. Observou-se que 43\% das mulheres apresentaram neutropenia, que analisadas entre os ciclos de quimioterapia foram estatisticamente significantes para os ciclos dois e três da neoadjuvância com valores de $\mathrm{p}$ de 0,0016 e 0,0009 respectivamente, para os ciclos dois e três da adjuvância com valores de p de 0.0014 e 0.0030 respectivamente, para o final do tratamento neoadjuvante, anterior ao tratamento cirúrgico sendo o $\mathrm{p}$-valor $=<0.0001$ e para o final do tratamento adjuvante, com p-valor $=<0.0004$. Quanto à ocorrência de anemia, esta não esteve relacionada com a presença ou não de neutropenia, entretanto observou-se que houve uma queda nos valores de HB durante a neoadjuvância, com ligeira recuperação no período de adjuvância, porém, não houve recuperação aos valores médios anteriores ao tratamento quimioterápico. A redução da dose foi utilizada para seis mulheres em decorrência da toxicidade hematológica. Registrou-se 152 atrasos entre os ciclos de quimioterapia. Realizado o teste do Log-Rank para o tempo de tratamento e de sobrevida, concluiu-se que esta foi igual para os dois grupos de mulheres. Conclusão: Por meio dos resultados deste estudo demonstra-se a necessidade de elaboração e implementação de protocolos de cuidados de enfermagem para pacientes oncológicos com a finalidade de avaliação dos eventos adversos e manejo mais adequado dos mesmos.

Palavras-chave: Enfermagem. Neoplasias mamárias. Protocolos de Quimioterapia Combinada Antineoplásica. Efeitos adversos. 


\section{ABSTRACT \\ GOZZO, T.O. Toxicity to chemotherapy treatment in women with breast cancer.}

2008. 113 p. Thesis (Doctoral) - School of Nursing of Ribeirão Preto of the University of São Paulo, Ribeirão Preto, 2008

Method: Thais study data were collected retrospectively reviewing the chart of 72 women with breast cancer, underwent to chemotherapy for the first time, that used epirubicin and docetaxel to neoadjuvant treatment and epirubicin and ciclophosphamid to adjuvant treatment. The data collection was done with the charts of women, with 30 to 60 years, treated in 2003 to 2006 in followed in the onco-gynecology and mastology sector- Gynecology and Obstetric Department of the University of São Paulo at Ribeirão Preto Medical School Hospital das Clínicas. Results: The participants had been divided in two groups, one with 31 women who had presented neutropenia and the other with 41 that had not presented. The average of age of the participants was of 47,8 years. The gastrointestinal toxicities during the neoadjuvant and adjuvant treatment observed mucositis (8.4\% and $2 \%$ ), nausea (18.6\% and $18 \%$ ) and vomiting $(3.3 \%$ and $18 \%)$. Another observed toxicity was the extravasation during the chemotherapy treatment that occurred in $17(23.6 \%)$ women. Was observed that $43 \%$ of the women had respectively presented neutropenia, who analyzed between the chemotherapy cycles had been statistical significant for cycles two and three of the neoadjuvant with values of $p=0,0016$ and 0,0009 respectively, for cycles two and three of the adjuvant with values of $p=0.0014$ and 0.0030 . And for the end of the neoadjuvant treatment, previous treatment to the surgical treatment being $\mathrm{p}$-valor $=<0,0001$ and for the end of the adjuvant treatment, with $p$-valor $=<0.0004$. To anemia occurrence, this was not related with the presence or not of neutropenia, however it was observed that had a fall in the values of HB during the neoadjuvant, with fast recovery in the period of adjuvant. However, did not have recovery to previous the average values to the chemoterapy treatment. The reduction of the dose was used for six women in result of the hematologic toxicity. Was registered 152 doses delays between the chemotherapy cycles. The Log-Rank test for the time of treatment and survival, concluded that was equal for both groups. Conclusion: Through the results of this study demonstrates the necessity of develop and implement protocols for nursing care to women with breast cancer in order to assess the adverse events and most appropriate management of them.

Key word: Nursing. Neoplasias mammary. Antineoplastic combined chemotherapy protocols. Adverse effects 


\section{RESUMEN}

GOZZO, T.O. Toxicidad por tratamiento quimioterápico en mujeres con cáncer

de mama. 2008. 113 p. Tesis (Doctorado)- Escuela de Enfermería de Ribeirão Preto de la Universidad de São Paulo, Ribeirão Preto, 2008

Método: fue realizado un estudio retrospectivo, por medio del análisis de historias clínicas de mujeres con diagnóstico de cáncer de mama, sometidas a quimioterapia neoadyuvante con epirrubicina y docetaxel y no adyuvante, epirrubicina y ciclofosfamida. Las historias clínicas analizadas correspondieron a mujeres entre $30 \mathrm{y}$ 60 años de edad, que recibían atención en el Consultorio de Mastología del departamento de Ginecología y Obstetricia del Hospital de las Clínicas de la Facultad de Medicina de Ribeirão Preto de la Universidad de São Paulo (HCFMRP-USP) y que recibieron tratamiento quimioterápico entre los años 2003 y 2006. Resultados: Las participantes fueron divididas en dos grupos: un formado por 31 mujeres que presentaron neutropenia y otro por 41 mujeres que no presentaron neutropenia. La media de edad de las participantes fue de 47,8 años de edad. Entre la toxicidad gastrointestinal durante la quimioterapia neoadyuvante y adyuvante se observó mucositis $(8,4 \%$ y $2 \%)$, náusea $(18,6 \%$ y $18 \%)$, vómito $(3,3 \%$ y $18 \%)$. Otra intercurrencia observada fue el extravasamiento durante el tratamiento de quimioterapia que ocurrió en $17(23,6 \%)$ mujeres. Se observó que $43 \%$ de las mujeres presentaron neutropenia, cujas análisis entre los ciclos de quimioterapia fueron estadísticamente significantes para los ciclos dos y tres de la quimioterapia neoadyuvante con valores de p: 0,0016 y 0,0009 , respectivamente, para el final del tratamiento de quimioterapia neoadyuvante, anterior al tratamiento quirúrgico correspondiendo a $\mathrm{p}<0,001$ y $\mathrm{p}<0,0004$ para el final del tratamiento de quimioterapia adyuvante. En relación a la ocurrencia de anemia, esa no estuvo relacionada con la presencia o no de neutropenia, pero se observó un disminución de HB durante la quimiterapia neoadyuvante, con la recuperación rápida con ligera recuperación en el periodo de quimioterapia adyuvante, pero no hubo recuperación de los valores medios anteriores al tratamiento quimioterápico. La reducción de la dosis fue utilizada para seis mujeres en consecuencia de la toxicidad hematológica. Se registraron 152 retrasos en los ciclos de quimioterapia y fue realizado el test de Log_Rank par el tiempo de sobrevida, se concluye que esta fue igual para los dos grupos mujeres. Conclusión: Por medio de los resultados del estudio se identifica la necesidad de elaboración y aplicación de protocolos de cuidados de enfermería para pacientes oncológicos con la finalidad de evaluar los eventos adversos e identificar el manejo más adecuado de los mismos.

Palabras-clave: Enfermaría. Neoplasias de la mama. Protocolos de Quimioterapia Combinada. Antineoplásica. Efectos adversos. 


\section{INTRODUÇÃO}

\section{I. a. O câncer de mama}

Os tumores malignos determinam altas taxas de morbimortalidade, afetando pessoas de todas as idades e em diferentes proporções. A mortalidade por estes tumores varia muito entre os países e eleva-se gradualmente, à medida que a industrialização e o controle de doenças infecto- parasitárias aumentam (MICHELONI, 2002).

Apesar de o câncer ser conhecido há muitos séculos, somente nas últimas décadas do século passado configurou-se como evidente problema de saúde pública mundial, pois a sua prevalência tem aumentado no contexto das doenças crônicas nãotransmissíveis. Diversos fatores têm contribuído para o aumento da incidência de câncer na população, como: o intenso processo de urbanização, além de avanços tecnológicos no setor da saúde, ações de promoção e recuperação da saúde que proporcionaram aumento na longevidade da população (CARVALHO, 2003; BRASIL, 2007).

No Brasil, a previsão do Instituto Nacional do Câncer (INCA) para os anos de 2008 e 2009, é de 466.730 casos novos de câncer, sendo 231.860 para o sexo masculino e 234.870 para o sexo feminino (BRASIL, 2007).

Para as mulheres brasileiras, as neoplasias malignas da mama continuam sendo o tumor mais incidente, quando não considerado os tumores de pele não melanoma. $\mathrm{O}$ número de casos novos estimados, para 2008, é de 49.400, com risco de 51 casos para cada 100.000 mulheres no Brasil e considerando a região sudeste este risco aumenta para 68 casos para cada 100.000 mulheres (BRASIL, 2007).

As causas do câncer de mama permanecem desconhecidas até hoje, e não se dispõe ainda medidas específicas de prevenção primária a serem aplicadas à população. Entretanto estudos epidemiológicos e pesquisas básicas têm identificado diversas condições que, predispõe à mulher ao câncer de mama. À medida que estudos sobre fatores de risco são desenvolvidos, observa-se que um maior número de fatores estão associados ao aumento da incidência desta neoplasia. Entre os fatores de risco estudados destacam-se: as mulheres de melhor nível socioeconômico e elevada escolaridade, que em geral apresentam idade mais tardia da primeira gestação e menor número de filhos, além de menarca precoce e menopausa tardia, nuliparidade, uso de anticoncepcionais orais, terapia de reposição hormonal, idade (as taxas de incidência aumentam 
rapidamente até os 50 anos) e mutações nos genes BRCA1 e BRCA2 (PINOTTI; BRENELLI, 1991; TESSARO; BREZOLIN, 2006; BRASIL, 2007).

Além destes, aspectos relacionados ao ambiente têm sido investigados como fatores promotores do câncer de mama, dentre os quais podemos citar o tabagismo, o alcoolismo, a obesidade e o sedentarismo (ALMEIDA, 1997; BRASIL, 2004; TESSARO; BREZOLIN, 2006).

Assim, o câncer de mama tem sua importância fundada em diversos fatores: alta incidência, elevado índice de mortalidade e dificuldade de um diagnóstico precoce, e apesar dos avanços sobre diagnóstico e tratamento, ocorridos nos últimos anos, ainda não é possível o reconhecimento de lesões precursoras do carcinoma, como nos casos do câncer de colo de útero, endométrio e vulva (HEGG, 2000).

Estratégias de prevenção primária para este tipo de neoplasia ainda tem se mostrado como um desafio, pois os fatores de risco são variados e ainda existem as características genéticas do tumor. Na falta de estratégias de prevenção primária, atenção especial tem sido dada àquelas relacionadas à prevenção secundária, priorizando ações que visem à detecção precoce quando a eficácia do tratamento já é reconhecida. O Ministério da Saúde (MS) recomenda o exame de mamografia pelo menos a cada dois anos para mulheres na faixa etária de 50 a 69 anos e o exame clínico das mamas deve ser realizado em toda mulher que procura o serviço de saúde, independente da idade, como parte do atendimento à saúde da mulher. O MS recomenda ainda, exame clínico das mamas e mamografia anuais para mulheres a partir dos 35 anos consideradas de risco elevado, isto é, mulheres com história familiar de câncer de mama em parentes de primeiro grau (BRASIL, 2004a; BRASIL, 2007).

A descoberta de um nódulo palpável de mama gera muita ansiedade na vida da mulher. Entretanto $80 \%$ de todos os nódulos de mama são benignos, não aumentando o risco para desenvolver câncer de mama. Em geral a descoberta acontece pela própria mulher por meio do auto-exame, uma modalidade de avaliação que deve ser estimulada e associada às medidas de prevenção secundárias. Não existem dados que demonstrem que a prática do auto-exame diminua a mortalidade por câncer de mama, porém as mulheres que o realizam regularmente detectam tumores menores, tem menos comprometimento axilar e mais freqüentemente são submetidas a cirurgias conservadoras (MENKE et al., 1999). 
O diagnóstico precoce do câncer de mama influencia diretamente no tratamento e na cura. A mamografia, associada ao exame físico, são responsáveis por mais de $40 \%$ da detecção do câncer de mama em estádio inicial. A combinação destes, com biópsia, têm sido a melhor alternativa para diagnóstico e planejamento do tratamento (BOFF; RUARO; SCHUH, 2006).

A anatomia patológica e a citopatologia estão cada vez mais integradas na prática da Mastologia, proporcionando, além do diagnóstico, as diretrizes para o acompanhamento e tratamento de pacientes com doenças de mama, em especial o câncer (COELHO; COELHO, 2006).

O material utilizado para as análises anatomo-histopatológicas, pode ser obtido por meio de diferentes tipos de biópsias, como:

- Biópsia por punção aspirativa (PBA) - em que se obtém um aspirado para exame citológico das lesões mamárias. Em muitos estudos, a sensibilidade dos resultados variou de 68 a $100 \%$ e o índice de material insuficiente de 2 a $36 \%$;

- Biópsia por agulha grossa (Tru-cut) - tem a vantagem de reduzir o número de amostras inadequadas, de permitir avaliação estrutural da lesão e promover diagnóstico específico. Também garante material para pesquisa de marcadores hormonais;

- Biópsia cirúrgica - são as biópsias incisionais, que atualmente são menos utilizadas, sendo indicadas quando o tumor é de fácil acesso e/ou há necessidade de documentação histopatológica prévia à quimioterapia neoadjuvante, (SOUZA; SHIOZAWA; BRUSA, 2005; DE CARLI, 2006).

O exame histopatológico das células comprometidas possibilita uma melhor compreensão da progressão da doença, e desta forma, os tumores podem ser classificados segundo o tipo histológico.

Vários subtipos histológicos de câncer de mama podem ser identificados: carcinoma ductal e lobular in situ ou invasor, Doença de Paget, tumor phyllodes, sarcomas e linfomas, tanto de mama, quanto de mamilo. Dentre os carcinomas de mama mais comuns, está o carcinoma ductal invasor, também chamado de carcinoma ductal 
infiltrante, que perfaz um total de $50-80 \%$ de todos os tipos de câncer de mama (RILKE; DI PALMA, 1998; PEREZ-MESA, 1995).

O carcimona inflamatório é pouco freqüente, diagnosticado de 2 a $4 \%$ dos casos, entretanto apresenta um prognóstico sombrio independente do tratamento (MENKE et al., 1999).

Após a confirmação do diagnóstico, o tumor é estadiado, ou seja, classificado de acordo com a extensão da doença. O estadiamento clínico proporciona esta avaliação, pois procura situar a mulher em grupos de evolução e prognóstico compatíveis. Além disto, este procedimento auxilia a equipe de saúde a indicar o melhor tratamento disponível para aquele tipo de tumor, oferecer um prognóstico e ainda permitir comparação dos resultados (MENKE et al., 1999).

O estadiamento clínico procura determinar a extensão local da doença, o estado da axila, o estado da mama oposta e a existência de metástases à distância. A classificação mais utilizada é o sistema TNM, que avalia o tamanho do tumor, número de nódulos comprometidos e evidência de metástases distantes. O sistema TMN está apresentado no Anexo A e a descrição do estadiamento do câncer de mama no Anexo B, (INCA, 2004; MENKE et al., 1999).

\section{I. b. O tratamento para o câncer de mama}

Após a confirmação diagnóstica, com a definição do estadiamento, das características histológicas do tumor e de sua sensibilidade hormonal, o oncologista pode definir o melhor tratamento para o câncer. Além dos aspectos relacionados ao tumor, devem-se levar em consideração as condições clínicas da mulher. Este tratamento, em geral, além de complexo, é variado e muito sofisticado (SOUZA; AGUIAR; HEGG, 2000).

Os avanços obtidos na compreensão da doença, seja em termos de seu comportamento clínico ou quanto à patogênese molecular, traduziram-se em progressos importantes no âmbito do tratamento. Diversos estudos randomizados realizados nos últimos anos avaliaram esquemas quimioterápicos com diferentes drogas, tanto no préoperatório quanto no pós-operatório, comparando também a eficácia de cirurgias radicais com cirurgias mais conservadoras e o uso da radioterapia. Os resultados encontrados têm encorajado os especialistas em oncologia a elaborar estratégias 
multimodais de novos e complexos tratamentos (KAUFMANN et al., 2003; GOGAS; FOUNTZILAS, 2003; FISHER; MAMOUNAS, 1995; TRUDEAU; SINCLAIR; CLEMONS, 2005; BOUGHEY et al., 2006; DAWOOD et al., 2008; FISHER et al., 1997; HUTCHEON et al., 2003; BEAR et al., 2003; RASTOGI et al., 2008; ROCHÉ, et al., 2006; EBCTCG, 2005; PICCARD et al., 2001).

Os estudos têm colaborado para a cura de alguns tipos de tumores e aumentado a sobrevida para outros. Assim, para muitos indivíduos, o câncer passou de uma doença rapidamente fatal, a uma condição crônica, que requer meses, e às vezes anos de tratamento com terapias complexas e tóxicas. Como consequiência, clínicos e pesquisadores têm monitorado e avaliado os novos tratamentos quanto à eficácia das intervenções, em relação à quantidade e à qualidade de vida do doente (DANCEY et al., 1997; VELIKOVA; STARK; SELBY, 1999).

O tratamento do câncer de mama tem como objetivos principais: aumentar a sobrevida e se possível, a cura, o intervalo livre da doença, além de melhorar a qualidade de vida da mulher. A cirurgia e a radioterapia fazem o controle loco regional, que reduz o risco de recorrência do câncer na mama, e em alguns casos, podem prevenir a disseminação do câncer e até reduzir a mortalidade. $\mathrm{O}$ tratamento sistêmico é feito por meio da quimioterapia e da hormonioterapia, que visam à diminuição da recorrência sistêmica e da mortalidade por câncer de mama. Dessa forma, o tratamento ideal da doença deve abranger a combinação destas quatro modalidades terapêuticas (SHAPIRO; RECHT, 2000; SOUZA; AGUIAR; HEGG, 2000).

Estas modalidades de tratamento podem ser definidas, resumidamente, como:

- Cirurgia: tem por finalidade promover o controle local da doença e da sua disseminação venosa e linfática. Durante décadas as mulheres com câncer de mama, independente do estádio, foram submetidas a cirurgias radicais, como a mastectomia tipo Halsted. Os resultados de 20 anos de pesquisa publicados por Veronezi, na Itália, e Fisher, nos EUA, que avaliaram mulheres submetidas à mastectomia total comparando-as com as submetidas à cirurgia conservadora associada à radioterapia, confirmaram a segurança do tratamento loco regional conservador. Atualmente, a possibilidade de cirurgias mais conservadoras, como a tumorectomia e a quadrantectomia, ser empregada em substituição de mastectomias radicais, favorece os resultados estéticos, psicológicos e curativos. 
$\mathrm{Na}$ abordagem da axila também tem sido empregada técnicas menos radicais do que a linfonodectomia axilar como a utilização da técnica do linfonodo sentinela. Entretanto, a avaliação das mulheres a serem submetida à cirurgia deve ser criteriosa para definir, com mais precisão, a extensão local da doença e utilizar os critérios de seleção para o tratamento conservador. $\mathrm{Na}$ escolha do tratamento conservador é necessário observar as contra indicações como: necessidade de radioterapia local para todo tratamento conservador, doença multicêntrica conhecida, proporção entre o tamanho das mamas e do tumor, mamas volumosas, localização do tumor, e gestação (RICCI et al., 2003; MENKE et al., 2006; TIEZZI, 2007).

- Radioterapia é um tratamento loco-regional que utiliza radiação (raios-X, raios gama, elétrons, nêutrons, entre outros) para eliminar células tumorais. Seu emprego depende do tipo e do estádio do tumor a ser tratado, porém em geral, é administrada em toda mama ou onde esta se localizava antes da remoção (plastrão) e é aplicada por período e dosagem variados. É a essência do tratamento conservador, em que se estima que 75 a $80 \%$ das mulheres com câncer de mama são candidatas à cirurgia conservadora e radioterapia pósoperatória. A indicação da radioterapia é variada, pode ser utilizada como curativa, no controle loco-regional e no aumento da sobrevida, ou como paliativa, no alívio de sintomas e na melhora da qualidade de vida (MOTTA; OBST; MOTTA, 2006; BARLETTA, 2006).

- Hormonioterapia tem ação sistêmica, e sabe-se que metade dos tumores mamários tem dependência hormonal. Esta dependência é determinada pela dosagem dos receptores hormonais de estrógeno e progesterona. Entre as mulheres com receptores positivos utiliza-se o Tamoxifeno®, e seu uso nas mulheres em pré-menopausa pode ser visto como uma alternativa à ooforectomia (SOUZA; AGUIAR; HEGG, 2000; PINOTTI, 2000).

O tratamento quimioterápico será abordado detalhadamente a seguir.

Para a avaliação da resposta do tumor ao tratamento, existem duas medidas principais: a sobrevida e a redução tumoral. Estas medidas podem ser definidas como (KAUFMANN et al., 2003; BONASSA, 2005; MIEOG; VAN DER HEGE; VAN DE VELDE, 2007; DAWOOD et al., 2008): 
- Sobrevida: o principal objetivo do tratamento oncológico é favorecer que os indivíduos com câncer, sobrevivam ao máximo e com a mesma qualidade de vida, que teriam caso não estivessem doentes;

- Redução tumoral: é avaliação da resposta ao tratamento em curto prazo. A classificação é baseada na avaliação do tumor, e divide-se em:

○ Resposta clínica completa: não detecção de massa palpável ou por exames de imagem;

○ Resposta patológica completa: não detecção do carcinoma no exame histológico;

○ Resposta parcial: redução da área tumoral em pelo menos 50\%;

- Doença estável: sem alterações nas lesões mensuráveis, porém sem evidências de novas lesões;

○ Progressão da doença: aumento de pelo menos $25 \%$ da área tumoral.

\section{I. c. A quimioterapia e o câncer de mama}

Existem evidências do uso de agentes quimioterápicos já no século I d.C, quando Dioscorides utilizou a colchicina para tratamento de tumores iniciais. Os primeiros registros de tratamento quimioterápico datam do final do século XIX, com a descoberta da solução de Fowler (arsenito de potássio) por Lissauer em 1885 e da toxina de Coley (combinação de produtos bacterianos) em 1890. Durante a Segunda Guerra Mundial, foram identificadas substâncias citotóxicas, como o gás mostarda, que despertaram interesse de farmacologistas clínicos a serviço do Pentágono norteamericano, que o utilizaram em pacientes com linfoma de Hodking e leucemia crônica, obtendo regressão de curta duração (BONASSA, 2005; ALMEIDA, 2004).

Desde então, muitos compostos têm sido usados no tratamento do câncer. Atualmente são empregadas para o tratamento oncológico, cerca de 50 agentes quimioterápicos. Entretanto, pesquisadores estão sempre investigando, não somente com o intuito de descobrir novos compostos, mas principalmente, de planejar esquemas mais eficientes e com menor toxicidade dos compostos já conhecidos.

A quimioterapia antineoplásica, ou a utilização de agentes químicos, isolados ou em combinação, com o objetivo de tratar tumores malignos, tem sido uma das principais modalidades de tratamento para esta doença. Da mesma forma que as outras modalidades a quimioterapia têm como base, indicadores obtidos no estadiamento da 
doença. Um aspecto importante é a cinética tumoral que permite conhecer o processo de proliferação celular do tumor, determinando sua maior ou menor sensibilidade à terapêutica.

Os agentes antineoplásicos agem, sistemicamente, em nível celular, mais especificamente em células que estão em processo de divisão celular ativa, interferindo no processo de crescimento e divisão das células (SCHAFER, 1996; BONASSA, 2005).

Os agentes utilizados no tratamento do câncer em geral, afetam tanto as células normais quanto as neoplásicas, porém acarretam maiores danos a células malignas devido às diferenças quantitativas entre os processos metabólicos destes dois tipos celulares (ALMEIDA, 2004).

É sabido que a carcinogênese é um processo de múltiplas etapas. No núcleo celular encontram-se os genes, que irão participar do processo de divisão celular. Estes genes são compostos por moléculas de DNA (ácido dexorribonucleico) que especificam as seqüências de ligações dos aminoácidos para formarem uma determinada proteína, que é responsável por realizar determinado efeito biológico no gene (BRENNA; SYRJANEN, 2003).

Duas classes de genes são responsáveis pela proliferação celular descontrolada presentes nos tumores apresentados pelo homem. Estes genes em sua função normal coordenam o ciclo celular em toda sua sequiência de eventos, para que as células cresçam e se dividam (CHEN; HUNTER, 2005).

O ciclo celular, tanto para as células normais quanto para as células neoplásicas, é composto de quatro fases distintas, como descritas a seguir e visualizadas na Figura 1 (BRENNA; SYRJANEN, 2003):

- G1: a célula tem seu tamanho aumentado e prepara-se para replicar seu DNA;

- S: também chamada de síntese, fase em que ocorre a replicação do DNA, permitindo que a célula duplique seu material genético;

- G2: após a replicação, a célula se prepara para a próxima fase, a mitose $(\mathrm{M})$;

- M: fase em que a célula-mãe aumentada, se divide em duas célulasfilhas, com igual número de cromossomos e imediatamente estas duas células entram na fase G1 e podem reiniciar o ciclo celular. 


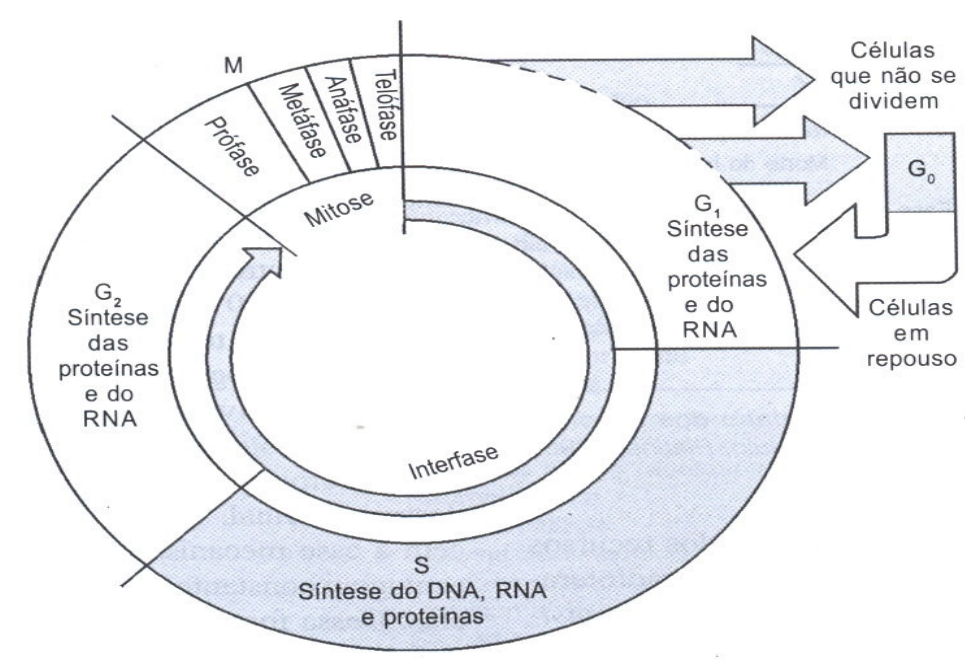

FIGURA 1: Ciclo celular. Fonte: Baquiram e Gallagher (1998) ${ }^{1}$

A diferença entre a divisão destes dois grupos de células está no fato das células normais se dividirem para suprir as necessidades do organismo, havendo um equilíbrio entre as células que nascem e as que morrem.

As células tumorais têm um crescimento acelerado e desordenado no início, seguido por uma fase, em que a aglomeração celular passa a sofrer com a falta de nutrientes e de espaço para continuar seu crescimento. Nessa fase, as células passam a produzir o fator de angiogenese tumoral. Este fator irá possibilitar a produção de novos vasos sanguíneos e assim as células terão novamente o suprimento para continuar seu crescimento, que mais uma vez será acelerado. Este padrão de crescimento obedece a uma curva de crescimento gompertziano (Figura 2), que se caracteriza pelo crescimento acelerado do volume tumoral em um curto período de tempo. À medida que o tumor aumenta de tamanho, a velocidade de crescimento diminui progressivamente (BONASSA, 2005).

\footnotetext{
${ }^{1}$ BAQUIRAN, D.C; GALLAGHER, J. Cancer chemotherapy handbook. $1^{\text {st }}$ ed. Lippicott (1998).
} 


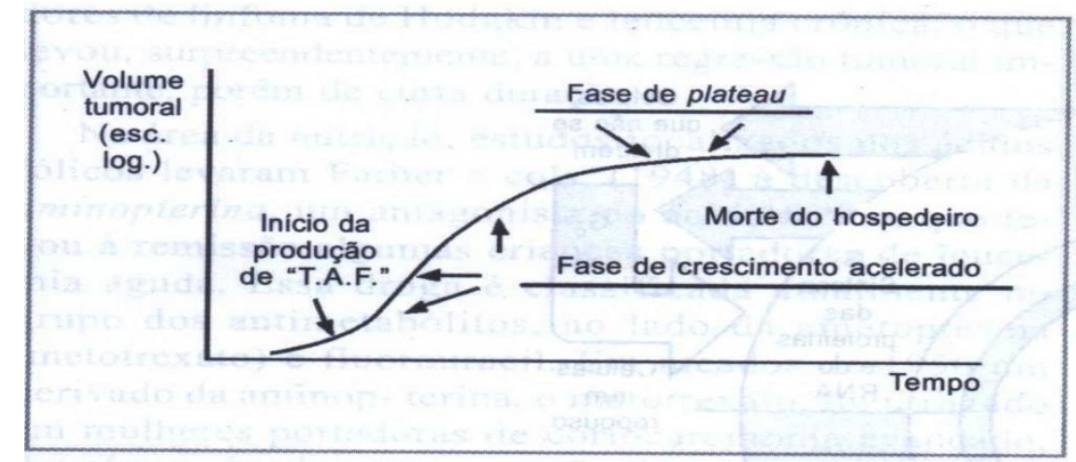

Figura 2: Curva de crescimento gompertziano dos tumores. Fonte: Srougi e Simon (1990) ${ }^{2}$

Os chamados proto-oncogênese são os estimuladores deste processo de divisão celular, enquanto que os genes supressores inibem este processo. Quando ocorrem mutações em um gene que podem levar a alterações na célula quanto à quantidade de proteínas ou sua atividade normal, esta situação pode inativar os genes supressores e estes passarão a contribuir com o desenvolvimento do câncer, pois a célula está sem os controles fundamentais para a inibição de um crescimento rápido e inapropriado. As mutações também podem levar os proto-oncogênes a tornarem-se oncogenes, que são carcinogênicos, e levam a célula a um crescimento descontrolado (RIVOIRI et al., 2006).

Em geral, os agentes quimioterápicos são tóxicos para os tecidos de rápida proliferação, caracterizados por ciclos celulares curtos. Deste modo, são mais eficazes quando utilizados precocemente, pois o tumor, quando pequeno, tem crescimento exponencial. Esta abordagem sistêmica tornou possível a cura de alguns tipos de câncer, como as leucemias, e permitiu o tratamento precoce de metástases não detectáveis (SCHAFER, 1996; BONASSA, 2005).

Devido à capacidade da célula neoplásica de sofrer mutações que podem levar a uma resistência destas aos quimioterápicos, têm sido empregados esquemas poliquimioterápicos, isto é, a combinação de mais de um agente citostático, com mecanismos de ação distintos, pois a exposição destas células há mais de um agente, pode ser capaz de retardar o mecanismo de resistência tumoral. Podem também, serem empregados em doses menores, o que diminui os efeitos tóxicos, e os efeitos colaterais são menos intensos e limitantes, favorecendo melhores resultados no tratamento (BONASSA, 2005).

\footnotetext{
${ }^{2}$ SROUGI, M.; SIMON, S.D. Câncer urológico. Editora Platina, São Paulo, 1990.
} 
Para o uso da poliquimioterapia, devem-se seguir algumas recomendações que aumentam sua eficácia e diminuem os efeitos tóxicos, a saber: drogas com diferentes mecanismos de ação; drogas com diferentes toxicidades; drogas que sejam efetivas quando aplicadas isoladamente; drogas com períodos diferentes para as toxicidades; drogas com bases bioquímicas para sinergismo, uma droga potencializando o efeito da outra, torna os resultados superiores do que quando utilizadas isoladamente (BONASSA, 2005).

Além das combinações de droga, os objetivos do tratamento quimioterápico permitem a classificação deste tratamento em (BONASSA, 2005; ALMEIDA, 2004):

- Neo-adjuvante: tem como objetivo a redução tumoral, para posterior tratamento local adequado, e também combate a micrometástases;

- Adjuvante: usada após outra modalidade de tratamento, com a finalidade de combater micrometástases;

- Paliativo: usado em pacientes com metástases diagnosticadas ou com recidiva do câncer, onde a possibilidade de cura é remota.

Em relação ao câncer de mama, os primeiros conhecimentos relacionados à quimioterapia, são oriundos de resultados alcançados com o tratamento da doença avançada (AMORIM; WISISNTAINER, 2006).

A administração de agentes citostáticos no pré ou pós-operatórios tem eficácia similar. Conseqüentemente, a quimioterapia neoadjuvante é, na atualidade, amplamente aceita.

A quimioterapia neo-adjuvante, também chamada de primária ou de indução, foi introduzida como terapia para o câncer de mama há cerca de 20 anos. Inicialmente era indicada para mulheres com tumores de mama localmente avançados e inflamatórios, comumente considerados inoperáveis no diagnóstico, e tinham como finalidade reduzir a massa tumoral e favorecer o uso de tratamentos cirúrgicos e radioterápicos mais eficientes. Atualmente tem sido amplamente aceita como uma opção de tratamento para outros estadios da doença (KAUFMANN et al., 2003; BOUGHEY et al., 2006; MIEOG; VAN DER HAGE; VAN DE VELDE, 2007).

Este tipo de terapêutica consiste na administração do quimioterápico antes do tratamento cirúrgico, e vem sendo utilizado com freqüência crescente. Suas vantagens práticas e teóricas são: reduzir o tamanho do tumor, permitindo assim, um maior número de cirurgias conservadoras; tornar operáveis tumores localmente avançados; 
impedir o crescimento de focos metastáticos após a remoção do tumor primário; diminuir o potencial de clones quimio-resistentes; avaliar a sensibilidade tumoral in vivo em resposta a um regime ou droga em particular; melhorar a chegada da droga no tumor, pois a vascularização ainda não foi alterada pelo procedimento cirúrgico; permitir o estudo dos marcadores biológicos, sem aumento da toxicidade ou prejuízo ao prognóstico (KAUFMANN et al., 2003; GOGAS, 2003; FISHER; MAMOUNAS, 1995; TRUDEAU; SINCLAIR; CLEMONS, 2005; BOUGHEY et al., 2006; MIEOG; VAN DER HAGE; VAN DE VELDE, 2007; DAWOOD et al., 2008; CAMERON; AAPRO, 2008).

No International Expert Panel, Kaufmann et al. (2006), recomendam o uso de quimioterapia neoadjuvante como opção de tratamento para mulheres com câncer de mama que apresentem as seguintes características:

- Mulheres com indicação de mastectomia, mas que desejam uma cirurgia menos extensa;

- Mulheres que possam ser submetidas à cirurgia conservadora, mas que a aparência pode ficar prejudicada sem a aplicação da quimioterapia préoperatória;

- Mulheres que possam ter vantagem da resposta tumoral com a quimioterapia antes do tumor ser retirado. A quimioterapia neoadjuvante, com boa resposta, pode gerar um efeito positivo na confiança da mulher com a terapia futura;

- Mulheres que apresentem contra-indicação médica para a cirurgia ou que desejem adiá-la. Por exemplo, mulheres grávidas, que poderão receber a quimioterapia no segundo ou terceiro trimestre e assim adiar a cirurgia e a radioterapia para depois do parto.

Diversos estudos randomizados têm sido realizados com a finalidade de documentar a eficácia da quimioterapia neoadjuvante. Pesquisadores diferem em relação aos resultados com destaque para o tempo de uso e tipo de associação de drogas, porém as observações realizadas durante tratamento têm demonstrado controle local da doença, cirurgias mais conservadoras, como observado nos estudos citados a seguir. 
O primeiro grande estudo que comparou a quimioterapia neoadjuvante com a adjuvante foi o National Surgical Adjuvant Breast and Bowel Project (NSABP) B18, desenhado para determinar qual terapia era mais efetiva em prolongar o período livre de doença e a sobrevida e foram comparados as respostas dos ciclos de quimioterapia pré e pós-operatória. Este estudo avaliou 1500 mulheres divididas em dois grupos, um recebeu tratamento pré-operatório com Doxorrubicina e Ciclofosfamida (AC) realizadas em quatro ciclos a cada 21 dias, e o segundo recebeu o mesmo tratamento, porém no período de pós-operatório (FISHER et al., 1997).

Os resultados demonstraram que as mulheres que realizaram ciclos de quimioterapia antes da cirurgia apresentaram redução no tamanho do tumor e na incidência de nódulos axilares positivos, aumentando assim, o número de cirurgias conservadoras, com maior segurança (FISHER et al., 1997).

Entretanto, não foram encontradas vantagens estatisticamente significantes para a quimioterapia neoadjuvante quando comparada com a quimioterapia adjuvante em relação à sobrevida e o período livre da doença em seguimento durante cinco anos. $\mathrm{O}$ estudo B-18 demonstrou a segurança do uso da quimioterapia pré-operatória para mulheres com tumores de grandes volumes permitindo a realização de cirurgias mais conservadoras sem comprometer a sobrevida (FISHER et al., 1997).

Com a intenção de melhorar os resultados da quimioterapia neoadjuvante, têm sido empregadas estratégias como o uso de altas doses do tratamento clássico com as antraciclinas (epirrubicina e doxorrubicina), bem como a incorporação de novas drogas, como os taxanos (docetaxel e paclitaxel), que são, atualmente, as drogas mais ativas contra o câncer de mama, com resposta de até 30\% em doença avançada (NABHOLTZ et al., 2003; ROCHÉ et al., 2006).

Um dos principais estudos que avaliou a adição dos taxanos aos antracíclicos foi o NSABP-B27, que randomizou 2411 mulheres em três grupos. No primeiro, as participantes receberam quatro ciclos de $\mathrm{AC}\left(60 \mathrm{mg} / \mathrm{m}^{2}\right.$ e $600 \mathrm{mg} / \mathrm{m}^{2}$ respectivamente) no período de pré-operatório; no segundo grupo as participantes receberam quatro ciclos de $\mathrm{AC}\left(60 \mathrm{mg} / \mathrm{m}^{2}\right.$ e $600 \mathrm{mg} / \mathrm{m}^{2}$ respectivamente) seguido de quatro ciclos de docetaxel $\left(100 \mathrm{mg} / \mathrm{m}^{2}\right)$ no pré-operatório e no terceiro grupo as participantes receberam quatro ciclos de AC $\left(60 \mathrm{mg} / \mathrm{m}^{2}\right.$ e $600 \mathrm{mg} / \mathrm{m}^{2}$ respectivamente) no pré-operatório e quatro ciclos de docetaxel $\left(100 \mathrm{mg} / \mathrm{m}^{2}\right)$ no pós-operatório. Todas as participantes foram avaliadas 
quanto ao tipo de cirurgia indicada para cada caso, antes da randomização (BEAR et al., 2003).

Todas as participantes receberam o esquema proposto a cada 21 dias e iniciaram o uso de Tamoxifeno® no primeiro dia do primeiro ciclo, e o utilizaram durante cinco anos. Todas as mulheres que foram submetidas à cirurgia conservadora, receberam tratamento radioterápico após (BEAR et al., 2003).

Os resultados para o primeiro e o terceiro grupos foram de $45,4 \%$ de resposta clínica parcial, 40,2\% de resposta clínica completa e 10\% de resposta patológica completa. Enquanto que para o segundo grupo a resposta clínica parcial foi de $27,1 \%$, a resposta clínica completa de $63,6 \%$ e a resposta patológica completa de 18,9\%. Esses resultados demonstram que o emprego dos taxanos em quimioterapia primária é seguro e eficaz, além de apresentar respostas clínica e patológica completas, sobrevida livre de doença e sobrevida global, maiores do que as obtidas somente com o uso dos protocolos baseados nos antraciclicos (BEAR et al., 2003; TRUDEAU; SINCLAIR; CLEMONS, 2005; RASTOGI et al., 2008).

Boughey et al. (2006), em estudo retrospectivo, re-analisaram os casos de 509 mulheres com câncer de mama, em estádios I a IIIa, tratadas em estudos randomizados entre 1998 e 2005, divididas em dois grupos, um que recebeu quimioterapia neoadjuvante e outro que recebeu quimioterapia adjuvante. Os protocolos usados foram: o primeiro utilizou paclitaxel semanal ou paclitaxel a cada três semanas seguido de 5fluorouracil, ciclofosfamida e doxorrubicina (FAC) tanto para pré quanto para o pósoperatório, e o segundo era composto de paclitaxel semanal ou docetaxel e capecitabina a cada três semanas seguido de 5-fluorouracil, epirrubicina e ciclofosfamida (FEC), também utilizado tanto para pré quanto para o pós-operatório, porém não se referem às dosagens de cada drogas utilizada.

Os autores não fazem referência quanto ao número de ciclos de quimioterapia utilizado em cada protocolo, afirmam, somente, que o protocolo de quimioterapia neoadjuvante proposto foi concluído de três a quatro semanas antes do procedimento cirúrgico. Das 332 mulheres que receberam quimioterapia neoadjuvante, 182 (55\%) foram submetidas à mastectomia e 150 (45\%) à cirurgia conservadora. Entre as 177 que receberam quimioterapia adjuvante, 86 (49\%) foram submetidas à mastectomia e 91 (51\%) à cirurgia conservadora (BOUGHEY et al., 2006). 
A conclusão do estudo foi que as mulheres, que no diagnóstico apresentavam tumores grandes e que receberam a quimioterapia pré-operatória, foram submetidas à ressecções menos extensas quando comparadas às que receberam somente a quimioterapia pós-operatória. $\mathrm{O}$ menor volume tecidual retirado durante a cirurgia não apresentou risco posterior de ampliação de margens cirúrgicas, pois estas foram negativas no intra-operatório. Além disso, os resultados cosméticos das cirurgias conservadoras têm se tornado cada vez mais importante para as mulheres, especialmente com o aumento da sobrevida (BOUGHEY et al., 2006).

Em estudo fase II utilizando mono quimioterapia com docetaxel $\left(100 \mathrm{mg} / \mathrm{m}^{2}\right)$ por seis ciclos a cada 21 dias em 86 mulheres com câncer de mama operável e não metastático, Amat et al. (2003) obtiveram 76 procedimentos cirúrgicos. Destes 72,4\% (55) das mulheres foram submetidas à cirurgia conservadora e 27,6\% (21) à mastectomia. Concluíram que, mesmo esquemas de mono quimioterapia, quando utilizados no pré-operatório favorecem a indicação de cirurgia conservadoras.

Espinosa et al. (2004) em estudo, fase II, utilizando epirrubicina $\left(120 \mathrm{mg} / \mathrm{m}^{2}\right)$ e docetaxel $\left(75 \mathrm{mg} / \mathrm{m}^{2}\right)$ a cada 21 dias, repetidos por quatro ciclos antes do procedimento cirúrgico,contaram com a participação de 50 mulheres com câncer de mama, destas 46 foram submetidas à cirurgia, sendo $12 \%$ (6) cirurgias conservadoras e $80 \%$ (40) mastectomia. Em seguimento de 22 meses, os autores obtiveram $20 \%$ de resposta clínica completa e $58 \%$ de resposta parcial.

Outros esquemas com a utilização de novas drogas têm sido empregados. Dentre as drogas, utiliza-se o trastuzumab, anticorpo monoclonal com receptor de membrana para HER-2, associado aos taxanos e antracíclicos para a quimioterapia neoadjuvante. Protocolos com a utilização desta droga têm mostrado respostas patológicas completas em até 66,7\% (BUDZAR et al., 2005).

O tratamento quimioterápico neoadjuvante deve ser oferecido a toda mulher que possa ser candidata ao tratamento adjuvante, que por sua vez é baseado na responsividade endócrina do tumor, status dos linfonodos, idade, status menopausal, tamanho do tumor e estadiamento no diagnóstico (KAUFMANN et al., 2006).

A duração do tratamento neoadjuvante não está bem estabelecida. Em diferentes estudos, segundo Kaufmann et al. (2006), a variação de tempo de tratamento é de oito a 36 semanas e um mínimo de quatro ciclos. Entretanto, reconhecem que algumas mulheres requerem tratamento mais longo, enquanto que outras, obtém o máximo de 
benefícios em um curto período de tratamento, mas, até o presente, estes casos não são possíveis de serem identificados antecipadamente.

A quimioterapia adjuvante está baseada na combinação de drogas citotóxicas com a finalidade de diminuir o risco de recorrência local após a ressecção do tumor, reduzir o risco de metástases e aumentar a sobrevida. Teve seu papel consolidado na década de sessenta, quando se compreendeu, que o câncer de mama era uma doença sistêmica, o que mudou o paradigma da doença e seu tratamento (EBCTCG 2005; AMORIM; WISINTAINER, 2006).

Os benefícios da quimioterapia adjuvante são maiores em mulheres com idade abaixo de 50 anos e na pré-menopausa, em contraste com a hormonioterapia adjuvante com Tamoxifeno®, que, aparentemente, beneficia mulheres de todas as idades que tenham tumor com receptor de estrógeno positivo (SHAPIRO; RECHT, 2000).

Dentre os agentes quimioterápicos, os mais utilizados no tratamento adjuvante do câncer de mama são os agentes alquilantes, principalmente, a ciclofosfamida (C); os antimetabólicos, como o 5-fluorouracil (F) e o metrotexate (M); os antracíclicos, como a epirrubicina (E) e doxorrubicina (A), e, mais recentemente, os taxanos, como o paclitaxel e docetaxel (T) (ROCHÉ et al., 2006).

Grandes avanços têm sido observados no tratamento de mulheres com câncer de mama com diagnóstico precoce, com a avaliação de regimes mais eficazes, com a associação de agentes quimioterápicos.

As antraciclinas e os taxanos são, atualmente, as drogas citostáticas mais ativas no tratamento do câncer de mama. A quimioterapia adjuvante baseada nestes dois grupos de drogas, entretanto, está associada com risco de mielossupressão e anemia. Historicamente, o tempo de recuperação da contagem de neutrófilos tem sido o fator limitante nos regimes quimioterápicos, pois muitos protocolos são administrados a cada três semanas para permitir a recuperação medular, e em particular a contagem de glóbulos brancos (HENDERSON et al., 2003).

Bonadonna et al. (2005), em 1975, demonstraram o primeiro relato da eficácia do CMF em tratamento adjuvante para mulheres com câncer de mama,e apresentaram estudo retrospectivo avaliando 30 anos de experiência com o uso de CMF em quatro sucessivos estudos clínicos, com a participação de 1020 mulheres. Os esquemas quimioterápicos utilizados foram $\mathrm{C}\left(100 \mathrm{mg} / \mathrm{m}^{2}\right.$ por via oral do primeiro ao décimo quarto dias), M (40mg/m² $/ \mathrm{m}^{2}$ por via endovenosa nos dias um e oito do ciclo) e $\mathrm{F}$ 
$\left(600 \mathrm{mg} / \mathrm{m}^{2}\right.$ por via endovenosa nos dias um e oito do ciclo) repetido a cada quatro semanas por seis ou 12 ciclos, ou C $\left(600 \mathrm{mg} / \mathrm{m}^{2}\right.$ por via endovenosa), M $\left(40 \mathrm{mg} / \mathrm{m}^{2}\right.$ por via endovenosa) e F $\left(600 \mathrm{mg} / \mathrm{m}^{2}\right.$ por via endovenosa) repetido a cada três semanas por seis ou 12 ciclos. Todos os estudos foram iniciados de duas a quatro semanas após o procedimento cirúrgico, e foi permitido o uso de radioterapia para as mulheres submetidas à cirurgia conservadora, iniciada de seis a oito semanas após a cirurgia independente de o tratamento quimioterápico ter sido finalizado.

Os autores concluem que o seguimento, de longo prazo, da coorte de mulheres participantes de estudos clínicos realizados entre 1973 e 1985, confirmam que seu uso contribuiu para melhorar o tratamento. A análise também permitiu demonstrar que a quimioterapia adjuvante foi capaz de suprimir micro-metástases. Atualmente além do uso do regime de CMF, a inclusão de novas drogas, como as antraciclinas e os taxanos, tem melhorado ainda mais a resposta ao tratamento quimioterápico adjuvante (BONADONNA et al., 2005).

Diferentes estudos têm demonstrado os benefícios do tratamento quimioterápico adjuvante, em especial, os regimes baseados nas antraciclinas; outros confirmam que os taxanos melhoram o prognóstico de mulheres com alto risco para recidiva, por exemplo, aquelas com metástases em linfonodos axilares (EBCTCG, 2005; PICCARD et al., 2001).

A administração de quatro ciclos de AC passou a ser considerado tratamento padrão para a quimioterapia adjuvante, após ter sido demonstrado que o mesmo é equivalente ao CMF em dois estudos do NSABP, o B-15 e o B-23. Nenhum outro esquema de quimioterapia administrada em quatro ciclos havia se mostrado mais eficiente (FISHER et al., 2001; JONES et al., 2006).

Em estudo fase III realizado, na França, com 565 mulheres randomizadas em dois grupos, um com o uso de FEC 50 (5- fluorouracil $500 \mathrm{mg} / \mathrm{m}^{2}$, epirrubicina 50 $\mathrm{mg} / \mathrm{m}^{2}$, ciclofosfamida $100 \mathrm{mg} / \mathrm{m}^{2}$ ) a cada três semanas e o outro grupo com uso de FEC 100 (epirrubicina $100 \mathrm{mg} / \mathrm{m}^{2}$ e as outras drogas na mesma dosagem) a cada três semanas, observou-se que o segundo regime obteve uma sobrevida global, em 5 anos, de $77,4 \%$ contra $65,3 \%$ do primeiro esquema. Entretanto, as mulheres que foram submetidas ao esquema que utilizou o FEC 100 apresentaram maiores toxicidades, 
como a neutropenia de graus III e IV, sendo 25,2\% para o FEC 100 e 11,1\% para o FEC 50 (FRENCH ADJUVANT STUDY GROUP, 2001).

Jones et al. (2006) realizaram estudo fase III, com 1016 mulheres que haviam sido submetidas ao procedimento cirúrgico e foram randomizadas em dois grupos. No primeiro, as participantes recebiam $\mathrm{AC}\left(60 \mathrm{mg} / \mathrm{m}^{2}\right.$ e $600 \mathrm{mg} / \mathrm{m}^{2}$ respectivamente) em quatro ciclos realizados a cada 21 dias, e no segundo recebiam TC (docetaxel $75 \mathrm{mg} / \mathrm{m}^{2}$ e ciclofosfamida $600 \mathrm{mg} / \mathrm{m}^{2}$ ) também em quatro ciclos realizados a cada 21 dias. Após o término do esquema de quimioterapia, as participantes receberam Tamoxifeno® ou radioterapia, conforme indicação.

As participantes foram acompanhadas durante cinco anos e os autores concluíram que os resultados foram mais favoráveis àquelas do grupo TC, que apresentaram período livre de doença em $86 \%$ contra $80 \%$ do grupo $\mathrm{AC}$, e em relação à sobrevida os resultados também foram favoráveis ao grupo TC, com $90 \%$ conta $87 \%$ do grupo AC (JONES et al., 2006).

Outro estudo realizado na França por Toledano et al. (2007), em que randomizaram 716 mulheres pós-cirurgia por câncer de mama em dois grupos, um deles fez uso de mitoxantrona $\left(12 \mathrm{mg} / \mathrm{m}^{2}\right)$, 5-fluorouracil $\left(500 \mathrm{mg} / \mathrm{m}^{2}\right)$ e ciclofosfamida $\left(500 \mathrm{mg} / \mathrm{m}^{2}\right)$ por seis ciclos repetidos a cada 21 dias, e após três a cinco semanas radioterapia; no segundo grupo o esquema quimioterápico foi o mesmo, mas a radioterapia teve início no primeiro dia do primeiro ciclo de quimioterapia.

Apesar dos autores não citarem a freqüência e o período de tempo de realização da radioterapia, afirmam não terem encontrado diferença estatisticamente significativa entre os dois grupos para o período livre da doença no seguimento de cinco anos, alcançando uma taxa de $80 \%$. Porém quando avaliados o período livres de metástases, o grupo seqüencial apresentou $87 \%$ contra $84 \%$ do grupo com tratamento concomitante; e para o período livre de recorrência local, os resultados foram de $92 \%$ e $95 \%$ respectivamente. Concluem que este protocolo pode ser a primeira opção para mulheres com alto risco de recorrência, ou seja, aquelas que apresentam lifonodos axiliares positivos (TOLEDANO et al., 2007).

No estudo fase III realizado por Linden et al. (2007), que randomizaram 3114 mulheres com câncer de mama após a cirurgia, em dois grupos de tratamento, sendo o primeiro com o uso de $\mathrm{AC}\left(54 \mathrm{mg} / \mathrm{m}^{2}\right.$ e $1,2 \mathrm{~g} / \mathrm{m}^{2}$ respectivamente) por seis ciclos a cada três semanas, e o segundo com A $\left(45,5 \mathrm{mg} / \mathrm{m}^{2}\right)$ nos dias um e dois do ciclo a cada 21 
dias por quatro ciclos e posteriormente $\mathrm{C}\left(2,4 \mathrm{~g} / \mathrm{m}^{2}\right)$ a cada 21 dias por três ciclos. Após cinco anos de seguimento, os autores concluíram que não houve diferença entre os grupos quanto à sobrevida, ficando com $88 \%$ para o primeiro e $89 \%$ para o segundo grupo; os resultados não mostraram superioridade com o uso dos quimioterápicos em separado, mas as participantes deste braço de tratamento apresentaram mais efeitos adversos do que do grupo 1.

Pode-se observar uma grande variedade de estudos com emprego de diferentes esquemas de tratamento quimioterápico, com drogas, dosagens, combinações e associação da radioterapia visando obter uma melhor resposta com uma menor toxicidade para o tratamento adjuvante.

\section{I. d. Efeitos adverso da quimioterapia}

Para o National Cancer Institute (1999) no Common Toxicity Criteria Manual, toxicidade não é um termo claramente definido, mas continua sendo utilizado por razões históricas. Recomendam o uso do termo evento adverso, que significa qualquer sintoma, sinal ou doença não favorável, incluindo achados laboratoriais anormais, temporariamente, associado com o uso do tratamento ou procedimento médico. $\mathrm{O}$ evento adverso tem uma atribuição com o agente investigado podendo ser classificado como possível, provável ou definitivo.

Para o tratamento do câncer, a quimioterapia é realizada sob forma de ciclos, durante os quais o paciente recebe as drogas pela via de administração planejada, sendo a mais utilizada, a endovenosa.

Os estudos laboratoriais e as observações clínicas sugerem que a sequiência e o intervalo entre os ciclos devem se basear nos aspectos farmacológicos e citocinéticos de cada droga. O intervalo entre os ciclos baseia-se, também, na premissa de que o quimioterápico deve ser administrado, novamente, antes que ocorra a retomada de crescimento tumoral, entretanto, o intervalo entre as aplicações deve considerar ainda a recuperação dos tecidos normais (BONASSA, 2005).

Uma vez decidido o tipo de tratamento quimioterápico a ser utilizado, o oncologista planeja tal tratamento por meio de um protocolo em que está especificada a droga ou combinação de drogas a ser utilizada, a via de administração, a dosagem e os intervalos entre as aplicações.

Existem inúmeras dificuldades para identificar e estimar a freqüência dos efeitos adversos relacionados ao tratamento. Essas informações em geral, são derivadas de 
estudos retrospectivos, de caso e controle, sendo que muitos destes estudos são de décadas atrás, quando inúmeros dos agentes utilizados já foram substituídos, como o melfalano que aumentava o risco para leucemia mielóide, demonstrado no estudo do NSABP, entre 1972 e 1981, que foi substituído pela ciclofosfamida (SHAPIRO; RECHT, 2000).

Os efeitos adversos ocasionados pelos quimioterápicos relacionam-se ao fato da sua não-especificidade pelas células tumorais. Esses efeitos predominam nas células de rápida divisão celular, como as do tecido hematopoiético, do tecido germinativo, do folículo piloso, do revestimento gastrointestinal, e alguns outros órgãos que podem ser afetados em maior ou menor grau, de forma precoce ou tardia, aguda ou crônica, cumulativo e irreversível, (BONASSA, 2005).

Cada quimioterápico tem seu perfil de toxicidade e efeitos colaterais, ressaltando-se a necessidade do uso racional de drogas para evitar os efeitos adversos acumulativos.

A evolução de antibióticos, de drogas antieméticas, do desenvolvimento de fatores de crescimento de células hematopoiéticas, tem aumentado a segurança e a tolerabilidade do tratamento quimioterápico. Entretanto, a diversidade de efeitos adversos causados pelas drogas quimioterápicas, como a mielosupressão, com conseqüentes riscos de infecção e sangramento, a náusea, o vômito, a fadiga, a alopecia, entre outros, fazem com que o paciente sinta-se doente, o que muitas vezes não ocorre em relação à própria doença. Por exemplo, a alopecia é considerada por muitos pacientes como um emblema do câncer e de seu tratamento (TCHEN et al., 2001; FRITH; HARCOURT; FUSSELL, 2007).

Os efeitos adversos dos quimioterápicos apresentam frequiência e intensidade variadas de acordo com as drogas utilizadas, e podem ser divididos em toxicidade não hematológica, em que estão incluídas as toxicidades gastrointestinais, pulmonares, cardíacas, hepáticas, neurológicas, renais, vesicais, dermatológicas, disfunções reprodutivas, alterações metabólicas, reações alérgicas e a fadiga; e toxicidade hematológica, que engloba leucopenia, anemia, trombocitopenia e neutropenia febril (BONASSA, 2005).

Os indivíduos submetidos à quimioterapia devem ser monitorizados para determinar a ocorrência e a duração da mielosupressão. $O$ tempo transcorrido entre a aplicação do agente quimioterápico e o aparecimento dos menores valores das 
contagens hematológicas, é denominado de Nadir, período variável para cada droga. Por exemplo, a epirrubicina, apresenta um período de Nadir de 8 a 14 dias após a administração, voltando aos valores normais dentro de 21 dias.

Assim antes do cada ciclo de quimioterapia, a medula deve estar praticamente recuperada, com produção normal de leucócitos e níveis de glóbulos brancos no sangue periférico, normais ou próximos do normal (BONASSA, 2005).

Deve-se considerar ainda, variações individuais para o cálculo da dose e o aprazamento entre os ciclos, daí a necessidade da monitorização rigorosa da contagem hematológica antes de cada novo ciclo de quimioterapia.

O Serviço de Mastologia do Hospital das Clínicas da Faculdade de Medicina de Ribeirão Preto da Universidade de São Paulo (HCFMRP-USP) utiliza, para a quimioterapia de mulheres com câncer de mama em tratamento neoadjuvante, preferencialmente, o protocolo com a combinação de Epirrubicina $50 \mathrm{mg} / \mathrm{m}^{2}$ e Docetaxel $75 \mathrm{mg} / \mathrm{m}^{2}$. Após completar esta fase do tratamento, as mulheres são submetidas ao procedimento cirúrgico e, a seguir o tratamento quimioterápico adjuvante, em que é utilizado Ciclofosfamida $600 \mathrm{mg} / \mathrm{m}^{2}$ e Epirrubicina $60 \mathrm{mg} / \mathrm{m}^{2}$ ou outros esquema, como AC, FEC e CMF, de acordo com a indicação, que considera a resposta anterior ao tratamento neoadjuvante e resultado do anátomo-patológico.

Para cada droga utilizada espera-se que ocorra efeitos adversos, e os mais comuns serão descritos a seguir (ALMEIDA, 2004; BONASSA, 2005):

ㅁ Docetaxel

$\checkmark$ Hematológicos- mielosupressão (leucopenia, trombocitopenia, anemia, neutropenia febril);

$\checkmark$ Gastrointestinais- náuseas e vômitos, mucosite, diarréia;

$\checkmark$ Neurológico: neuropatia periférica, parestesia reversível, sensação de queimação, letargia, sonolência de leve à moderada e cefaléia;

$\checkmark$ Cardiovascular- edema, derrame pericárdio e pleural, edema periférico e ascite;

$\checkmark$ Reações alérgicas- rash local ou generalizado, urticária, prurido, febre, tremores, dor lombar;

$\checkmark$ Cutâneos- alopecia, rash cutâneo, droga irritante quando extravasada fora do vaso sanguíneo;

$\checkmark$ Outros- hepatotoxicidade, dispnéia, fadiga, artralgia, mialgia. 


\section{o Epirrubicina}

$\checkmark$ Hematológicos- mielosupressão (leucopenia, trombocitopenia, anemia);

$\checkmark$ Gastrointestinais- náuseas e vômitos, anorexia, estomatite, diarréia;

$\checkmark$ Cardiocirculatório- cardiotoxicidade, arritmias agudas, risco de insuficiência cardíaca congestiva e insuficiência ventricular esquerda;

$\checkmark$ Cutâneos- alopecia, hiperpigmentação cutânea e do leito ungueal, urticária, prurido, tromboflebite em veias utilizadas para aplicação, se ocorrer extravasamento, pode levar a grave lesão tecidual e necrose;

$\checkmark$ Outros- hepatotoxicidade, urina avermelhada até 48 horas após a infusão, fadiga e cefaléia.

\section{- Ciclofosfamida}

$\checkmark$ Hematológicos- mielosupressão (leucopenia, trombocitopenia, anemia);

$\checkmark$ Gastrointestinais- náuseas e vômitos, anorexia, estomatite, diarréia, desconforto ou dor abdominal;

$\checkmark$ Cutâneos- alopecia, hiperpigmentação cutânea, dermatite, urticária, escurecimento do leito ungueal, flebite no local da punção;

$\checkmark$ Genitourinário- cistite hemorrágica ou não- hemorrágica, fibrose de bexiga, supressão gonadal levando à esterilidade;

$\checkmark$ Outros- hepatotoxicidade, nefrotoxicidade, cardiotoxicidade, fibrose pulmonar, etc.

$\mathrm{Na}$ literatura encontramos estudos acerca da quimioterapia neoadjuvante, combinando docetaxel e epirrubicina, como o protocolo em uso no local do presente estudo, em que observaram efeitos hematológicos, destacando-se a neutropenia, ocorrendo de 6 a $81 \%$ e neutropenia febril, de 1 a 22\% (ARDAVANIS et al., 2001; BORREGA et al., 2001; AMAT et al., 2003; ESPINOSA et al., 2004; HIRANO et al., 2006; BEAR et al., 2003).

No estudo NSABP-B27, entre as mulheres que estavam no grupo de tratamento com o esquema de quimioterapia $\mathrm{AC}, 7,3 \%$ apresentaram neutropenia febril enquanto que as dos braços com docetaxel esta ocorrência alcançou 22,2\%. Os autores relataram que durante a realização do trabalho, no grupo com 2400 participantes recebendo AC ocorreram três mortes. As causas das mortes foram: hemorragia cerebral, falência hepática e suicídio, entretanto os autores apontam que elas podem estar relacionadas ao 
tratamento. Nos grupos com uso de docetaxel, com 1584 participantes, ocorreram sete mortes que, também, podem estar relacionadas ao tratamento (três por sepse, uma por perfuração intestinal, duas mortes súbitas e uma por falência hepática), (BEAR et al., 2003).

Ramaswamy et al. (2005), em estudo com 25 mulheres com câncer de mama usando docetaxel $100 \mathrm{mg} / \mathrm{m}^{2}$ endovenoso, administrado em três ciclos a cada três semanas, seguido de três ciclos a cada três semanas de epirrubicina $100 \mathrm{mg} / \mathrm{m}^{2}$ endovenoso obtiveram como resultado $28 \%$ (7) de mulheres com neutropenia febril e $16 \%$ (4) com neutropenia grau IV sem febre, todas nos ciclos de docetaxel.

Amat et al. (2003), em estudo com 88 pacientes recebendo mono terapia com docetaxel, relataram $70,5 \%$ de neutropenia sendo $48,9 \%$ de grau III e 43,2\% de grau IV, além de $18,2 \%$ de anemia grau I e 1,1\% de anemia grau IV.

No estudo com 50 participantes recebendo epirrubicina e docetaxel, realizado por Espinosa et al. (2004), houve a ocorrência de 10\% de neutropenia febril, $14 \%$ de neutropenia de graus I e II e $32 \%$ de neutropenia de graus III e IV, $82 \%$ de anemia de graus I e II e $6 \%$ de anemia de graus III e IV, além de $26 \%$ de trombocitopenia de graus I e II e $4 \%$ de trombocitopenia de graus III e IV.

Hirano et al. (2006), em estudo fase II, com a participação de 21 mulheres com câncer de mama utilizando epirrubicina $\left(70 \mathrm{mg} / \mathrm{m}^{2}\right)$ e docetaxel $\left(60 \mathrm{mg} / \mathrm{m}^{2}\right)$ realizado em 6 ciclos repetidos a cada 21 dias, observaram a ocorrência de neutropenia grau IV em $81 \%$ da paciente e uma ocorrência de neutropenia febril.

No estudo conduzido por Ardavanis et al. (2001), em que 28 participantes receberam epirrubicina $\left(100 \mathrm{mg} / \mathrm{m}^{2}\right)$ e docetaxel $\left(100 \mathrm{mg} / \mathrm{m}^{2}\right)$, os autores referem que a toxicidade foi moderada, $70 \%$ das mulheres apresentaram neutropenia graus III/IV e cinco apresentaram neutropenia febril.

Quanto aos casos de óbitos relacionados ao tratamento, Tfayli et al. (2006) referem a ocorrência de um óbito por sepse e neutropenia febril, e Marwane et al. (2001), que apesar de afirmarem que não houveram complicações durante o tratamento quimioterápico, referem a ocorrência de três $(16,7 \%)$ óbitos neste período.

Os efeitos não hematológicos mais freqüentes, excetuando alopecia que foi apresentada como universal em todos os estudos revisados, foram: náusea e vômito, diarréia, estomatite, fadiga e infecção (ARDAVANIS et al., 2001; BORREGA et al., 2001; AMAT et al., 2003; ESPINOSA et al., 2004; RAMASWAMY et al., 2005 ). 
No estudo de Ramaswamy et al. (2005), entre as 25 participantes, 4\% apresentaram mucosite e $12 \%$ diarréia, todas de grau III, como as toxicidades não hematológicas mais freqüentes. Amat et al. (2003), relataram 48,9\% de toxicidade gastrointestinal, 37,5\% de toxicidade cutânea e 44,3\% de reações de hipersensibilidade.

Entre toxicidades não hematológicas, Espinosa et al. (2004), citam como as mais freqüentes, alopecia (80\%), fadiga (56\%), náuseas e vômitos (38\%), estomatite (38\%) e diarréia (34\%) e Ardavanis et al. (2001) encontraram 20\% de náusea e vômito.

Quanto aos efeitos colaterais dos esquemas de quimioterapia adjuvante combinando ciclofosfamida e epirrubicina, como no protocolo do presente estudo, encontramos escassa literatura sobre a ocorrência de efeitos hematológicos. Em estudo utilizando EC para câncer de mama metastático, Luck et al. (2000) referem uma incidência de neutropenia de graus III/IV em $45 \%$ das participantes e $2 \%$ de neutropenia febril.

Encontram-se na literatura, com maior freqüência, estudos acerca do uso de AC, e os mesmos consideram as combinações AC e EC similares e apontam preferência para o uso de AC, apesar, de a doxorubicina ser mais cardiotoxica do que a epirrubicina e os efeitos adversos hematológicos serem similares,

Em dois estudos utilizando o esquema $\mathrm{AC}$, os resultados de neutropenia graus III/IV foram de 12 e $43 \%$ respectivamente, para Jones et al. (2006) e de 29\% para Linden et al. (2007).

Os efeitos não hematológicos mais freqüentes foram semelhantes ao do tratamento neoadjuvante, com referência dos autores à náusea, vômito, estomatite, fadiga, infecção, febre e diarréia (PICCART et al., 2007).

Piccart et al. (2007), realizaram estudo fase III com 777 mulheres randomizadas em três grupos sendo o primeiro CMF $\left(100 \mathrm{mg} / \mathrm{m}^{2}\right.$ por via oral do D1 ao D14; $40 \mathrm{mg} / \mathrm{m}^{2}$ nos dias um e oito; $600 \mathrm{mg} / \mathrm{m}^{2}$ nos dias um e oito respectivamente) aplicado por seis ciclos e repetidos a cada 28 dias, no segundo grupo EC $\left(60 \mathrm{mg} / \mathrm{m}^{2}\right.$ e $500 \mathrm{mg} / \mathrm{m}^{2}$ respectivamente) por oito ciclos repetidos a cada 21 dias, e o terceiro grupo HEC (100 $\mathrm{mg} / \mathrm{m}^{2}$ e $830 \mathrm{mg} / \mathrm{m}^{2}$ respectivamente) por oito ciclos repetidos a cada 21 dias. Quando indicado foram utilizados Tamoxifeno ${ }^{\circledR} 40 \mathrm{mg} / \mathrm{m}^{2}$ e/ou radioterapia, iniciados após o término da quimioterapia. 
Os efeitos adversos não hematológicos para o grupo EC, no qual fizeram parte 267 mulheres foram: $25 \%$ de náusea, $1 \%$ de mucosite e $1 \%$ de infecção. Para o grupo HEC: $27 \%$ de náusea, $3 \%$ de mucosite e $1 \%$ de infecção. Todos os eventos adversos citados pelos autores foram de graus III ou IV (PICCART et al., 2007).

No estudo de Carmichael (2001) utilizando seis ciclos de EC $\left(75 \mathrm{mg} / \mathrm{m}^{2}\right.$ e 600 $\mathrm{mg} / \mathrm{m}^{2}$ ) como primeira linha para câncer metastático, o autor refere uma incidência de $2 \%$ de mucosite de graus III/IV e $11 \%$ de infecção.

Nos estudos utilizando $\mathrm{AC}$, os eventos adversos graus III/IV foram 8 e $1 \%$ respectivamente para infecção, 7 e $1 \%$ para náusea, 5 e $1 \%$ para vômito e $1 \%$ para estomatite (JONES et al., 2006). Para Linden et al. (2007) os eventos adversos graus III/IV foram 3\% para infecção, $11 \%$ para náusea, $10 \%$ para vômito e $5 \%$ para estomatite.

Outro evento que pode ocorrer durante o tratamento quimioterápico, é o extravasamento, termo usado para descrever a administração não-intencional de droga vesicante em áreas fora do sistema venoso. A morbidade depende da droga, da quantidade extravasada, da concentração, da localização do extravasamento, das condições do paciente e do intervalo entre o a ocorrência do fato, seu reconhecimento e tratamento (SCHULMEISTER, 2007; BONASSA, 2005).

A incidência de extravasamento de drogas vesicantes publicado na literatura científica, segundo Schulmeister (2007), é de 0,01 a 6,5\%. Entretanto, para Bonassa (2005) a incidência desta ocorrência é subnotificada.

As drogas vesicantes provocam irritação severa com formação de vesículas e destruição tecidual, enquanto as drogas irritantes provocam reações cutâneas de menor intensidade, como dor e queimação, entretanto mesmo quando infundidas adequadamente podem causar dor e reação inflamatória ao longo do vaso sanguíneo utilizado na infusão (BONASSA, 2005).

Os extravasamentos de drogas vesicantes podem causar danos nos tecidos, como a necrose; danos funcionais; alterações neurológicas; alterações na imagem corporal e principalmente a perda da confiança do paciente no profissional de saúde (SCHULMEISTER, 2007). 
Para cada droga vesicante existe procedimentos e antídotos que devem ser administrados imediatamente após a ocorrência do extravasamento, através da mesma agulha, após a aspiração da maior quantidade possível da droga infiltrada e, posteriormente, por via subcutânea, ao redor do local do extravasamento.

O objetivo da aplicação dos antídotos está em limitar o processo inflamatório local, inativar e remover a droga restante. $\mathrm{O}$ uso destes antídotos deve ser prescrito pelo médico ou estar definido por protocolo aprovado pela instituição (BONASSA, 2005).

Alguns sinais e sintomas podem estar presentes imediatamente ou alguns dias após a infusão. As reações imediatas são: queimação, desconforto local e eritema, enquanto as tardias incluem: dor, edema, enduração, ulceração, vesículas, necrose, celulite e inflamação (BONASSA, 2005).

Na Central de Quimioterapia do HCFMRP-USP existe um protocolo para a administração de quimioterápicos, com informações quanto ao tempo de infusão, tipo e calibre do infusor, modo de infusão, se gravitacional ou por bomba de infusão, além de informações sobre as drogas anti-neoplásicas e de condutas a serem tomadas na ocorrência de extravasamento, apresentado no Anexo C.

De acordo com o protocolo, na ocorrência de extravasamento de epirrubicina deve-se aplicar $25 \mathrm{mg}$ de hidocortisona antes da retirada do infusor, aplicar dexametasona e bicarbonato de sódio subcutâneo e gelo local. As outras drogas, por não serem vesicantes ou irritantes, não são necessárias nenhuma conduta a não ser a parada da infusão e retirada da punção.

A enfermeira que atua na área de Oncologia deve deter conhecimento técnico e científico específico e essencial à prática, estando atenta à imprevisibilidade ocasionada pelos efeitos adversos comuns ao tratamento.

Atuando como enfermeira da área de Oncoginecologia na assistência a mulheres, em todas as fases do tratamento do câncer de mama e, sendo o tratamento quimioterápico uma delas, observamos que o conhecimento acerca dos efeitos colaterais é fundamental para o planejamento do cuidado de enfermagem e a adoção de protocolos que incluam avaliação, implementação de cuidados e seguimento.

Questionamos, ainda, se o planejamento do cuidado tem levado em consideração esses efeitos colaterais, e se as orientações fornecidas têm facilitado o controle dos mesmos para quem está sendo submetido ao tratamento. 
Consideramos que o conhecimento dos efeitos colaterais e das alternativas para controle e prevenção destes é indispensável para o manejo dos pacientes oncológicos. $\mathrm{O}$ cuidado aos pacientes e seus familiares incluem orientações acerca dos efeitos adversos relacionados ao tratamento quimioterápico, e devem estar fundamentadas em informações assimiláveis, reforçando os benefícios das drogas e das alternativas para o manejo dos efeitos colaterais.

Mediante o exposto, este estudo tem como objetivos gerais:

- Analisar a ocorrência de toxicidade hematológica e não hematológica induzida por drogas utilizadas no protocolo de quimioterapia neoadjuvante entre mulheres seguidas no Ambulatório de Mastologia do Hospital das Clínicas da Faculdade de Medicina de Ribeirão Preto da Universidade de São Paulo;

- Analisar a ocorrência de toxicidade hematológica e não hematológica provocada por drogas utilizadas no protocolo de quimioterapia adjuvante entre mulheres seguidas no referido serviço.

E como objetivos específicos:

- Traçar o perfil geral das mulheres com câncer de mama em tratamento quimioterápico;

- Descrever as variáveis hematológicas selecionadas durante a quimioterapia neo e adjuvante;

- Analisar as variáveis de tempo de tratamento, de tempo entre os ciclos e de tempo de sobrevida a partir do tratamento. 


\section{PROCEDIMENTOS METODOLÓGICOS}

\section{II. a. Tipo de estudo}

Estudo retrospectivo, quantitativo, descritivo e exploratório. Descritivo, pois tem como finalidade observar, descrever e documentar os aspectos da situação estudada. Fazem parte da descrição quantitativa a prevalência, o tamanho e os atributos mensuráveis do fenômeno pesquisado. Exploratório, pois visa à investigação dos fatores associados à ocorrência dos efeitos hematológicos e não hematológicos durante o tratamento quimioterápico em mulheres com câncer de mama. E retrospectivo, pois o estudo inicia-se com uma variável independente e segue em busca do efeito presumido (POLIT, BECK, HUNGLER, 2004).

\section{II. b. Local do estudo}

Este estudo foi realizado no HCFMRP-USP, na Unidade do Campus Universitário, utilizando prontuários de mulheres com câncer de mama, atendidas no Ambulatório de Mastologia, entre os anos de 2003 e 2006. Este ambulatório acontece duas vezes por semana e atende em torno de 200 mulheres semanalmente.

Neste ambulatório são realizadas consultas de mulheres com alterações nas mamas, realização de procedimentos diagnósticos, como punções de nódulos mamários, acompanhamento daquelas que tiveram diagnóstico de câncer de mama e estão em tratamento tanto com quimioterapia, radioterapia ou hormonioterapia. São também acompanhadas aquelas que terminaram o tratamento e as mulheres que apresentam recidiva local e/ou metástases.

O Ambulatório de Mastologia possui atendimento multiprofissional, com a equipe de enfermagem, psicologia, além dos médicos ginecologistas, oncologistas clínicos e radiologistas.

As mulheres passam pelo atendimento médico, e aquelas que irão iniciar o tratamento quimioterápico são orientadas, pela enfermeira do setor, quanto às rotinas de retorno, coleta de exames e funcionamento da Central de Quimioterapia, além de orientações quanto aos efeitos colaterais esperados da quimioterapia e o manejo dos mesmos. Após as orientações, elas são encaminhadas à Central de Quimioterapia com agendamento prévio. 
As mulheres que já iniciaram o tratamento quimioterápico, também fazem retornos periódicos no ambulatório, quando são avaliadas pelo médico, que checa os resultados de exames e as condições clínicas para que estas continuem o tratamento quimioterápico. Em seguidas são, novamente, orientadas pela enfermagem quanto à coleta dos exames, retorno no ambulatório e efeitos colaterais. Estes procedimentos são utilizados para as mulheres em tratamento quimioterápico neoadjuvante ou adjuvante.

A Central de Quimioterapia do HCFMRP-USP conta com 14 leitos, sendo 11 acomodações em poltronas em ambiente coletivo e três divãs, em salas de atendimento individual, e são realizadas, diariamente, uma média de 25 atendimentos. Na falta de vaga neste setor, as mulheres podem ser admitidas na Enfermaria de Ginecologia e Obstetrícia, para receberem a quimioterapia, em regime de internação, também de acordo com a disponibilidade de vagas.

A Enfermaria de Ginecologia e Obstetrícia está localizada no oitavo andar do HCFMRP-USP e conta com 26 leitos para as diversas especialidades da Ginecologia, destes, nove leitos são para mulheres com câncer ginecológico em tratamento e dois leitos de isolamento, que podem ser utilizados para outros tipos de atendimento.

Para o procedimento cirúrgico, as mulheres são internadas no dia anterior à cirurgia, ou com um período mais longo, quando necessário a conclusão de exames préoperatórios ou de avaliação de outras especialidades médicas, durante a avaliação de risco cirúrgico.

Durante todo o tratamento, quando estas mulheres apresentam intercorrências, fora do período de internação ou do retorno ambulatorial, são orientadas a procurarem a Unidade de Emergência do HCFMRP-USP, onde também podem permanecer em observação ou internadas. Quando necessário elas podem ser re-encaminhadas para internação na Enfermaria de Ginecologia do Campus.

\section{II. c. Princípios Éticos}

Este estudo foi aprovado pelo Departamento de Ginecologia e Obstetrícia e pelo Comitê de Ética do HCFMRP-USP, segundo as diretrizes e normas regulamentadoras de pesquisas envolvendo seres humanos, regulamentada pela Resolução CNS 196/96. O parecer do Comitê de Ética está no Anexo D. 
Foi aprovada a dispensa do Termo de Consentimento Livre e Esclarecido, pois, como se trata de revisão de prontuários de mulheres submetidas a tratamento de câncer de mama, muitas delas já tiveram alta do serviço, foram a óbito, perderam o seguimento ou abandonaram o tratamento.

\section{II. d. Procedimentos de coleta de dados}

Os dados foram coletados por meio da revisão de prontuários de mulheres em tratamento para o câncer de mama, que o iniciaram com a quimioterapia neoadjuvante, seguido de tratamento cirúrgico e após, pela quimioterapia adjuvante.

Foram revisados os prontuários de todas as mulheres que foram submetidas ao tratamento para o câncer de mama proposto neste estudo, nos anos de 2003 a 2006. Optou-se por iniciar o estudo no ano de 2003, pois foi neste ano que se iniciou o uso de Ciclofosfamida e Epirrubicina como uma das opções de tratamento adjuvante.

Para inclusão no estudo as mulheres deveriam ter iniciado com a quimioterapia neoadjuvante, utilizando o esquema Epirrubicina e Docetaxel, seguido do procedimento cirúrgico, e após a quimioterapia adjuvante, utilizando o esquema de Epirrubicina e Ciclofosfamida.

\section{II. d. 1. Critérios de inclusão e exclusão}

Os critérios de inclusão do estudo foram:

- Prontuários de mulheres na faixa etária de 30 a 60 anos;

- Tratamento quimioterápico como primeira opção;

- Uso dos esquemas quimioterápicos de neoadjuvância e adjuvância propostos para este estudo;

- Tratamento quimioterápico finalizado até dezembro de 2006.

Os critérios de exclusão do estudo foram:

- Prontuário de mulheres no ciclo gravídico-puerperal;

- Prontuário de mulheres que apresentavam doença metastática ou outro tipo de câncer durante o tratamento;

- Prontuário de mulheres que já haviam realizado quimioterapia anteriormente, por câncer de mama ou qualquer outro tipo de câncer;

- Prontuários que não tivessem os dados necessários para o estudo. 


\section{II. e. Amostra em estudo}

Inicialmente foi obtida, na Central de Quimioterapia do HCFMRP-USP, uma relação das mulheres submetidas ao tratamento quimioterápico, no período estudado, computando 441 mulheres com câncer ginecológico.

Em uma primeira revisão desta relação, foram excluídas 37 mulheres submetidas ao tratamento quimioterápico por outros tipos de câncer ginecológico, como câncer de colo de útero e de ovário.

Restaram 404 prontuários que foram revisados, e destes foram excluídos 329 dos quais: em 67 as mulheres tinham idade superior a 60 anos no início do tratamento; em 12, idade inferior a 30 anos; em 23, as mulheres receberam o primeiro tratamento quimioterápico em anos anteriores ao período proposto; em três, as mulheres apresentavam câncer metastático; em 121, as mulheres foram submetidas à esquemas quimioterápicos neoadjuvantes e/ou adjuvantes distintos do proposto; em 75, as mulheres receberam somente o tratamento quimioterápico adjuvante; em 26, terminaram o tratamento somente no ano de 2007, o de uma mulher que estava no período gravídico-puerperal, durante o tratamento e o de uma mulher que abandonou o tratamento.

Preencheram os critérios de seleção 75 prontuários de mulheres com câncer de mama, entretanto foram incluídos 72 , pois no prontuário de três delas não foram encontrados os resultados de exames.

A amostra foi constituída, portanto, de 72 prontuários de mulheres com câncer de mama submetidas ao tratamento quimioterápico neo e adjuvante com esquema proposto para o estudo, no período de 2003 a 2006.

\section{II. f. Variáveis do estudo}

As variáveis sócio-demográficas são:

- Idade: definida a partir da data de nascimento constante no prontuário e a data do diagnóstico

- Raça: aquela que constava no prontuário

- Superfície Corporal (SUPCORP): definido por valores registrados no prontuário e obtido através da tabela constante no Anexo E;

- Co-morbidade: definida pela presença de patologias prévias ao câncer de mama; 
- Menopausa: definida pela data da última menstruação registrada no prontuário;

- Estadio: registrado no prontuário pelo médico no diagnóstico.

Foram definidos como variáveis não hematológicos as listadas a seguir, e graus de toxicidade das mesmas estão demonstrados com no Anexo E, (ALMEIDA, 2004; BONASSA, 2005, NATIONAL CANCER INSTITUTE, 1999):

- Alopecia: têm início de duas a três semanas após o início do tratamento, é reversível após o seu término, entretanto é descrito pelos pacientes como o mais devastador e terrível efeito colateral do tratamento, já que os cabelos são parte importante da aparência física e sua perda altera profundamente a auto-imagem e as relações sociais.

- Fadiga: definida como persistente e subjetiva sensação de cansaço relacionado à doença ou ao seu tratamento e que interfere nas atividades usuais.

- Hiperpigmentação: em geral ocasionada por quimioterápicos vesicantes, mesmo quando infundidos adequadamente. Pode ocorrer após algumas semanas a seguir da aplicação dos quimioterápicos. É mais evidente nas unhas e dobras cutâneas, em geral é transitória, e mais acentuada nos pacientes não protegidos da exposição solar.

- Toxicidade dermatológica local: variam desde um desconforto passageiro na área da aplicação da droga até quadros de necrose tissular severa causada por extravasamento de drogas quimioterápicas vesicantes nos tecidos próximos à veia puncionada, que pode levar a um comprometimento irreversível de nervos e tendões.

-Vômitos: expulsão forçada do conteúdo do estômago, duodeno e/ou jejuno proximal, através da boca e/ou nariz.

- Náuseas: desagradável sensação, mal estar ou sensação de desconforto no epigástrio, região de garganta e/ou abdome.

- Náuseas e vômitos: são os efeitos mais estressantes e incômodos, referidos pelos pacientes. Podem ocorrer juntos ou separadamente, com variações individuais e de acordo com as drogas antineoplásicas utilizadas. Devem ser avaliados separadamente, pois são eventos distintos, com causas também distintas, entretanto aparecem com freqüência juntos e acompanhados por sinais e sintomas, como palidez cutânea, taquicardia entre outros.

- Mucosite: consiste na resposta inflamatória das mucosas à ação dos agentes quimioterápicos. 
As variáveis hematológicas são: glóbulos brancos (GB) e hemoglobina (HB).

Estão apresentadas a seguir, e os graus de toxicidade das mesmas estão demonstrados com no Anexo E (ALMEIDA, 2004; BONASSA, 2005, NATIONAL CANCER INSTITUTE, 1999):

- Mielossupressão ou mielotoxicidade: considerada um dos efeitos adversos mais importantes, é fator dose-limitante e responsável pelo intervalo entre as aplicações. Este efeito é variado para cada droga quimioterápica. É classificada de acordo com o elemento do sangue que se encontra no limite ou abaixo dele:

- Neutropenia: é a queda nas taxas de neutrófilos, que são os leucócitos mais numerosos, seus valores normais são 3.200 a $6.000 / \mathrm{mm}^{3}$ de sangue ou de 54 a 62\%. A neutropenia é o principal fator de risco isolado para quadros infecciosos em indivíduos com câncer, já que os sinais clássicos de infecção podem não ocorrer em função do número limitado de células fagocitárias. Quando ocorre o número de neutrófilos está abaixo de 3000/ $\mathrm{mm}^{3}$;

- Anemia: consiste na redução da concentração de glóbulos vermelhos ou eritrócitos circulantes, que para as mulheres os valores normais de glóbulos vermelhos são de $4.000 \times 10^{3}$ a $5.000 \times 10^{3} / \mathrm{mm}^{3}$ de sangue e de hemoglobina de 12 a 15,5 g\%. Nos pacientes oncológicos a anemia pode ocorrer em diversas situações como perda sanguínea, deficiências nutricionais, tratamento quimioterápico, entre outras. As drogas citostáticas, em doses convencionais raramente levam à anemia severa, a ponto da necessidade de transfusão sanguínea. É caracterizada por apresentar valores abaixo de $12 \mathrm{~g} \%$;

Os valores laboratoriais utilizados neste estudo, tanto para normais quanto para alterados, foram os de referência do Laboratório de Hematologia do HCMRP-USP, que estão descritos no Anexo F.

As variáveis de Tempo e de Tratamento

- Tempo de atraso;

- Tempo de tratamento;

- Tempo de sobrevida;

- Tempo entre os ciclos. 


\section{II. g. Coleta de dados}

Para a coleta de dados foram utilizados os instrumentos descritos abaixo (Apêndices A e B).

\section{II. g. 1. Instrumentos para a coleta de dados}

Foram utilizados dois instrumentos, um para avaliação do tratamento quimioterápico como um todo, e outro instrumento para avaliação das internações necessárias durante o tratamento, exceto para as internações para procedimentos cirúrgicos.

O primeiro instrumento contém informações quanto ao diagnóstico, realização de biópsia, resultado do exame anátomo-patológico, resultado dos hemogramas realizados antes de cada ciclo de quimioterapia, esquema quimioterápico proposto para neoadjuvancia e para adjuvancia, efeitos colaterais pós-quimioterapia, uso de cateter totalmente implantado, intercorrências durante a administração dos quimioterápicos, como reações alérgicas e extravasamento de quimioterápicos, além de dados sobre o procedimento cirúrgico. Estas informações foram obtidas pela pesquisadora, através de revisão do prontuário médico das mulheres atendidas no serviço.

$\mathrm{Na}$ primeira parte do instrumento (quimioterapia neoadjuvante), procurou-se identificar:

- Dados pessoais;

- Patologias associadas;

- Estado menopausal;

- Superfície corporal;

- Biópsia realizada;

- Tipo de câncer e estadiamento clínico;

- Esquema quimioterápico neoadjuvante proposto;

- Dosagem dos quimioterápicos a serem utilizadas;

- Hemograma pré-quimioterapia e anterior a cada ciclo;

- Efeitos hematológicos e não-hematológicos a cada ciclo;

- Atrasos para iniciar o ciclo seguinte e motivo do atraso;

- Internação durante a quimioterapia;

- Redução da dose do quimioterápico em função de toxicidade;

- Implantação de cateter totalmente implantado. 
$\mathrm{Na}$ segunda parte do instrumento (procedimento cirúrgico), procurou-se identificar:

- Hemograma pré-operatório;

- Intervalo entre o último ciclo de quimioterapia neoadjuvante e a cirurgia;

- Tipo de cirurgia;

- Intercorrências no pós-operatório;

- Intervalo entre a cirurgia e o primeiro ciclo de quimioterapia adjuvante.

$\mathrm{Na}$ terceira parte do instrumento (tratamento adjuvante), procurou-se identificar:

- Esquema quimioterápico adjuvante proposto;

- Dosagem dos quimioterápicos a serem utilizadas;

- Hemograma pré-quimioterapia e anterior a cada ciclo;

- Efeitos hematológicos e não-hematológicos a cada ciclo;

- Atrasos para iniciar o ciclo seguinte e motivo do atraso;

- Internação durante a quimioterapia;

- Redução da dose do quimioterápico em função de toxicidade;

- Implantação de cateter totalmente implantado;

- Hemograma após o último ciclo de quimioterapia;

- Data do óbito, se este tiver ocorrido.

E o segundo instrumento, com dados voltados para o período de internação, como fase do tratamento, diagnóstico na admissão, resultado do hemograma realizado na admissão hospitalar, resultado de hemocultura e medicações utilizadas. Estas informações foram obtidas pela pesquisadora, através de revisão do prontuário médico das mulheres atendidas no serviço.

- Fase do tratamento no memento da internação;

- Tempo total (em dias) de internação;

- Diagnóstico na intenção;

- Resultados de exames colhidos (hemograma, hemocultura e urocultura);

- Laudo de raio X, quando realizados;

- Se havia ou não infecção e o sítio infeccioso;

- Antibióticos usados durante a internação;

- Necessidade de transfusão de hemoderivados;

- Uso de fatores de crescimento hematopoiéticos; 
- Medicação para uso domiciliar.

Para a coleta destes dados, foi realizada a leitura do prontuário das mulheres que preencheram os critérios de inclusão, sendo obtidos no atendimento médico, no atendimento de pós-consulta de enfermagem do ambulatório, em impresso padronizado da Central de Quimioterapia, evolução de enfermagem da enfermaria, e no impresso de atendimento da Unidade de Emergência do HCFMRP-USP, para as mulheres que foram internadas nesta unidade, além dos resultados dos exames.

Uma avaliação objetiva da toxicidade do tratamento quimioterápico, foi realizada utilizando uma Tabela de Toxicidade (Anexo E), que estabelece os diversos graus de toxicidade e permite classificar o paciente em escalas de toxicidade maior ou menor, de forma precisa, uniforme e sistemática. A tabela utilizada neste estudo foi baseada na apresentada por Bonassa (2005) que se baseou na tabela do National Cancer Institute (disponível no site: http://safetyprofiler-ctep.nci.nih.gov/CTC/CTC.aspx.)

\section{II. h. Análise dos dados}

Baseado nos objetivos realizou-se:

- Análise descritiva de todas as variáveis;

- Análise descritiva das variáveis: GB e HB para cada ciclo em dois períodos, neoadjuvante (cinco ciclos) e adjuvante (seis ciclos);

- Análise comparativa das variáveis GB e HB para cada ciclo em dois períodos neoadjuvante (cinco ciclos) e adjuvante (seis ciclos);

- Análise comparativa para a variável tempo de atraso, em que se considerou a data do hemograma anterior ao ciclo e a data em que a mulher recebeu o tratamento. Os tempos foram comparados em média nos dois grupos definidos pela variável NEUFINAL (mulheres que apresentaram ou não pelo menos um episódio de neutropenia durante o tratamento). Utilizaram-se testes paramétricos (teste T)

- Análise comparativa entre os dois grupos (NEUFINAL) considerando as variáveis tempo de tratamento e tempo de vida, em que foram obtidas curvas de Kaplan-Meier e estimativas de tempo mediano ou médio para cada grupo. Utilizou-se o teste-não paramétrico de log-Rank para a comparação dos grupos. 


\section{RESULTADOS E DISCUSSÃO}

\section{III. a. Caracterização da amostra}

A amostra foi composta por 72 prontuários de mulheres submetidas ao tratamento de câncer de mama, entre anos de 2003 a 2006, no Setor de Oncoginecologia e Mastologia do HCFMRP-USP.

As mulheres participantes do estudo tinham idade entre 30 a 60 anos, distribuídas em três $(4,1 \%)$ na faixa etária de 30 a 35 anos, 12 (16,6\%) de 36 e 40 anos, $16(22,2 \%)$ de 41 a 45 anos; nove (12,5\%), de 46 e 50 anos; 20 (28\%), de 51 e 55 anos e $12(16,6 \%)$ de 56 e 60 anos (Tabela 1). A média de idade das participantes foi de 47,8 anos.

Os dados obtidos quanto à faixa etária, são pertinentes com a literatura científica que, demonstram que, um maior número de mulheres é acometido pelo câncer de mama após os 45 anos (BOUGHEY et al., 2006; TOLEDANO et al., 2007; LINDEN et al., 2007; STEGER et al., 2007).

A maioria das mulheres, (60-83,3\%), era da raça branca; 10 pardas (14\%), e duas eram $(2,7 \%)$ negras (Tabela 1$)$.

Nos estudos revisados, a maiorias das mulheres também pertenciam à raça branca (BOUGHEY et al., 2006; LINDEN et al., 2007; PEINTINGER et al., 2006; JONES et al., 2006).

No que diz respeito à lateralidade do câncer de mama, observou-se que 42 (58\%) mulheres tiveram a mama esquerda comprometida e $30(42 \%)$, a mama direita (Tabela 1), dado concordante com os outros estudos (BOUGHEY et al., 2006; TOLEDANO et al., 2007; BONNETERRE et al., 2005).

Entre as mulheres estudadas, na época do diagnóstico do câncer de mama, 30 (42\%) eram menopausadas e 42 (58\%) estavam na pré-menopausa (Tabela 1)

Nos dados obtidos na literatura quanto ao status menopausal das mulheres com câncer de mama, observou-se um predomínio da pré-menopausa, como nos dados deste estudo (CITRON et al., 2003; BONNETERRE et al., 2005; PICCART et al., 2001; BOUGHEY et al., 2006; LINDEN et al., 2007). 
Tabela1: Distribuição das mulheres submetidas à quimioterapia para câncer de mama, segundo idade, cor, lateralidade do tumor e status menopausal. Ribeirão Preto, 2008 (N=72).

\begin{tabular}{cc} 
Característica & $\begin{array}{c}\text { Número e porcentagem (\%) } \\
\text { de mulheres }\end{array}$ \\
$30-35$ anos & $3(4,1 \%)$ \\
36 e 40 anos & $12(16,6 \%)$ \\
41 a 45 anos & $16(22,2 \%)$ \\
46 e 50 anos & $9(12,5 \%)$ \\
51 e 55 anos & $20(28 \%)$ \\
56 e 60 anos & $12(16,6 \%)$ \\
Cor & \\
Branca & $60(83,3 \%)$ \\
Negra & $2(2,7 \%)$ \\
Parda & $10(14 \%)$ \\
Eateralidade do tumor & \\
Esquerdo & $42(58 \%)$ \\
Status menopausal & $30(42 \%)$ \\
Pré-menopausa & \\
Menopausa & $42(58 \%)$ \\
\hline
\end{tabular}

\section{III. b. Dados sobre a doença}

A neoplasia mais freqüente foi o carcinoma ductal invasor, que acometeu 51 (71 $\%)$ mulheres estudadas, seguido por carcinoma ductal infiltrante com 14 (19,3\%) mulheres, além de quatro $(5,5 \%)$ que apresentaram carcinoma lobular, uma $(1,4 \%)$ Doença de Paget; uma $(1,4 \%)$ carcinoma intraductal e uma $(1,4 \%)$ carcinoma inflamatório (Tabela 2).

Entre as neoplasias malignas de mama, outros estudos, também, identificam o carcinoma ductal, como o mais freqüente (BOUGHEY et al., 2006; PIEDBOIS et al., 2007; TOLEDANO et al., 2007; NATOLI et al., 2007; PEINTINGER et al., 2006; JONES et al., 2006).

Para confirmação do diagnóstico a técnica da biópsia é utilizada amplamente nas suas diferentes modalidades. No presente estudo a mais utilizada foi a biópsia incisional, realizada em 30 (41,6\%) mulheres e em associação a PBA com a incisional, realizada em $24(33,3 \%)$ mulheres. Os outros tipos de biópsias utilizadas foram: PBA em duas $(2,7 \%)$ mulheres, Tru-cut em sete (10\%), PBA associada à Tru-cut em cinco (7\%) e Tru-cut com incisional em quatro $(5,5 \%)$, como observa-se na Tabela 2 a seguir. 
O estádio clínico do câncer de mama mais observado neste estudo foi o IIIa, com uma freqüência de 25 (34,7\%) mulheres, seguido do IIIb em 20 (27,7\%) mulheres, IIb em 15 (21\%) mulheres e IIa em 12 (16,6\%) mulheres (Tabela 2).

Os resultados obtidos neste estudo diferem da literatura internacional quanto ao estádio, que apresentam uma maior incidência de estádios que variam de I a IIb (BOUGHEY et al., 2006; PEINTINGER et al., 2006; BOURDETTE-RADOUX et al., 2007).

Thuler e Mendonça (2005) analisaram retrospectivamente, o estadiamento feito no diagnóstico do câncer de mama em mulheres brasileiras atendidas no Sistema Único de Saúde (SUS). O estudo foi realizado em duas etapas, a primeira entre os anos de 1990 e 1994, em que avaliaram as informações de 18 hospitais e obtiveram 7458 casos. Destes $21 \%$ tiveram o estádio informado no diagnóstico, e apresentavam um percentual mediano de $14,7 \%$ para o estádio I, 32,9\% para o II, 46,8\% para o III e 3,9\% para o IV.

Na segunda fase entre os anos de 1995 e 2002, buscaram informações em 89 hospitais e sete serviços isolados de quimioterapia ou radioterapia e obtiveram 43.442 casos de câncer de mama, com 80,5\% deles com o estádio informado no diagnóstico. Destes, o percentual mediano foi de 10,9\% para o estádio I, 42,6\% para o II, 32,6\% para o III e 12,3\% para o IV (THULER; MENDONÇA, 2005).

Os autores concluíram que da primeira fase para a segunda fase do estudo, os valores encontrados quanto ao estádio avançado sofreram queda progressiva, passando de $52,5 \%$ para $45,5 \%$. Entretanto estes valores ainda permanecem altos, quando comparados a países desenvolvidos, como os Estados Unidos que apresentam apenas 7,9\% de estádios avançados, IIIb e IV (THULER; MENDONÇA, 2005).

Os dados sobre o estadiamento do câncer de mama no diagnóstico obtidos no presente estudo e em outros da literatura nacional, que apresentam altas taxas de diagnósticos nos estádios III e IV, apontam para que se envide esforços na implementação das diretrizes da detecção precoce (BRASIL, 2004a). A implementação das diretrizes se justifica pelo fato de que a detecção precoce aumenta a eficácia do tratamento e a sobrevida, acrescida de uma melhor qualidade de vida. 
Tabela 2: Distribuição das mulheres submetidas à quimioterapia para câncer de mama, segundo o tipo de neoplasia, biópsia e estádio da doença. Ribeirão Preto, 2008 (N=72).

$\begin{array}{cc}\text { Característica } & \begin{array}{c}\text { Número e porcentagem (\%) } \\ \text { de mulheres }\end{array} \\ \text { Tipo de neoplasia } & 51(71 \%) \\ \text { Ductal invasor } & 14(19,3 \%) \\ \text { Ductal infiltrante } & 4(5,5 \%) \\ \text { Lobular } & (1,4 \%) \\ \text { Doença de Paget } & (1,4 \%) \\ \text { Intraductal } & (1,4 \%) \\ \text { Inflamatório } & \\ \text { Tipo de biópsia } & 30(41,6 \%) \\ \text { Incisional } & 24(33,3 \%) \\ \text { PBA + incisional } & 2(2,7 \%) \\ \text { PBA } & 7(10 \%) \\ \text { Tru-cut } & 5(7 \%) \\ \text { PBA + Tru-cut } & 4(5,5 \%) \\ \text { Tru-cut + incisional } & \\ \text { Estádio da doença } & 12(16,6 \%) \\ \text { IIa } & 15(21 \%) \\ \text { IIb } & 25(34,7 \%) \\ \text { IIIa } & 20(27,7 \%) \\ \text { IIIb } & \end{array}$

Entre as mulheres estudadas $40(55,5 \%)$ não apresentaram outras patologias associadas, enquanto $10(13,8 \%)$ eram hipertensas, seis (8,3\%) apresentavam hipertensão arterial (HAC) e diabete mellitus (DM); quatro (5,5\%) apresentavam depressão; duas (2,7\%) apresentavam anemia e $10(13,8 \%)$ apresentavam outras patologias.

Dentre as cirurgias a que as mulheres estudadas se submeteram, registrou-se que 31 (40\%) foram tumorectomias com linfadenectomia axilar (LA); 25 (34,7\%) fizeram mastectomia com LA; cinco (7\%) foram submetidas a tumorectomia e plástica mamária no mesmo tempo cirúrgico; quatro $(5,5 \%)$ quandrantectomias com LA; três $(4,1 \%)$ mastectomia com LA com reconstrução mamária no mesmo tempo cirúrgico; 1 (1,4\%), ampliação de margem com LA; uma (1,4\%) mastectomia Halsted e duas $(2,7 \%)$ não foram submetidas ao procedimento cirúrgico, pois foram a óbito durante o tratamento quimioterápico neoadjuvante. 
Tabela 3: Distribuição das mulheres submetidas à quimioterapia para câncer de mama, segundo o tipo de cirurgia. Ribeirão Preto, 2008 (N=72).

\begin{tabular}{cc}
\hline Tipo de cirurgia & $\begin{array}{c}\text { Número e porcentagem (\%) } \\
\text { de mulheres }\end{array}$ \\
\hline Mastectomia + LA & $25(34,7 \%)$ \\
Tumorectomias +LA & $31(40 \%)$ \\
Tumorectomia +LA + plástica mamária & $5(7 \%)$ \\
Quandrantectomias + LA & $4(5,5 \%)$ \\
Mastectomia + LA + reconstrução mamária & $3(4,1 \%)$ \\
Ampliação de margem + LA & $1(1,4 \%)$ \\
Mastectomia Halsted+ LA & $1(1,4 \%)$ \\
Não realizaram cirurgia & $2(2,7 \%)$ \\
\hline
\end{tabular}

Muitas mulheres com câncer de mama em estádio iniciais (I e II) são candidatas à cirurgia conservadora, e a quimioterapia neoadjuvante tem sido uma alternativa muito empregada na atualidade para aumentar os índices de cirurgias conservadoras, para mulheres com tumores inicialmente inoperáveis (TIEZZI, 2007).

Como demonstrado na Figura 3 à freqüência de cirurgias radicais neste estudo, entre elas a mastectomia simples e a Halsted, foi 38\% (29) enquanto as cirurgias conservadoras, que incluíram as tumorectomias e as quandrantectomias totalizaram 59\% (41).

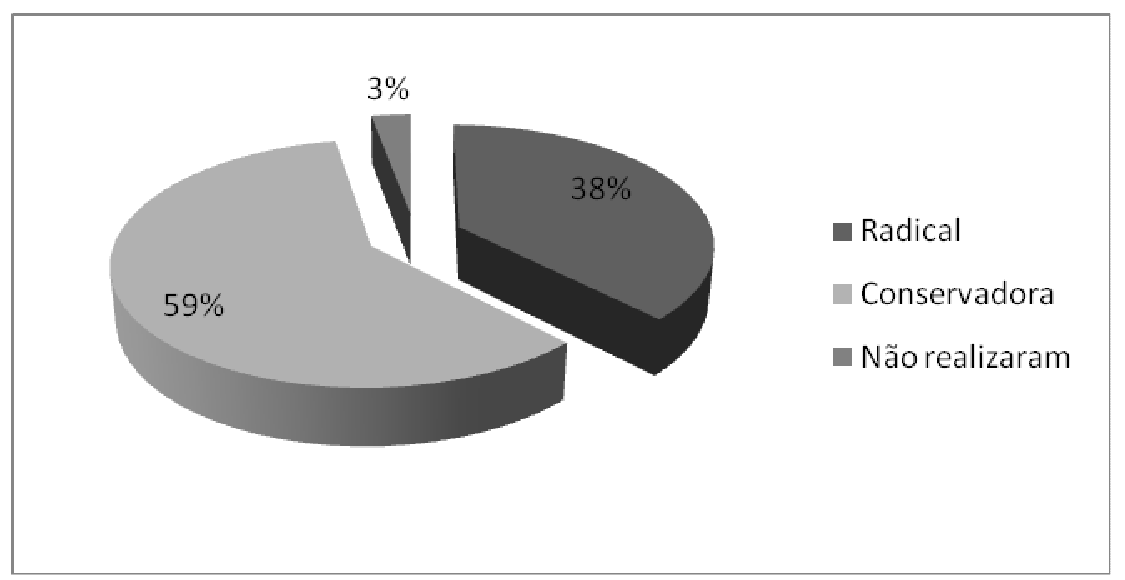

Figura 3: Distribuição das mulheres submetidas à quimioterapia para câncer de mama, segundo o tipo de cirurgia. Ribeirão Preto, 2008 (N=72). 
$\mathrm{Na}$ literatura encontramos estudos randomizados realizados com diferentes esquemas de drogas para quimioterapia neoadjuvante que demonstraram ser efetivos quanto à regressão da doença, sobrevida e aumento do número de cirurgias conservadoras.

Em estudo realizado na Áustria, com 288 mulheres recebendo epirrubicina e docetaxel, 197 (68\%) participantes foram submetidas à cirurgia conservadora e 79 (27\%) à mastectomia (STEGER et al., 2007).

Um estudo retrospectivo nacional, realizado na cidade de São Paulo, 164 mulheres, em estádios variando de IIA a IIIA, foram submetidas à quimioterapia neoadjuvante com FEC por três ciclos. Os autores encontraram que delas realizaram $62,2 \%$ (102) cirurgias conservadoras de mama e 37,8\% (62) mastectomias após o tratamento neoadjuvante. Concluíram que a quimioterapia neoadjuvante favorece a cirurgias mais conservadoras, e quando associada com a avaliação intra-operatória das margens cirúrgicas não observaram recorrência local (KURBET; BARROS; PINOTTI, 2006).

\section{III. c. O tratamento quimioterápico}

Iniciaram o tratamento quimioterápico neoadjuvante, 72 mulheres, entretanto finalizaram o tratamento quimioterápico adjuvante 70 , pois entre os prontuários analisados ocorreram dois óbitos por neutropenia febril durante o tratamento neoadjuvante.

Para o cálculo das dosagens utiliza-se os valores de superfície corporal (SC), que pode ser calculada através da fórmula: $\mathrm{SC}\left(\mathrm{m}^{2}\right)=0,007184 \mathrm{x}$ altura $\left(\mathrm{cm}^{2}\right)$ ou estimada através de tabelas com os valores mais comuns de peso e altura (Anexo G). Entretanto, observa-se que estes valores não foram sistematicamente utilizado para as mulheres do presente estudo.

Para o tratamento neoadjuvante, encontraram-se valores de dosagens que variaram de 100 a 140mg para o docetaxel (DTX), e de 70 a 110mg para a epirrubicina (EPI). Nas Figuras 4 e 5, demonstra-se que para um mesmo valor de superfície corporal as dosagens de drogas utilizadas foram diferentes. Observa-se que a dose de $120 \mathrm{mg}$ de docetaxel foi utilizada para superfícies corporais que variaram de 1,4 a 1,8 $\mathrm{m}^{2}$, enquanto que a dose de $80 \mathrm{mg}$ de epirrubicina foi utilizada para superfície corporal que variou de menos de 1,4 a $1,8 \mathrm{~m}^{2}$. 


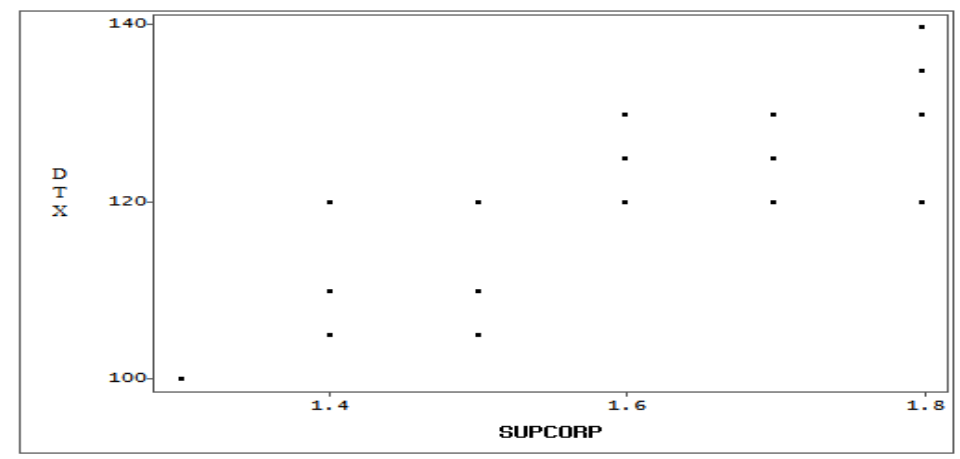

Figura 4: Distribuição das mulheres submetidas à quimioterapia para câncer de mama segundo a superfície corporal e dosagem de docetaxel para o tratamento neoadjuvante. Ribeirão Preto, 2008.

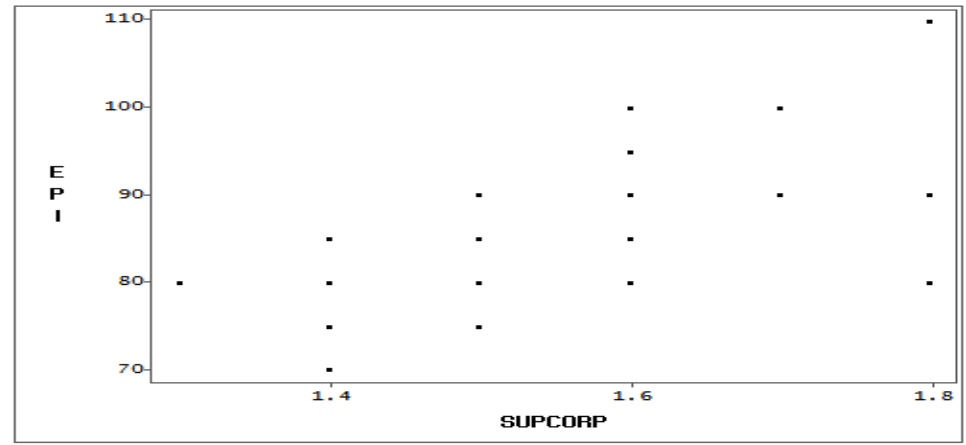

Figura 5: Distribuição das mulheres submetidas à quimioterapia para câncer de mama segundo a superfície corporal e dosagem de epirrubicina para o tratamento neoadjuvante. Ribeirão Preto, 2008.

O mesmo observou-se para o tratamento adjuvante, que apresentou dosagens de 65 a 110mg para a epirrubicina (EPI) e de 800 a 1100mg para a ciclofosfamida (CICLO). Observa-se para um mesmo valor de superfície corporal, que as dosagens foram diferentes como demonstrado nas Figuras 7 e 8 a seguir. No caso da epirrubicina, a dose de 90mg foi utilizada para superfícies corporais que variaram de 1,4 à 1,8 $\mathrm{m}^{2}$, enquanto para a ciclofosfamida, a dose de 1000mg foi utilizada para superfícies corporais de 1,4 a $1,8 \mathrm{~m}^{2}$. 


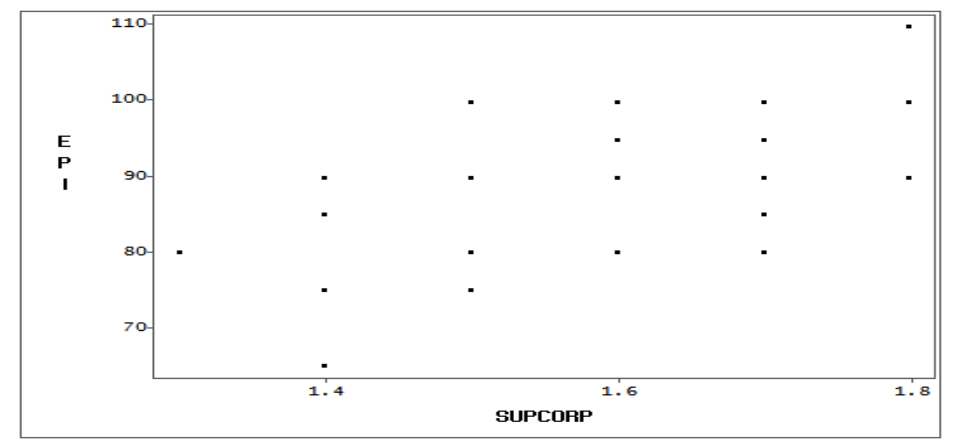

Figura 6: Distribuição das mulheres submetidas à quimioterapia para câncer de mama segundo a superfície corporal e dosagem de epirrubicina para o tratamento adjuvante. Ribeirão Preto, 2008.

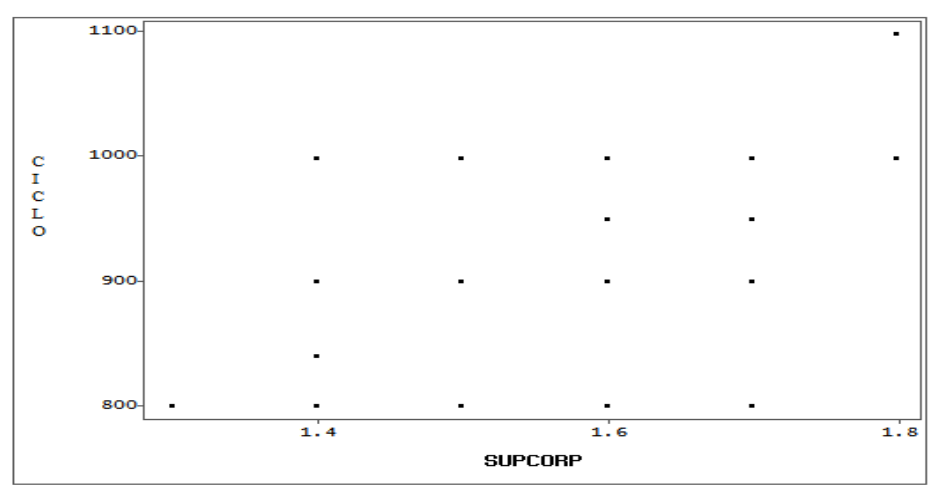

Figura 7: Distribuição das mulheres submetidas à quimioterapia para câncer de mama segundo a superfície corporal e dosagem de ciclofosfamida para o tratamento adjuvante. Ribeirão Preto, 2008.

Estes dados demonstram que, apesar de existir um conceito para o cálculo da dosagem a ser empregada no tratamento quimioterápico, os valores têm sido aproximados, sugerindo estudos prospectivos que avaliem a eficácia dos regimes de tratamento implementados, com ajustes de dose.

Ressalta-se que as dosagens registradas, no presente estudo, foram aquelas do início do tratamento, anteriores à ocorrência de efeitos colaterais que implicasse em ajustes de dose.

Para as 70 mulheres que concluíram o tratamento quimioterápico, incluindo o procedimento cirúrgico, a duração do mesmo variou de cinco a 10 meses, como demonstrado na Tabela 4. 
Tabela 4: Distribuição das mulheres submetidas à quimioterapia para câncer de mama, segundo o tempo de tratamento. Ribeirão Preto, $2008(\mathrm{~N}=70)$.

\begin{tabular}{cc}
\hline Tempo de tratamento em meses & Número de mulheres \\
\hline 5 & 17 \\
6 & 21 \\
7 & 16 \\
8 & 8 \\
9 & 6 \\
10 & 2 \\
\hline
\end{tabular}

O número total de ciclos de quimioterapia para todas as mulheres do estudo foi de 558, sendo 253 ciclos na fase de neoadjuvância e 305 na adjuvância.

Em cada fase do tratamento, o número de ciclo foi variado, sendo que, no tratamento neoadjuvante, $94,4 \%$ das mulheres foram submetidas a três ciclos, e no tratamento adjuvante $97,2 \%$ das mulheres foram submetidas a quatro ciclos. Somente sete $(9,7 \%)$ mulheres receberam cinco ciclos de quimioterapia neoadjuvante, 10 $(13,8 \%)$ mulheres receberam seis ciclos de quimioterapia adjuvante e duas $(2,7 \%)$ mulheres receberam sete ciclos de quimioterapia adjuvante.

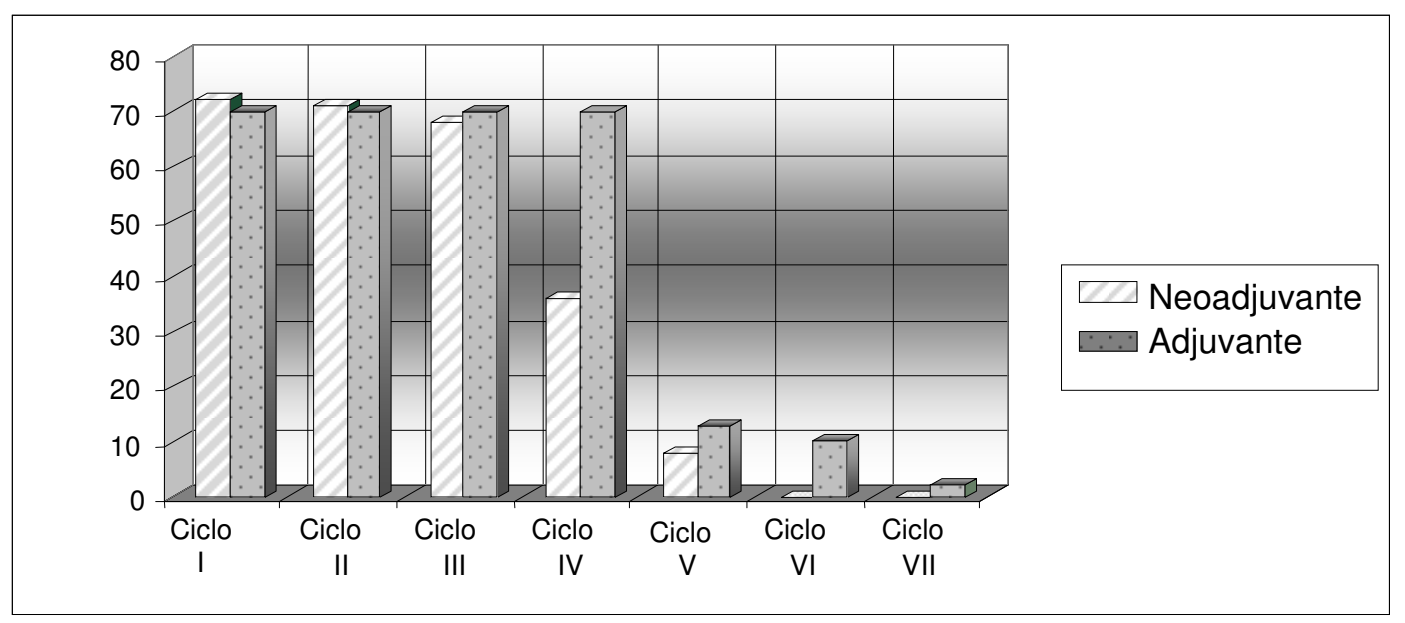

Figura 8: Distribuição das mulheres submetidas à quimioterapia para câncer de mama, segundo o período do tratamento e o número de ciclos. Ribeirão Preto, 2008 (N=72).

\section{III. d. Complicações e intercorrências durante o tratamento para câncer de mama}

\section{III. d. 1. Hospitalizações durante o tratamento quimioterápico}

Durante o tratamento quimioterápico, das 72 mulheres estudadas, $16(22,2 \%)$ foram internadas, num total de 22 internações. Entre estas internações não foram incluídas internações para risco ou procedimento cirúrgico. 
Em relação ao período de tratamento, 13 (59\%) internações ocorreram durante o período neoadjuvante, quatro (18\%) após a cirurgia, porém antes de iniciar o tratamento adjuvante e cinco $(22,7 \%)$ no tratamento adjuvante.

Os motivos das internações foram variados, com um predomínio da neutropenia febril, que foi responsável por 13 das internações, sendo 11 no tratamento neoadjuvante e duas no adjuvante. Outro motivo, responsável por seis internações, foi deiscência de ferida operatória, gerando quatro internações após a cirurgia porém antes de iniciar a quimioterapia adjuvante e duas durante a adjuvância.

Durante o tratamento neoadjuvante outros dois motivos de internações foram: infecção de vias aéreas superiores (IVAS) e controle de perfil glicêmico. No tratamento adjuvante outro motivo de internação foi pneumonia. Vale ressaltar que em ambas as internações não tinham relação direta com o efeito da quimioterapia, comprovado pelos exames disponíveis nos prontuários.

Tabela 5: Distribuição das mulheres submetidas à quimioterapia para câncer de mama, segundo o motivo da internação durante o tratamento. Ribeirão Preto, 2008 (N=22).

\begin{tabular}{ccc}
\hline Período do tratamento & Motivo da internação & Número de mulheres \\
\hline Neoadjuvante & Neutropenia febril & 11 \\
& IVAS & 1 \\
& Controle de perfil glicêmico & 1 \\
Pós-cirúrgico & Deiscência de ferida operatória & 4 \\
\hline Adjuvante & Neutropenia febril & \\
& Pneumonia & 2 \\
& Deiscência de ferida operatória & 1 \\
\hline
\end{tabular}


Tabela 6: Distribuição das mulheres submetidas à quimioterapia para câncer de mama, segundo o sítio de infecção durante a internação. Ribeirão Preto, 2008 (N=22).

\begin{tabular}{|c|c|c|c|c|}
\hline \multirow{2}{*}{\multicolumn{5}{|c|}{$\begin{array}{l}\text { Período do } \\
\text { tratamento }\end{array}$}} \\
\hline & & & & \\
\hline Sem infecção & 6 & 0 & 0 & 6 \\
\hline IVAS & 1 & 0 & 1 & 2 \\
\hline Pneumonia & 1 & 0 & 1 & 2 \\
\hline Choque séptico & 1 & 0 & 0 & 1 \\
\hline Ferida operatória & 0 & 4 & 2 & 6 \\
\hline Mastite & 1 & 0 & 0 & 1 \\
\hline ITU & 1 & 0 & 0 & 1 \\
\hline Abscesso dentário & 1 & 0 & 0 & 1 \\
\hline $\begin{array}{l}\text { Cateter totalmente } \\
\text { implantado }\end{array}$ & 0 & 0 & 1 & 1 \\
\hline Não especificada & 1 & 0 & 0 & 1 \\
\hline
\end{tabular}

Entretanto, sabe-se que indivíduos com câncer, quando comparados com indivíduos com outras co-morbidades, apresentam risco aumentado para infecção. Fatores como cirurgias extensas, deficiências nutricionais, co-morbidades pré-existentes ou adquiriras recentemente e a imunossupressão tornam os indivíduos mais vulneráveis a infecções, destacando-se aquelas de vias respiratórias pela diminuição da mobilidade dos mesmos (SIPSAS; BODEY; KONTOYANNIS, 2005).

\section{III. d. 2. Complicações e intercorrências no pós-operatório}

Durante a coleta de dados, foi possível identificar que algumas mulheres apresentaram uma ou mais intercorrências de graus e intensidades variados no pósoperatório, tais como: seroma, hematoma, deiscência da ferida cirúrgica, infecção e necrose de pele.

Dentre as 72 mulheres estudadas, duas (3\%) não foram submetidas ao procedimento cirúrgico, 50 (69\%) não apresentam relato no prontuário quanto a complicações e 20 (28\%) apresentaram algum tipo de intercorrências após a cirurgia.

Destas 20 mulheres, quatro $(5,7 \%)$ apresentaram deiscência da ferida cirúrgica; quatro $(5,7 \%)$ seroma; quatro $(5,7 \%)$ por infecção da ferida cirúrgica; uma $(1,2 \%)$ necrose de pele; três $(4,2 \%)$ por hematoma, destas, uma precisou de re-exploração cirúrgica; uma $(1,2 \%)$ apresentou deiscência e hematoma; uma $(1,2 \%)$ deiscência e seroma; duas $(2,8 \%)$ apresentaram infecção e seroma. 
Todas as mulheres que apresentaram deiscência da ferida cirúrgica foram acompanhadas pela equipe de enfermagem do ambulatório de Ginecologia e Obstetrícia, responsáveis pelos curativos e avaliações da evolução da ferida na unidade. Este seguimento segue protocolo aprovado pela instituição e foi definido pelo Grupo de Estudos de Lesão de Pele do HCFMRP-USP.

Tabela 7: Distribuição das mulheres submetidas à quimioterapia para câncer de mama segundo, complicações/ intercorrências cirúrgicas. Ribeirão Preto, $2008(\mathrm{~N}=20)$.

\begin{tabular}{cc}
\hline Complicações / Intercorrências & Número de mulheres \\
\hline Infecção & $4(5,7 \%)$ \\
Deiscência & $4(5,7 \%)$ \\
Seroma & $4(5,7 \%)$ \\
Necrose & $1(1,2 \%)$ \\
Hematoma & $3(4,2 \%)$ \\
Mais de uma intercorrência & $4(5,7 \%)$ \\
Total de intercorrências & $20(28 \%)$ \\
Não apresentaram intercorrências & $50(71,4 \%)$ \\
Não foram submetidas à cirurgia & $2(3 \%)$ \\
Necessidade de internação por infecção & $6(8,5 \%)$ \\
\hline
\end{tabular}

O seroma pode ser definido como a coleção de linfa que se acumula na região operada, seja na mama ou na axila, e sua presença está associada a outras complicações como necrose, demora na cicatrização, infecção e linfedema (BARBOSA et al., 2004; POGSON; ADWANI; EBBS, 2003; BOMAN; LINDGREN; SANDELIN, 2002; STEHBENS, 2003).

Neste estudo observou-se que, sete $(9,7 \%)$ mulheres apresentaram seroma, isolado ou associado a outras intercorrências pós-operatória. Este dado apresenta valor abaixo dos encontrados na literatura que variam de 13 a 60\% (GOZZO, 2005; DALBERG, 2004).

Outra intercorrência, freqüente no processo de tratamento da mulher com câncer de mama, tem sido a infecção do sítio cirúrgico. Em estudos realizados nesta mesma instituição, Gozzo (2005) obteve $23,1 \%$ de mulheres com deiscência da ferida operatória e Barbosa et al. (2004) encontraram uma taxa de infecção cirúrgica de 20,7\%. A ocorrência de 8,5\% de infecção, encontrada neste estudo, está abaixo daquela encontrada nos estudos anteriormente citados que foram realizados na mesma instituição, podendo levar a se pensar em falta de registro desta ocorrência nos prontuários analisados. 
Barbosa et al. (2004) referem que existem discrepâncias na literatura quanto à taxa de infecção de cirurgias mamárias, por falta de uniformização das definições para a mesma. Acrescentam ainda, que a quimioterapia neoadjuvante é fator de risco para esta intercorrência, e que as infecções do sítio cirúrgico deixam efeitos nocivos para as mulheres, como seqüelas cosméticas e aumento do trauma psicológico.

\section{III. d. 3. Complicações e intercorrências nos ciclos de quimioterapia}

Durante o tratamento quimioterápico, foi realizado um total de 558 ciclos, e houveram intercorrências variadas, interferindo na duração do tratamento entre as mulheres. No tratamento neoadjuvante, houve 14 internações, sendo 13 por neutropenia febril e uma por diabetes mellitus descompensada e dois óbitos por neutropenia febril. Foram registrados 77 eventos adversos, sendo 59 por toxicidade não-hematológica e 59 por toxicidade hematológica, 37 atrasos entre os ciclos e uma redução da dose de quimioterápico.

Durante o tratamento adjuvante, o número de internações foi cinco, sendo duas por neutropenia febril e três por outros motivos (duas para tratamento de infecção de ferida operatória e uma por pneumonia). Foram registrados 75 eventos adversos, sendo 50 por toxicidade não-hematológica e 25 por toxicidade hematológica, porém o número de atrasos foi maior, com a ocorrência de 115 atrasos entre os ciclos e cinco reduções de dose dos quimioterápicos, como demonstra a Tabela 8.

Tabela 8: Distribuição das mulheres submetidas à quimioterapia para câncer de mama, segundo intercorrências entre os ciclos. Ribeirão Preto, 2008 ( N=558).

\begin{tabular}{lccc}
\hline & Neoadjuvante & Adjuvante & Total \\
\hline Número de ciclos realizados & 253 & 305 & 558 \\
& & & 152 \\
Número total de eventos adversos & 77 & 50 & 109 \\
Toxicidade não- hematológica & 59 & 25 & 43 \\
Toxicidade hematológica & 18 & & 19 \\
Número total de hospitalizações & 13 & 05 & 15 \\
Neutropenia febril & 13 & 02 & 4 \\
Outros motivos & 01 & 03 & 152 \\
& & & 06 \\
\hline Número de atrasos entre os ciclos & 37 & 05 & 0115 \\
\hline
\end{tabular}


O número de atrasos entre os ciclos foi muito variado para o tratamento neoadjuvante e o adjuvante. Apesar do registro de toxicidade hematológica ser de 18 para o neoadjuvante e 25 para o adjuvante, o número de total de atrasos, entre os ciclos por alterações nos exames hematológicos, é superior a estes. Neste estudo foi registrado como motivo do atraso para a realização da quimioterapia, o que o médico responsável pelo atendimento das mulheres no dia do atendimento registrou no prontuário. Os motivos são variados, como demonstra a Tabela 9.

Tabela 9: Distribuição das mulheres submetidas à quimioterapia para câncer de mama, segundo o motivo do atraso entre os ciclos. Ribeirão Preto, $2008(\mathrm{~N}=153)$.

\begin{tabular}{lccccc}
\hline \multicolumn{1}{c}{ Motivo do atraso } & \multicolumn{2}{c}{ Neoadjuvante } & \multicolumn{2}{c}{ Adjuvante } & Total \\
& Número & $\mathbf{\%}$ & Número & $\%$ & Número \\
\hline Não colheu exames & 5 & 13,1 & 6 & 5,2 & 11 \\
$\begin{array}{l}\text { Alteração nos } \\
\text { exames }\end{array}$ & 14 & 39,5 & 67 & 58,2 & 82 \\
Falta & 2 & 5,2 & 7 & 6,1 & 9 \\
Falta de vaga & 3 & 8 & 3 & 2,6 & 6 \\
Óbito & 2 & 5,2 & - & - & 2 \\
Não relatado & 8 & 21 & 20 & 17,4 & 28 \\
Outros & 3 & 8 & 12 & 10,5 & 15 \\
Total & 37 & 100 & 115 & 100 & 153 \\
\hline
\end{tabular}

\section{III. d. 3.1. Toxicidade não-hematológica}

Não foi possível, durante a revisão dos prontuários, identificar o grau de toxicidade dos efeitos adversos não-hematológicos, pois quando estes efeitos estavam registrados no atendimento médico ou de enfermagem, apareciam apenas citados, sem descrição, dificultando a avaliação do grau da toxicidade apresentada.

$\mathrm{Na}$ coleta de dados considerou-se cada vez que o evento foi mencionado no prontuário, tanto no atendimento médico quanto no de enfermagem, contabilizando apenas um evento quando o mesmo era registrado por ambos os profissionais no mesmo dia. 
Tabela 10: Distribuição da freqüência de toxicidade não-hematológica em mulheres submetidas à quimioterapia, Ribeirão Preto, 2008 (N=109).

\begin{tabular}{lccc}
\hline $\begin{array}{c}\text { Toxicidade não- } \\
\text { hematológica }\end{array}$ & Neoadjuvante & Adjuvante & Total \\
\hline \multicolumn{1}{c}{ Gastrointestinal } & Total $=27$ & Total $=27$ & $54(49,5 \%)$ \\
Mucosite & $5(8,4 \%)$ & $1(2 \%)$ & $4(3,6 \%)$ \\
Náusea & $11(18,6 \%)$ & $9(18 \%)$ & $20(18,3 \%)$ \\
Vômito & $2(3,3 \%)$ & $9(18 \%)$ & $11(10 \%)$ \\
Mais de um efeito & $9(15,2 \%)$ & $8(16 \%)$ & $17(15,5 \%)$ \\
\multicolumn{1}{c}{ Dermatológica } & Total $=26$ & Total $=11$ & $37(34 \%)$ \\
Trajeto venoso escurecido & $14(23,7 \%)$ & $6(12 \%)$ & $20(18,3 \%)$ \\
Veias endurecidas & $5(8,4 \%)$ & $5(10 \%)$ & $10(9,1 \%)$ \\
Outros & $2(3,3 \%)$ & - & $2(1,8 \%)$ \\
\multicolumn{1}{c}{ Outros } & Total $=6(10,1 \%)$ & Total $=12(24 \%)$ & $18(16,5 \%)$ \\
\multicolumn{1}{c}{ Total } & 59 & 50 & 109 \\
\hline
\end{tabular}

A infecção do trato urinário (ITU), não aparece como toxicidade, entretanto entre as mulheres estudadas, 10 apresentaram ITU, sendo duas na neoadjuvância e oito na adjuvância. Cabe mencionar que um dos eventos adversos relacionados ao uso da ciclofosfamida é a ocorrência de intercorrências vesicais, destacando-se a necessidade de uma melhor avaliação da mesma, associando uma constante orientação às mulheres acerca da hidratação oral e observação de sinais e sintomas que poderiam estar associados ao tratamento.

Nas Figuras 9 e $\mathbf{1 0}$ estão demonstradas as ocorrências de efeitos adversos relacionados à rede venosa da mulher, os efeitos gastrointestinais e outros efeitos, registrados por ciclos do tratamento quimioterápico, tanto para a neoadjuvância quanto para a adjuvância.

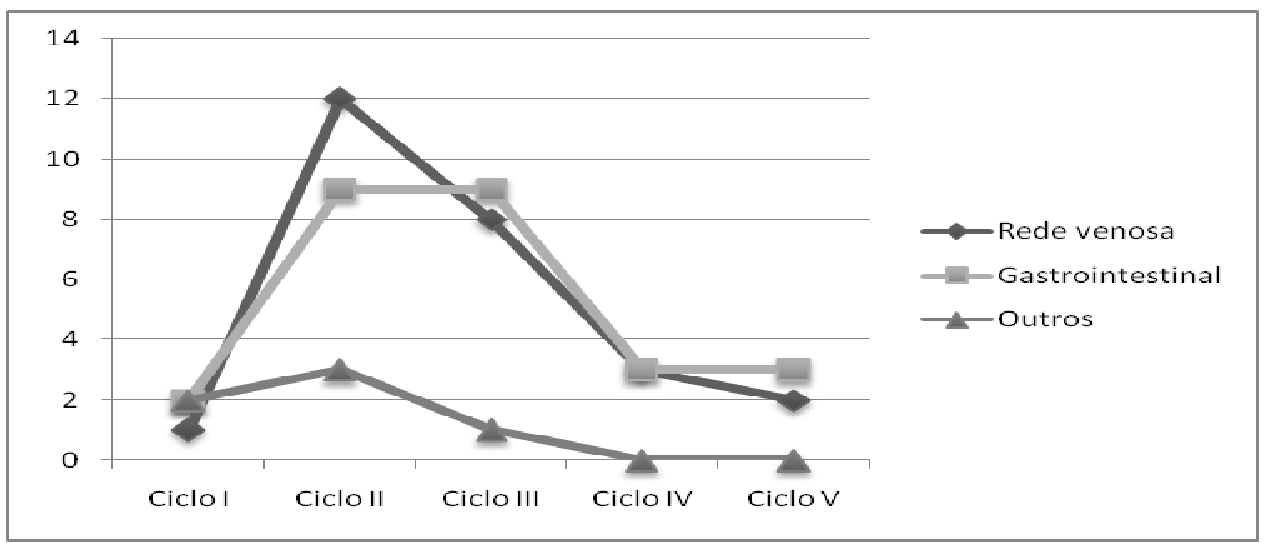

Figura 9: Distribuição da freqüência de toxicidade não-hematológica nas mulheres submetidas à quimioterapia neoadjuvante, Ribeirão Preto, 2008 (N=72). 


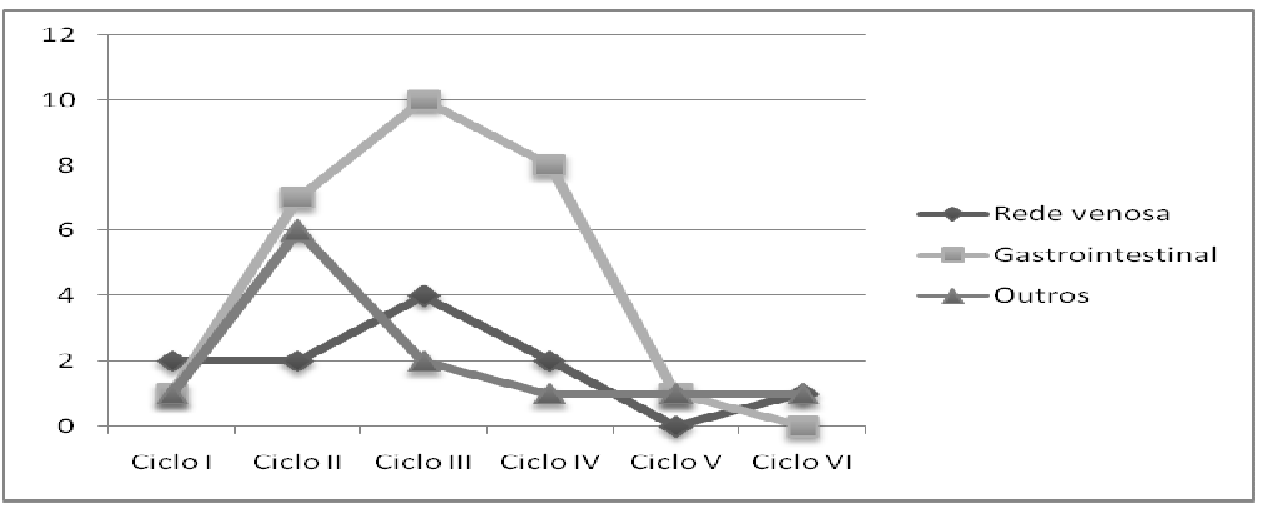

Figura 10: Distribuição da frequiência de toxicidade não-hematológica nas mulheres submetidas à quimioterapia adjuvante, Ribeirão Preto, $2008(\mathrm{~N}=70)$.

A ocorrência das toxicidades não-hematológicas neste estudo podem estar subestimadas devido à falta de registro das mesmas. Acredita-se que o questionamento das mulheres e o registro destes eventos ficam em segundo plano em razão do volume de atendimentos realizados pelas equipes médicas e de enfermagem e, por estes profissionais considerarem os eventos adversos como náusea, vômito e alopecia esperados e frequientes para indivíduos recebendo quimioterapia, deixando de registrar tais ocorrências.

Nos estudos utilizando os mesmos quimioterápicos (docetaxel e epirrubicina) para neoadjuvância, Ramaswamy et al. (2005) relatam 4\% de mucosite, Amat et al. (2003) relatam 48,9\% de toxicidade gastrointestinal, Espinosa et al. (2004) citam 38\% de náuseas e vômitos e 38\% de estomatite e Ardavanis et al. (2001) citam 20\% de náusea/vômito.

Para a adjuvância, os estudos revisados trazem valores de $25 \%$ de náusea e $1 \%$ de mucosite em Piccart et al. (2007), 2\% de mucosite em Carmichael (2001), Jones et al. (2006) referem 7\% de náusea, 5\% de vômito e 1\% de estomatite e Linden et al. (2007) apresentam 11\% de náusea, 10\% de vômito e 5\% de estomatite.

Apesar do registro dos eventos adversos não terem sido realizados para todas as pacientes em todas as consultas, os valores encontrados, neste estudo, para a toxicidade gastrointestinal durante a neoadjuvância e a adjuvância foram: para mucosite 8,4\% e $2 \%$, para náusea $18,6 \%$ e $18 \%$ e para vômito $3,3 \%$ e $18 \%$, respectivamente, sendo compatíveis com literatura na adjuvância e abaixo na neoadjuvância. 
Em relação aos registros de toxicidade dermatológica, observa-se que, em razão do impresso utilizado pela enfermagem na Central de Quimioterapia do HCFMRP-USP $($ Anexo $\mathrm{H})$ as ocorrências relacionadas à rede venosa são registradas sistematicamente.

Entre as ocorrências encontrou-se $23,7 \%$ de registro de trajeto venoso escurecido na quimioterapia neoadjuvante e $12 \%$ na adjuvante. Dados acerca de comprometimento vascular não são encontrados na literatura que, apresenta como evento adverso dermatológico as reações de hipersensibilidade e alopecia. Tal fato pode estar relacionado ao uso de cateteres de longa duração durante a realização deste tratamento, com menores comprometimentos venosos, fato que na instituição ainda não é rotineiro entre as mulheres com câncer de mama.

Para a toxicidade dermatológica, Amat et al. (2003) encontraram 37,5\% de toxicidade cutânea e 44,3\% de reações de hipersensibilidade; Espinosa et al. (2004), citam como as mais freqüente a alopecia, com $80 \%$ das ocorrências. Neste estudo a alopecia foi registrada somente para uma $(1,6 \%)$ paciente no tratamento neoadjuvante, apesar de observar-se como evento adverso universal para estas mulheres, e as reações de hipersensibilidade ao decetaxel para cinco $(8,4 \%)$ mulheres.

Outra intercorrência observada foi o extravasamento durante o tratamento quimioterápico que, ocorreu em 17 (23,6\%) mulheres, entretanto houve 20 registros de extravasamento, sendo que nove foram na fase de neoadjuvância e 11 na adjuvância. Este fato demonstra que algumas mulheres apresentaram mais de uma ocorrência de extravasamento em diferentes ciclos, ou até no mesmo ciclo.

O registro de extravasamento, também, é facilitado pelo impresso utilizado na Central de Quimioterapia, e os profissionais reconhecem, sua ocorrência, como relevante para o tratamento de indivíduos recebendo quimioterapia. 
Tabela 11: Distribuição das mulheres submetidas à quimioterapia para câncer de mama, segundo a ocorrência de extravasamento. Ribeirão Preto, 2008 (N=20).

\begin{tabular}{lccc}
\hline Extravasamento & Neoadjuvante & Adjuvante & Total \\
\hline Número de eventos & 09 & 11 & 20 \\
Droga & & & \\
Epirrubicina & 08 & 08 & 16 \\
Docetaxol & 01 & - & 01 \\
Ciclofosfamida & - & 03 & 03 \\
Ciclos & & & \\
1 & 04 & 02 & 06 \\
2 & 02 & 01 & 03 \\
3 & 02 & 02 & 04 \\
4 & 01 & 06 & 07 \\
\hline
\end{tabular}

Entre as drogas utilizadas, no protocolo estudado, a epirrucicina é uma droga vesicante, enquanto o docetaxel é irritante, porém pode causar necrose moderada do tecido dependendo do volume e concentração do extravasamento. A ciclofosfamida não é vesicante nem irritante não levando a comprometimento da rede venosa.

Drogas vesicantes têm sido utilizadas rotineiramente há décadas, e existe uma lacuna nas evidências informadas e no seu controle. Quando ocorre um extravasamento ou este é suspeito, é parada a infusão, e a área afetada deve ser inspecionada e utiliza-se o tratamento com antídoto adequado para aquela droga (SCHULMEITER, 2007).

Considerou-se para este estudo, extravasamento de quimioterápicos, todo registro realizado pelas enfermeiras da Central de Quimioterapia, mesmo quando havia dúvida se o extravasamento ocorrera, apesar da queixa da mulher, como no caso de preservação do retorno venoso. Nesses casos, era registrada a queixa da mulher e aplicado o protocolo.

$\mathrm{Na}$ Tabela 12 encontram-se os resultados das condutas relacionadas à ocorrência de extravasamento. Observa-se que apesar do protocolo definido pela instituição, os registros variaram quanto à sua aplicação na ocorrência do extravasamento pela mesma droga, como demonstrado a seguir. 
Tabela 12: Distribuição das mulheres submetidas à quimioterapia para câncer de mama, segundo a aplicação do protocolo de extravasamento. Ribeirão Preto, 2008 (N=20).

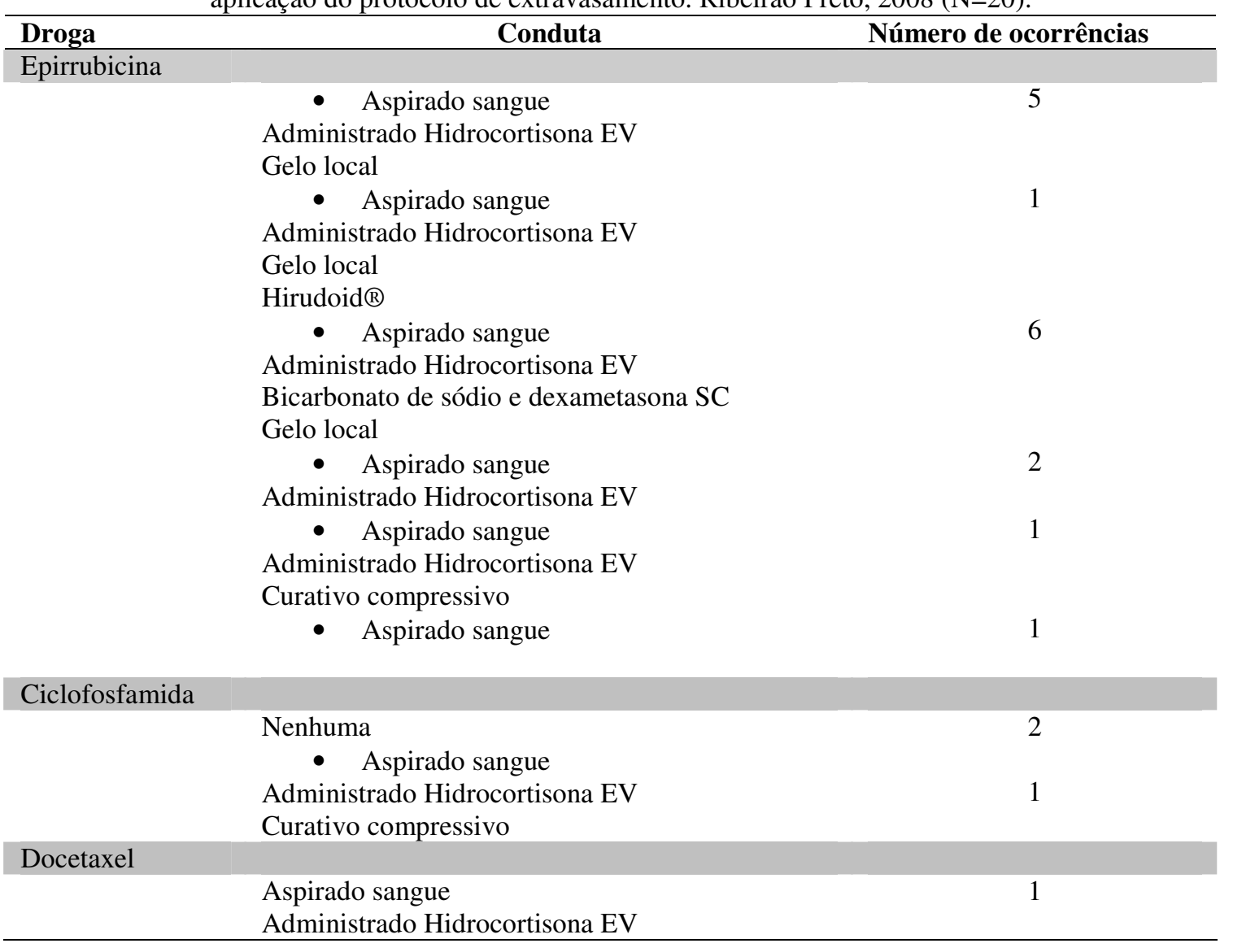

O seguimento e as conseqüências destes extravasamentos aparecem pobremente relatadas, e há poucos relatos registrados em prontuário, seja pela equipe de enfermagem da Central de Quimioterapia, do Ambulatório de Ginecologia ou da enfermaria.

Dos 20 registros de extravasamento, observou-se nove (45\%) na fase de neoadjuvância e as consequiências registradas no prontuário foram: duas $(22,2 \%)$ relatos de lesão endurecida no local, uma $(11,1 \%)$ referência de não apresentar alterações, uma $(11,1 \%)$ fibrose no local e uma $(11,1 \%)$ relato de dor, hiperemia e lesão endurecida no local, enquanto que para quatro $(44,4 \%)$ ocorrências não há registro do seguimento.

$\mathrm{Na}$ fase de adjuvância, dos 11 extravasamentos registrados, observou-se dois $(18, \%)$ relatos de lesão endurecida no local, uma $(9,1 \%)$ fibrose e dor local, que foi encaminhada à fisioterapia para implementar recursos que melhorassem a dor e a movimentação da mão afetada, e para oito $(72,7 \%)$ ocorrências não há registro do seguimento. 
Observa-se que a ocorrência de extravasamento de quimioterapia foi de 23,6\%, sendo mais elevada do que a literatura, que refere estar em torno 0,01 a $6,5 \%$, (SCHULMEISTER, 2007), porém são escassos os estudos que trazem o relato da ocorrência do extravasamento. Bonassa (2005) refere que a incidência desta ocorrência é subnotificada, entretanto essa ocorrência elevada neste estudo aponta para a capacitação dos profissionais que administram os quimioterápicos na instituição estudada que valorizam o registro da maioria destas ocorrências.

\section{III. d. 3.2. Toxicidade hematológica}

A toxicidade hematológica engloba eventos como a anemia, a neutropenia, a neutropenia febril, a lifocitopenia, a plaquetopenia e a leucopenia.

Destacam-se a neutropenia, a anemia e a neutropenia febril, como as mais freqüentes, que têm impacto significativo na saúde geral do indivíduo com câncer. Elas podem levar a atrasos entre os ciclos, reduções na dose dos quimioterápicos e até interrupção do tratamento, comprometendo o resultado final do mesmo (BONADONNA et al., 1995).

Entre as mulheres estudas observa-se a ocorrência de anemia, neutropenia, hospitalização e atrasos nos ciclos, tanto no tratamento neoadjuvante como no adjuvante, conforme apresentado nos gráficos 11 e 12.

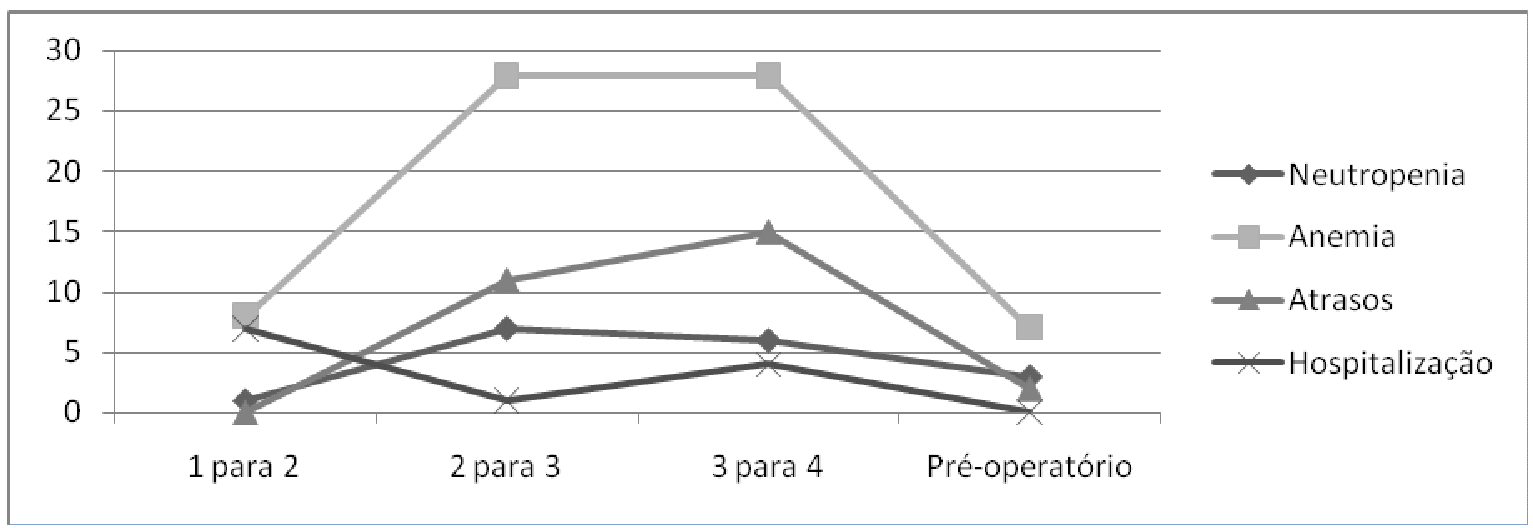

Figura 11: Distribuição da freqüência de toxicidade hematológica nas mulheres submetidas à quimioterapia neoadjuvante, Ribeirão Preto, 2008 (N=72). 


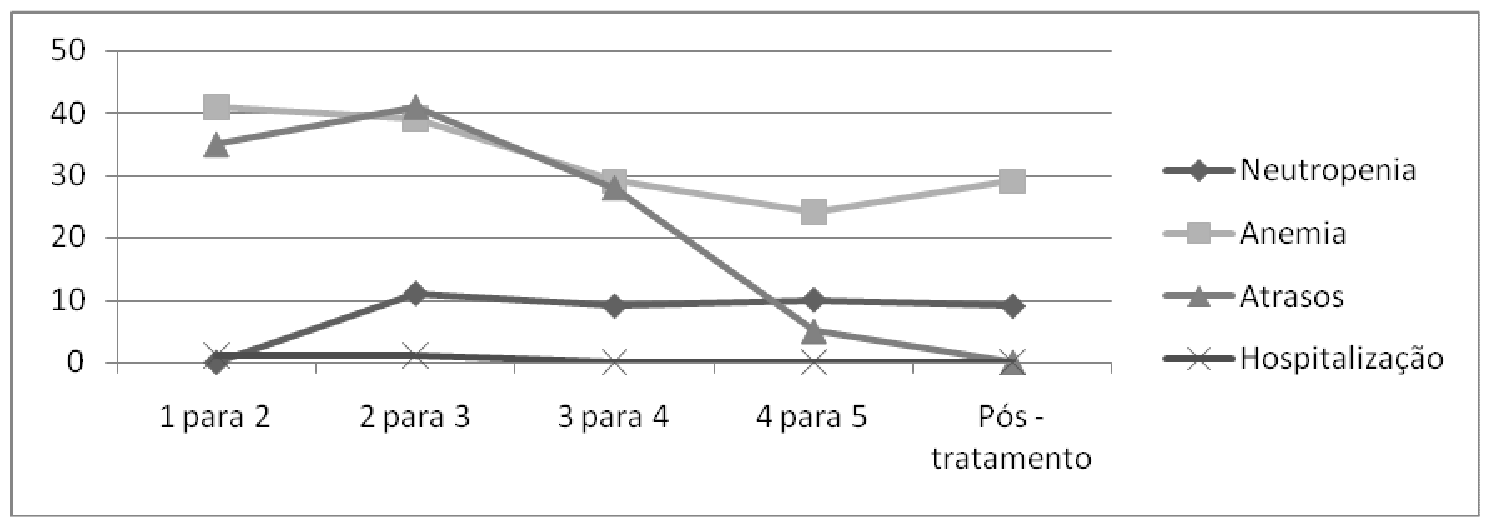

Figura 12: Distribuição da freqüência de toxicidade hematológica nas mulheres submetidas à quimioterapia adjuvante, Ribeirão Preto, 2008 (N=70).

\section{III. d. 3.2. 1. Neutropenia}

Os glóbulos brancos (GB) formam o grupo mais heterogêneo das células sanguíneas e os neutrófilos são os mais abundantes e altamente especializados. De modo geral desempenham papel importante na defesa do organismo, com funções específicas para cada subgrupo (COUTINHO; COUTINHO, 2004).

Muitas terapias anti-câncer baseiam-se na supressão de células de rápida divisão, como as células tumorais. Entretanto, as células da medula óssea, responsáveis pela produção de células hematopoiéticas, entre elas, os GB, que também, são células de rápida proliferação, são destruídas durante o tratamento quimioterápico, implicando em evento adverso importante que pode levar a atrasos nos ciclos, redução da dose e piora na qualidade de vida das mulheres (FORTNER et al., 2005).

A introdução dos taxanos e o aumento nas doses dos antracíclicos favoreceram o aumento da ocorrência das mielotoxicidades, resultando no risco de neutropenia febril (NF) e infecções durante o tratamento (DEBLED et al., 2007).

A neutropenia é a diminuição das células brancas do sangue, com contagem de GB abaixo de $3 \times 10^{9}$ células/L e o National Cancer Institute's Common Toxicity Criterias (1999) classifica a neutropenia em 5 graus, em que o grau cinco representa óbito do paciente.

A neutropenia é o evento que mais interfere no limite da dosagem do quimioterápico. Sua ocorrência está associada a aumento da mortalidade, morbidade e custos do tratamento, além de não ser possível prever quais pacientes irão apresentá-la (LYMAN et al., 2005; RIVERA et al., 2003). 
Ela predispõe à neutropenia febril (NF), que é uma complicação potencialmente fatal da quimioterapia, necessitando de hospitalização para tratamento empírico com antibióticos de amplo espectro, e pode levar ainda a redução da dose do quimioterápico ou atraso no tratamento, o que irá comprometer a resposta do mesmo (LYMAN et al., 2005; RIVERA et al., 2003; BONADONNA et al., 1995; SAVVIDES et al., 2001).

Este evento adverso preocupa toda a equipe de saúde envolvida no tratamento de pacientes oncológicos, e a relação entre a dose do quimioterápico, a redução de dose e o desfecho para o paciente está bem estudada na literatura médica.

Neste estudo observou-se que 31 (43\%) mulheres apresentaram, pelo menos, um episódio de neutropenia durante o tratamento quimioterápico enquanto 41 (57\%) não apresentaram.

A ocorrência de neutropenia observada na literatura, com o uso de protocolos quimioterápicos idênticos ao estudado é muito variada.

Na neoadjuvância, Amat et al. (2003), utilizando monoquimioterapia com docetaxel em 88 mulheres, observaram uma frequiência de 70,5\% (62) de pacientes com neutropenia graus de III/IV. Espinosa et al. (2004), com uso de epirrubicina e docetaxel em 50 mulheres e com uso de fator de crescimento hematopoiético, encontraram $32 \%$ (16) delas com neutropenia graus III/IV.

Ramaswamy et al. (2005) em estudo com 25 mulheres, obtiveram 16\% de neutropenia de grau IV, enquanto Hirano et al. (2006) em estudo com 26 mulheres, utilizando epirrubicina $\left(70 \mathrm{mg} / \mathrm{m}^{2}\right)$ e docetaxel $\left(60 \mathrm{mg} / \mathrm{m}^{2}\right)$ referem a ocorrência de $81 \%$ de neutropenia grau IV.

Apesar deste evento adverso importante, os protocolos em uso no tratamento do câncer de mama são considerados eficazes e bem tolerados (ESPINOSA et al., 2004; AMAT et al., 2003; HIRANO et al., 2006; RAMASWAMY et al., 2005).

No tratamento adjuvante, a variabilidade dos resultados para neutropenia, também é variada. Luck et al. (2000), utilizando epirrubicina e ciclofosfamida, referem uma incidência de neutropenia de graus III/IV em $45 \%$ das participantes do seu estudo.

Nos estudos utilizando adriamicina e ciclofosfamida, Linden et al. (2007) com a participação de 3114 mulheres, relatam a ocorrência de $29 \%$ de neutropenia de graus III/IV enquanto Jones et al. (2006), com 1016 participantes, encontraram freqüência de $12 \%$ de neutropenia de grau III e $43 \%$ de grau IV. 
No presente estudo, média de idade entre as mulheres que não apresentaram neutropenia foi de 48,5 anos, enquanto para aquelas que apresentaram foi de 46,7 anos. Observa-se que a variância entre os grupos é similar em relação aos valores de média, desvio padrão e valores mínimos e máximos, configurando homogeneidade entre os grupos estudados.

Tabela 13: Estatística descritiva da variável idade entre as mulheres que apresentaram ou não neutropenia durante a quimioterapia. Ribeirão Preto, $2008(\mathrm{~N}=72)$.

\begin{tabular}{ccccccc}
\hline Neutropenia & $\mathrm{N}$ & Média & Mediana & Desvio Padrão & Mínimo & Máximo \\
\hline Não & 41 & 48.5 & 51.0 & 7.25 & 33.0 & 60.0 \\
Sim & 31 & 46.7 & 46.0 & 7.83 & 30.0 & 60.0 \\
\hline
\end{tabular}

p-valor = 0,2955 obtido da comparação H0: a média das pacientes COM neutropenia é igual a média das pacientes SEM neutropenia, H1: são diferentes. Utilizou-se teste paramétrico adequado de acordo com o teste de igualdade de variâncias.

A média de idade das mulheres participantes de estudos clínicos randomizados foi semelhante à encontrada neste estudo, variando de 46 a 49 anos. Os autores apresentam a média de idade para todas as participantes, sem distinção entre as que apresentaram ou não neutropenia durante o tratamento, (ESPINOSA et al., 2004; AMAT et al., 2003; PICCART et al., 2001; RAMASWAMY et al., 2005).

Alguns estudos apontam que idades mais avançadas favorecem a ocorrência de neutropenia e esta afirmativa baseia-se na avaliação desta ocorrência entre mulheres acima de 65 anos, fato que não se pode observar no presente estudo, visto que a idade foi limitada em 60 anos (HAYES, 2001; GILLESPIE, 2001; WAGNER et al., 2008).

Analisando a variável GB para o tratamento neoadjuvante e para o adjuvante, observamos que 31 mulheres apresentaram, durante tratamento, pelo menos um episódio de neutropenia (Tabela 14).

A maioria das mulheres foram submetidas a três ciclos de quimioterapia neoadjuvante. Observa-se que no grupo que não apresentou neutropenia (41), as participante iniciaram o tratamento com valor médio de GB de $8,0 \times 10^{3} / \mathrm{mm}^{3}$ e mediana de $7,8 \times 10^{3} / \mathrm{mm}^{3}$, enquanto que o grupo que apresentou neutropenia, iniciou o tratamento com média de $6,8 \times 10^{3} / \mathrm{mm}^{3}$ de GB e mediana de $6,7 \times 10^{3} / \mathrm{mm}^{3}$. Destacase, portanto, que o grupo que apresentou neutropenia iniciou o tratamento com uma diferença de cerca de $1,2 \times 10^{3} / \mathrm{mm}^{3}$ de GB para menos, fato que deveria ser considerado no planejamento do cuidado a estas mulheres no seu seguimento (Tabela 14). 
No terceiro ciclo de tratamento, a média de GB foi de $8,5 \times 10^{3} / \mathrm{mm}^{3}$ e mediana de $8,0 \times 10^{3} / \mathrm{mm}^{3}$ para o grupo que não apresentou neutropenia e para aquela que apresentaram neutropenia, a média de GB foi de $6,2 \times 10^{3} / \mathrm{mm}^{3}$ e mediana de $5,8 \mathrm{x}$ $10^{3} / \mathrm{mm}^{3}$. A queda de $2,3 \times 10^{3} / \mathrm{mm}^{3}$ na concentração de GB do início para o meio do tratamento quimioterápico reforça a necessidade do controle dessa variável entre os ciclos e a implementação de cuidados para prevenir tal evento adverso (Tabela 14).

$\mathrm{Na}$ neoadjuvância, quando considerados os três primeiros ciclos, em que se concentram a maioria das participantes estudadas, os valores mínimos e máximos de GB foram: para o ciclo um $4,5 \times 10^{3} / \mathrm{mm}^{3}$ e $16,39 \times 10^{3} / \mathrm{mm}^{3}$, para o ciclo dois $3,7 \times 10^{3}$ $/ \mathrm{mm}^{3}$ e $14,39 \times 10^{3} / \mathrm{mm}^{3}$ e para o ciclo três $3,8 \times 10^{3} / \mathrm{mm}^{3}$ e $14,39 \times 10^{3} / \mathrm{mm}^{3}$ respectivamente, para as mulheres que não apresentaram neutropenia (Tabela 14).

Para aquelas que apresentaram neutropenia, estes valores foram: $3,4 \times 10^{3} / \mathrm{mm}^{3} \mathrm{e}$ $11,19 \times 10^{3} / \mathrm{mm}^{3}$ para o ciclo um, $0,40 \times 10^{3} / \mathrm{mm}^{3}$ e $11,3 \times 10^{3} / \mathrm{mm}^{3}$ para o ciclo dois e $1,3 \times 10^{3} / \mathrm{mm}^{3}$ e $12,3 \times 10^{3} / \mathrm{mm}^{3}$ para o ciclo três, respectivamente (Tabela 14).

O Teste de hipótese para a comparação entre as médias dos grupos, que apresentaram ou não neutropenia, aponta para valores estatisticamente significantes para os valores de GB antes de iniciar o tratamento, no ciclo 2 e 3 . Para os ciclos 4 e 5 estes valores não foram significantes, porém o número de mulheres submetidas à estes ciclos foi muito menor dos que nos outros (Tabela 14) 
Tabela 14: Estatísticas descritivas da variável GB entre as mulheres que apresentaram ou não neutropenia, durante a quimioterapia neoadjuvante. Ribeirão Preto, 2008 (N=72).

\begin{tabular}{|c|c|c|c|c|c|c|c|c|c|}
\hline $\begin{array}{l}\text { Neutropenia } \\
\text { neoadjuvante }\end{array}$ & $\mathbf{N}$ & Variável & $\mathbf{N}$ & Média & Mediana & $\begin{array}{l}\text { Desvio } \\
\text { Padrão } \\
\end{array}$ & Mínimo & Máximo & $\begin{array}{c}\text { p- } \\
\text { valor }\end{array}$ \\
\hline \multirow[t]{5}{*}{ Não } & 41 & GBN1 & 41 & 8.0 & 7.8 & 2.2 & 4.5 & 16.4 & 0,0166 \\
\hline & & GBN2 & 41 & 8.5 & 8.2 & 2.7 & 3.7 & 14.4 & 0,0016 \\
\hline & & GBN3 & 39 & 8.5 & 8.0 & 2.7 & 3.8 & 14.4 & 0,0009 \\
\hline & & GBN4 & 19 & 7.5 & 6.5 & 2.8 & 3.5 & 14.4 & 0,1663 \\
\hline & & GBN5 & $3 *$ & 6.3 & 6.5 & 1.2 & 5.1 & 7.5 & - \\
\hline \multirow[t]{5}{*}{ Sim } & 31 & GBN1 & 31 & 6.8 & 6.7 & 1.9 & 3.4 & 11.2 & \\
\hline & & GBN2 & 31 & 6.2 & 7.0 & 3.1 & 0.4 & 11.3 & \\
\hline & & GBN3 & 29 & 6.2 & 5.8 & 2.8 & 1.3 & 12.3 & \\
\hline & & GBN4 & 15 & 6.2 & 6.0 & 2.8 & 1.0 & 13.8 & \\
\hline & & GBN5 & 5 & 3.5 & 1.9 & 2.3 & 1.8 & 6.7 & \\
\hline
\end{tabular}

Os valores denominados de GBPRÉ são referentes ao final da quimioterapia neoadjuvante e anterior ao procedimento cirúrgico. Estes valores demonstram queda nos valores de GB e observa-se que a recuperação medular está comprometida até 21 dias após o término da quimioterapia. As médias para os grupos com e sem neutropenia foram de $5,4 \times 10^{3} / \mathrm{mm}^{3}$ para o primeiro grupo de e $7,8 \times 10^{3} / \mathrm{mm}^{3}$ para o segundo, respectivamente (Tabela 15).

$\mathrm{Na}$ adjuvância, quando considerados os quatro primeiros ciclos, em que se concentram a maioria das participantes, os valores mínimo e máximo de GB, para o ciclo um foram de $4,1 \times 10^{3} / \mathrm{mm}^{3}$ e $11,4 \times 10^{3} / \mathrm{mm}^{3}$, para o ciclo dois foram de $3,1 \times 10^{3}$ $/ \mathrm{mm}^{3}$ e $17,1 \times 10^{3} / \mathrm{mm}^{3}$, para o ciclo três foram de $3 \times 10^{3} / \mathrm{mm}^{3}$ e $11,8 \times 10^{3} / \mathrm{mm}^{3}$ e para o ciclo quatro foram de $3,3 \times 10^{3} / \mathrm{mm}^{3}$ e $10,6 \times 10^{3} / \mathrm{mm}^{3}$, respectivamente, para as mulheres que não apresentaram neutropenia (Tabela 15).

Para aquelas que apresentaram neutropenia, estes valores foram de 3,6 x10 3 $/ \mathrm{mm}^{3}$ e $20,8 \times 10^{3} / \mathrm{mm}^{3}$ para o ciclo um, $1,1 \times 10^{3} / \mathrm{mm}^{3}$ e $8,0 \times 10^{3} / \mathrm{mm}^{3}$ para o ciclo dois, $2,3 \times 10^{3} / \mathrm{mm}^{3}$ e $10,6 \times 10^{3} / \mathrm{mm}^{3}$ para o ciclo três e $1,7 \times 10^{3} / \mathrm{mm}^{3}$ e $12,3 \times 10^{3} / \mathrm{mm}^{3}$ para o ciclo quatro, respectivamente (Tabela 15). 
Avaliando o p-valor das médias os resultados dos GB para os grupos com e sem neutropenia, houve diferença estatisticamente significante para os ciclos dois e três e quatro, como demonstrado na Tabela 15.

Tabela 15: Estatísticas descritivas da variável GB entre as mulheres que apresentaram ou não neutropenia durante a quimioterapia adjuvante. Ribeirão Preto, 2008 (N=72).

\begin{tabular}{|c|c|c|c|c|c|c|c|c|c|}
\hline $\begin{array}{l}\text { Neutropenia } \\
\text { adjuvante }\end{array}$ & $\mathbf{N}$ & Variável & $\mathbf{N}$ & Média & Mediana & $\begin{array}{l}\text { Desvio } \\
\text { Padrão } \\
\end{array}$ & Mínimo & Máximo & $\begin{array}{c}\text { p- } \\
\text { valor }\end{array}$ \\
\hline \multirow[t]{8}{*}{ Não } & \multirow[t]{8}{*}{41} & GBPRÉ & 40 & 7.8 & 7.7 & 2.4 & 3.5 & 15.0 & $<0.0001$ \\
\hline & & GBA1 & 40 & 7.7 & 7.4 & 1.9 & 4.1 & 11,4 & 0.8075 \\
\hline & & GBA2 & 40 & 5.8 & 5.2 & 2.7 & 3.1 & 17,1 & 0.0014 \\
\hline & & GBA3 & 40 & 6.0 & 5.6 & 2.0 & 3.0 & 11.8 & 0.0030 \\
\hline & & GBA4 & 40 & 5.6 & 5.0 & 1.8 & 3.3 & 10.6 & 0.0163 \\
\hline & & GBA5 & $8^{*}$ & 5.1 & 5.0 & 1.2 & 3.2 & 7.5 & - \\
\hline & & GBA6 & $7 *$ & 5.0 & 4.5 & 2.0 & 3.0 & 9.5 & - \\
\hline & & GBPÓS & 39 & 6.20 & 5.69 & 2.90 & 3.20 & 20.79 & 0.0004 \\
\hline \multirow[t]{8}{*}{ Sim } & \multirow[t]{8}{*}{31} & GBPRÉ & 30 & 5.4 & 6.3 & 2.3 & 0.8 & 9.3 & \\
\hline & & GBA1 & 30 & 7.5 & 6.5 & 3.4 & 3.6 & 20.8 & \\
\hline & & GBA2 & 30 & 4.0 & 3.5 & 1.8 & 1.1 & 7.9 & \\
\hline & & GBA3 & 30 & 4.4 & 3.7 & 1.9 & 2.3 & 10.6 & \\
\hline & & GBA4 & 30 & 4.4 & 3.9 & 2.1 & 1.7 & 12.3 & \\
\hline & & GBA5 & $5^{*}$ & 3.6 & 3.5 & 0.9 & 2.5 & 5.0 & \\
\hline & & GBCA6 & $3 *$ & 4.8 & 4.7 & 0.2 & 4.7 & 5.2 & \\
\hline & & GBPOS & 30 & 4,1 & 4.0 & 1.5 & 1.7 & 8.4 & \\
\hline
\end{tabular}

- * não foi possível realizar o teste comparativo

- p-valor obtido da comparação H0: a média das pacientes COM neutropenia é igual a média das pacientes SEM neutropenia, H1: são diferentes. Utilizou-se teste paramétrico adequado de acordo com o teste de igualdade de variâncias.

Os resultados encontrados no presente estudo apontam a ocorrência de diminuição de GB na progressão do tratamento quimioterápico, fato condizente com o estudo de Leonard et al. (2003), que em auditoria realizada no Reino Unido, com mulheres que receberam o tratamento quimioterápico adjuvante por câncer de mama, encontraram que $29 \%$ delas apresentaram pelo menos um episódio de neutropenia 
durante o tratamento. Os autores classificaram os eventos de neutropenia de acordo com o protocolo de quimioterapia aplicado. Nos protocolos que utilizaram antraciclinas, as mulheres apresentaram 28\% de neutropenia e 8,5\% necessitou de hospitalização. Concluem que com a progressão do tratamento quimioterápico, os eventos neutropênicos parecem aumentar.

Os valores encontrados neste estudo de $43 \%$ (31) de neutropenia situa-se entre valores entre 16 e $81 \%$ encontrados na literatura, entretanto observa-se que apresenta-se com valores superiores a alguns estudos (ESPINOSA et al., 2004; AMAT et al., 2003; RAMASWAMY et al., 2005; HIRANO et al., 2006; LUCK et al., 2000; LINDEN et al., 2007; JONES et al., 2006; KHAN et al., 2007).

\section{III. d. 3.2. 2. $\underline{\text { Anemia }}$}

As hemáceas são os mais numerosos elementos figurados do sangue. Estas células contém hemoglobina (HB), que é o pigmento respiratório do sangue, com a função de transportar oxigênio do pulmão para os tecidos e dióxido de carbono no sentido inverso (MILLER, 1999). A concentração de HB no sangue varia de 13,5 a 18 $\mathrm{g} / \mathrm{dl}$ no homem e de 11,5 a 16,4 g/dl na mulher (MILLER, 1999).

A anemia é definida como a deficiência de hemáceas e de HB no sangue (YELLEN et al., 1997), caracterizada por níveis de HB abaixo de 11,5 g/dl, na mulher. É uma complicação comum entre os pacientes com câncer decorrente de perda sanguínea (cirurgias extensas, sangramento tumoral), deficiência nutricional, infiltração de tumor na medula óssea, quimioterapia sistêmica, radioterapia em áreas próximas à medula óssea e doença metastática (BERESFORD et al., 2006; BONASSA, 2005). Pode, também, estar associada a sintomas de fraqueza, fadiga e dificuldade de concentração (DRANITSARIS et al., 2005).

Em estudo que avaliou os eventos adversos sérios (SAE) ocorridos com mulheres com câncer de mama, com idade abaixo de 63 anos, recebendo quimioterapia $2,2 \%$ apresentaram SAE por queda dos níveis de HB. A anemia foi a quinta causa mais comum de SAE, ficando abaixo das ocorrências de infecção $(8,4 \%)$, neutropenia (5,5\%), desidratação (2,5\%) e náusea/vômito e diarréia (2,4\%) (HASSETT et al., 2006). 
Gianni et al. (2008), em estudo retrospectivo, em que avaliaram 2215 mulheres recebendo quimioterapia adjuvante com $\mathrm{AC}\left(60 \mathrm{mg} / \mathrm{m}^{2}\right.$ e $600 \mathrm{mg} / \mathrm{m}^{2}$ respectivamente) ou EC $\left(90 \mathrm{mg} / \mathrm{m}^{2}\right.$ e $600 \mathrm{mg} / \mathrm{m}^{2}$ respectivamente) por 4 ciclos repetidos a cada 21 dias, referem que $11 \%$ das mulheres apresentaram, pelo menos, uma ocorrência de anemia de qualquer grau, durante todo o tratamento.

No presente estudo 54,2\% (39) das participantes apresentaram pelo menos uma ocorrência de anemia, durante o tratamento quimioterápico, com valores de $\mathrm{HB} \leq 11,9$ gr/dl, conforme definido pelo National Cancer Institute (1999) no Common Toxicity Criteria Manual. Destaca-se que destas 41\% (16) apresentaram anemia de grau II e não foi observado nenhuma participante com anemia de graus III ou IV.

Comparando os valores de $\mathrm{HB}$ durante o tratamento neoadjuvante, entre as mulheres que, neste estudo, desenvolveram ou não neutropenia, observa-se um declínio na média e na mediana para os dois grupos na progressão do tratamento. Entretanto, quando observado o p-valor, estes dados não são estatisticamente significantes, como demonstrada na Tabela 16.

Tabela 16: Estatísticas descritivas da variável HB entre as mulheres que apresentaram ou não neutropenia durante a quimioterapia neoadjuvante. Ribeirão Preto, 2008 (N=72).

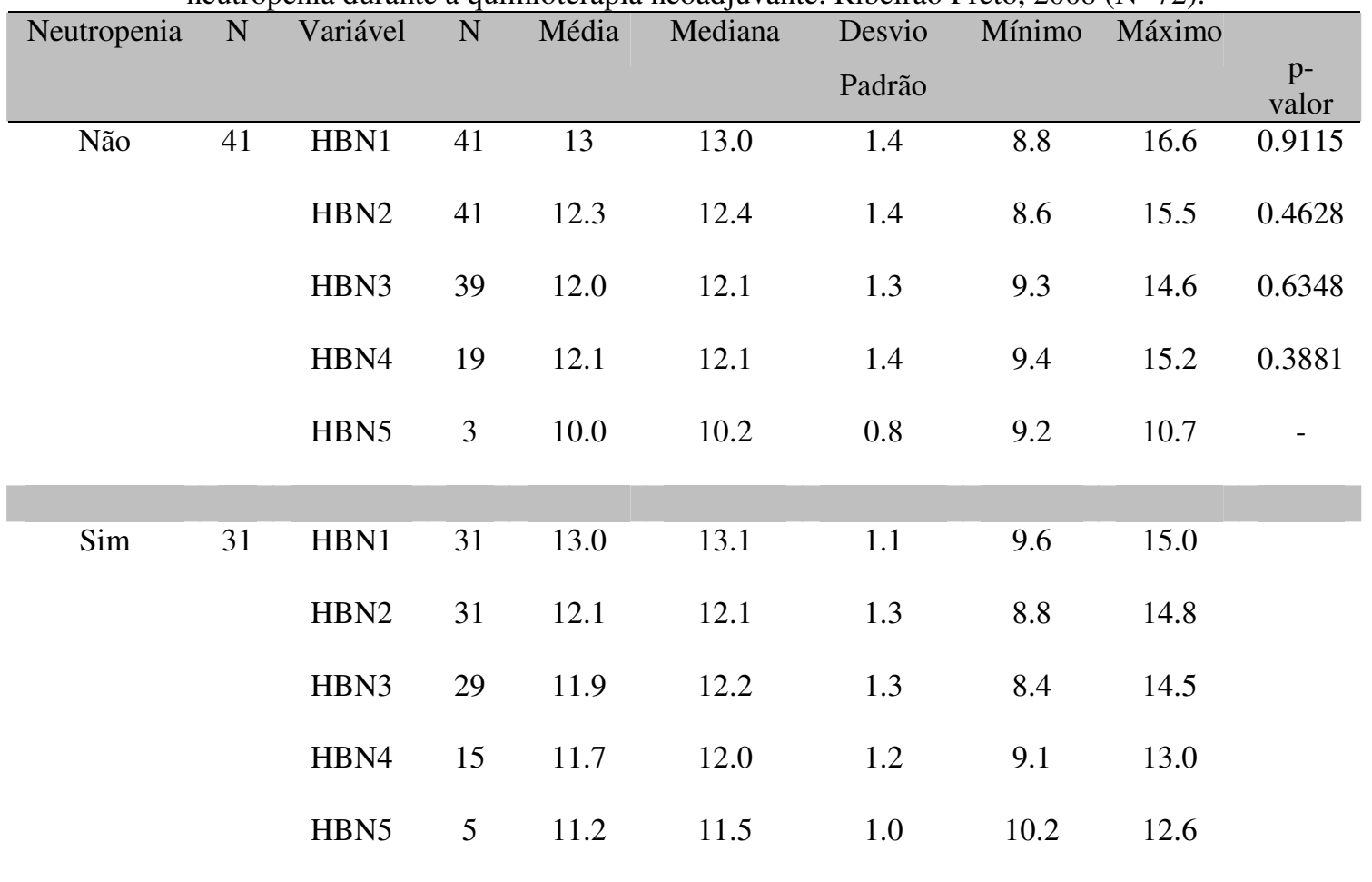

- * não foi possível realizar o teste comparativo

- $\quad$-valor obtido da comparação H0: a média das pacientes COM neutropenia é igual a média das pacientes SEM neutropenia, H1: são diferentes. Utilizou-se o teste paramétrico adequado de acordo com o teste de igualdade de variâncias. 
Observa-se que os valores de média e mediana de HB antes do procedimento cirúrgico estavam no limite inferior de normalidade, entretanto, durante o tratamento adjuvante houve recuperação e as mulheres finalizaram o tratamento quimioterápico com valores considerados dentro da normalidade. Os dados não são estatisticamente significantes, quando observado o p-valor para esta variável, na comparação da ocorrência de anemia entre os grupos de mulheres que desenvolveram ou não neutropenia como demonstrado na Tabela 17.

Tabela 17: Estatísticas descritivas da variável HB entre as mulheres que apresentaram ou não neutropenia durante a quimioterapia adjuvante. Ribeirão Preto, 2008 (N=70).

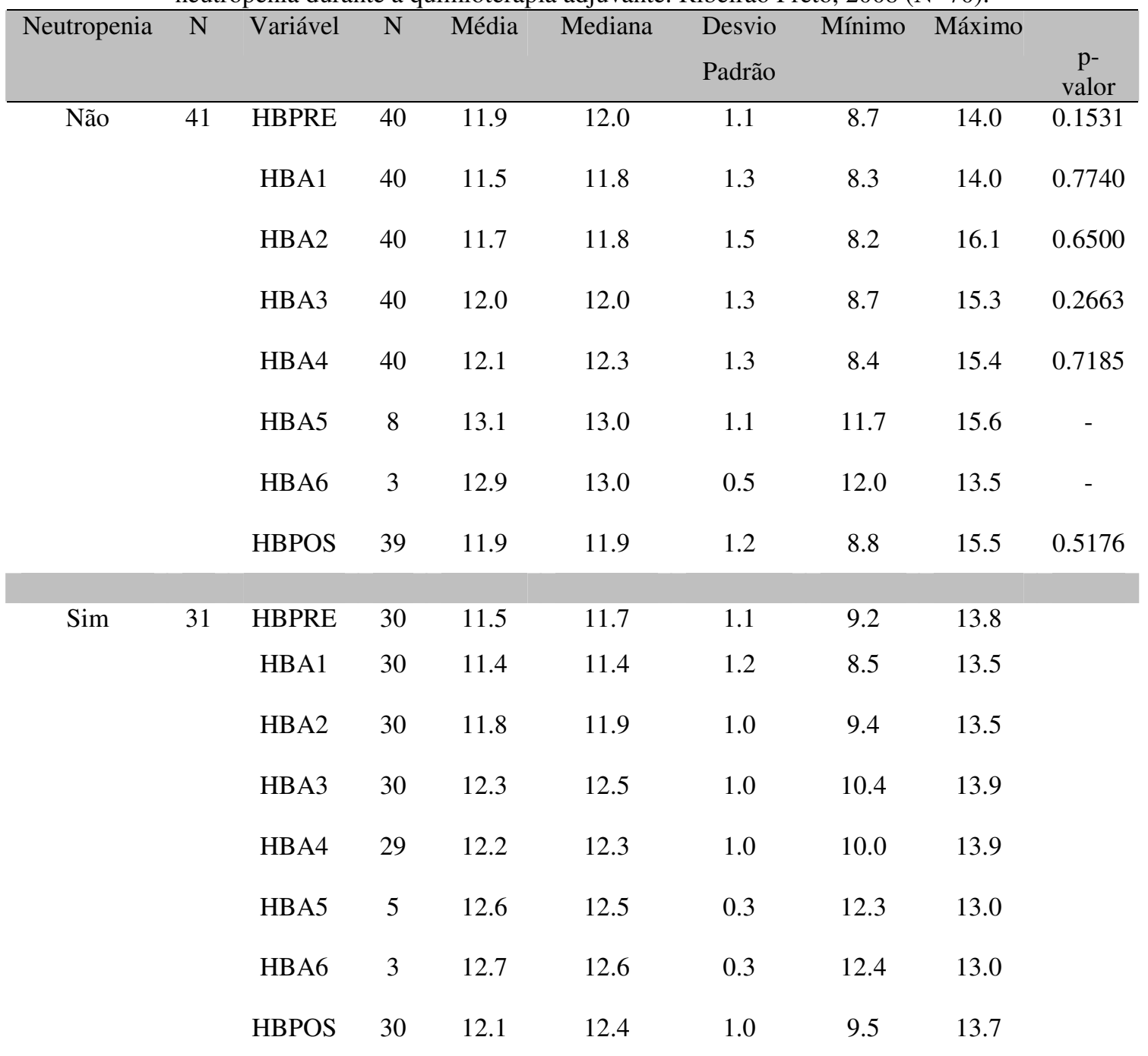

- * não foi possível realizar o teste comparativo

- p-valor obtido da comparação H0: a média das pacientes COM neutropenia é igual a média das pacientes SEM neutropenia, H1: são diferentes. Utilizou-se teste paramétrico adequado de acordo com o teste de igualdade de variâncias 
Observa-se que houve uma queda nos valores de HB durante a neoadjuvância, com ligeira recuperação no período de adjuvância, porém, não houve recuperação aos valores médios anteriores ao tratamento quimioterápico. A ocorrência deste evento adverso na neoadjuvância é compatível com o protocolo utilizado em que a droga docetaxel que é empregada na fase de neoadjuvância induz a ocorrência de anemia (BONASSA, 2005).

No estudo de Giani et al. (2008), que avaliaram 1.246 mulheres recebendo quimioterapia adjuvante com $\mathrm{AC}$ ou EC, encontraram $11 \%$ (238) que apresentaram pelo menos um episódio de anemia durante o tratamento, sendo que destas 4\% (96) apresentaram anemia de grau II e 1\% (16) de grau III. Concluíram que protocolos de quimioterapia que não continham taxanos, são raras as ocorrência de anemia severa ou moderada e que a incidência de anemia tende a aumentar com ciclos de quimioterapia posteriores.

Amat et al. (2003) referem a ocorrência de 18,2\% de anemia grau I e 1,1\% de anemia grau I, enquanto Espinosa et al. (2004) referem $82 \%$ de anemia de graus I e II e $6 \%$ de anemia de graus III e IV e Hassett et al. (2006) relatam 2,2\% de anemia. Todos estes estudos buscaram identificar a ocorrência de anemia em regimes de tratamento neoadjuvantes, com o uso do mesmo protocolo do presente estudo, e em todos eles, essa ocorrência apresenta-se como um evento que pode levar a atrasos no tratamento, principalmente, nos graus III e IV, diminuindo a eficácia do mesmo.

\section{III. d. 3.2. 3. Atrasos e reduções de dose}

A obtenção do máximo benefício do tratamento quimioterápico ocorre com a manutenção da dose total programada que deve ser mantida como um importante fator de resposta ao tratamento (LEONARD et al. 2003).

Estudos clínicos têm demonstrado que existe um melhor resultado quando a dose total de quimioterápico programada é administrada no tempo programado, em geral, com intervalos de 21 dias entre os ciclos. Isto se deve à proporção de células tumorais que sobrevivem ou que são afetadas após a quimioterapia, caracterizada pela fase do ciclo celular (GILLESPIE, 2001).

Porém, o atraso entre os ciclos tem sido a estratégia mais comumente utilizada para lidar com a ocorrência de eventos adversos como a neutropenia e a anemia, na tentativa de evitar a redução de dose do quimioterápico (LEONARD et al. 2003). 
Leonard et al. (2003), em estudo realizado com mulheres recebendo quimioterapia adjuvante, referem que, entre aquelas que receberam quimioterapia de protocolos com o uso de antraciclinas, $21 \%$ apresentaram atraso entre os ciclos e 5,5\% redução de dose do quimioterápico. Neste estudo, a neutropenia foi apontada como o evento significante na condição clínica das mulheres, com impacto na manutenção da dose programada. Além disso, apontam-na como o evento que interferiu na redução de dose e atraso entre os ciclos, o que leva a impacto na sobrevida da mulher.

Em estudo realizado nos Estados Unidos, Hays (2001) avaliou, retrospectivamente, 20.106 mulheres com câncer de mama e encontrou em 43,1\% (8.665) delas, atraso entre os ciclos de pelo menos cinco dias e redução da dose de quimioterapia programada em 25,7\% (5.167). A autora também encontrou diferença quanto à ocorrência de reduções de dose quando comparou mulheres com idade acima de 65 anos e as mais jovens (31,8\% e $24,5 \%$ respectivamente) e quanto aos atrasos entre os ciclos as diferenças foram de $50,3 \%$ versus $41,7 \%$.

O tempo de atraso entre os ciclos, no presente estudo, no tratamento neoadjuvante foi de um a 28 dias, sendo que não houve diferença estatisticamente significante entre as mulheres que desenvolveram neutropenia e aquelas que não desenvolveram (Tabela 18). Outros fatores, já descritos anteriormente podem ter influenciado nessa variável, destacando-se as a não coleta de sangue pelas mulheres e a falta de vagas na Central de Quimioterapia entre outras.

Entre as mulheres que não tiveram neutropenia, no tratamento neoadjuvante, o tempo médio de atraso entre os ciclos um a quatro variou de 3,5 a quatro dias, com um mínimo de um e máximo de 28 dias. O maior atraso ocorreu do primeiro para o segundo ciclo com duração de 28 dias (Tabela 18).

Para as mulheres que tiveram neutropenia o tempo médio de atraso entre os ciclos 4,7 a 5,1 dias, com um mínimo de um e máximo de 19 dias. O maior atraso ocorreu entre os ciclos dois e três com duração de 19 dias (Tabela 18). 
Tabela 18: Estatísticas descritivas da variável tempo de atraso entre os ciclos, para as mulheres que apresentaram ou não neutropenia durante a quimioterapia neoadjuvante. Ribeirão Preto, 2008 (N=72).

\begin{tabular}{lccccccccc}
\hline \multirow{2}{*}{ Neutropenia } & $\mathbf{N}$ & Variável & $\mathbf{N}$ & Média & Mediana & $\begin{array}{c}\text { Desvio } \\
\text { Padrão }\end{array}$ & Mínimo & Máximo & $\begin{array}{c}\text { p- } \\
\text { valor }\end{array}$ \\
\hline Não & 41 & TAN2 & 41 & 4.0 & 3.0 & 4.4 & 1.0 & 28.0 & 0.3044 \\
& & TAN3 & 39 & 3.5 & 3.0 & 2.7 & 1.0 & 12.0 & 0.1761 \\
& & TAN4 & 19 & 3.8 & 3.0 & 2.5 & 2.0 & 12.0 & 0.4007 \\
& & TAN5 & $3 *$ & 6.0 & 7.0 & 2.6 & 3.0 & 8.0 & - \\
\multirow{2}{*}{ Sim } & & & & & & & & 17.0 \\
& \multirow{2}{*}{31} & TAN2 & 30 & 5.1 & 3.0 & 4.2 & 1.0 & 19.0 \\
& & TAN3 & 29 & 4.7 & 3.0 & 4.0 & 2.0 & 1.0 \\
& & TAN4 & 15 & 4.7 & 3.0 & 3.5 & 1.0 & 1.0 \\
\hline
\end{tabular}

- * não foi possível realizar o teste comparativo

- p-valor obtido da comparação H0: a média das pacientes COM neutropenia é igual a média das pacientes SEM neutropenia, H1: são diferentes. Utilizou-se teste paramétrico adequado de acordo com o teste de igualdade de variâncias.

No tratamento adjuvante, o tempo de atraso, foi de um a 68 dias, sendo que não houve diferença estatisticamente significante entre as mulheres que desenvolveram neutropenia e aquelas que não desenvolveram (Tabela 19). Entre os fatores, já descritos anteriormente, que podem ter influenciado nessa variável, destacam-se a não coleta de sangue pelas mulheres, a falta de vagas na Central de Quimioterapia, além de procedimentos cirúrgicos complementares ou por complicações, entre outras.

Entre as mulheres que não apresentaram neutropenia, no tratamento adjuvante, o tempo médio de atraso entre os ciclos um a quatro variou de 6,0 a 14 dias com um mínimo de um e máximo de 38 dias. O maior atraso ocorreu do primeiro para o segundo ciclo com duração de 67 dias (Tabela 19). 
Tabela 19: Estatísticas descritivas da variável tempo de atraso entre os hemogramas e os ciclos, para as mulheres que apresentaram ou não neutropenia durante a quimioterapia adjuvante. Ribeirão Preto, 2008 $(\mathrm{N}=70)$.

\begin{tabular}{|c|c|c|c|c|c|c|c|c|c|}
\hline Neutropenia & $\mathbf{N}$ & Variável & $\mathbf{N}$ & Média & Mediana & $\begin{array}{l}\text { Desvio } \\
\text { Padrão }\end{array}$ & Mínimo & Máximo & $\begin{array}{c}\text { p- } \\
\text { valor }\end{array}$ \\
\hline \multirow[t]{7}{*}{ Não } & \multirow[t]{7}{*}{41} & TAPRE & 40 & 22.1 & 19.0 & 10.3 & - & 66.0 & 0.1814 \\
\hline & & TAA1 & 40 & 14.5 & 14.0 & 12.9 & 2.0 & 68.0 & 0.8533 \\
\hline & & TAA2 & 40 & 6.2 & 3.0 & 6.3 & 2.0 & 31.0 & 0.1289 \\
\hline & & TAA3 & 40 & 4.6 & 3.0 & 3.8 & 1.0 & 17.0 & 0.0923 \\
\hline & & TAA4 & 40 & 4.4 & 3.0 & 4.0 & 0 & 18.0 & 0.2050 \\
\hline & & TAA5 & $8^{*}$ & 4.4 & 4.0 & 2.9 & 1.0 & 9.0 & - \\
\hline & & TAA6 & $7 *$ & 5.0 & 3.0 & 5.0 & 1.0 & 16.0 & - \\
\hline \multirow[t]{7}{*}{ Sim } & \multirow[t]{7}{*}{31} & TAPRE & 30 & 19.4 & 18.5 & 6.1 & 9.0 & 34.0 & \\
\hline & & TAA1 & 30 & 14.0 & 11.0 & 11.4 & 2.0 & 38.0 & \\
\hline & & TAA2 & 30 & 10.0 & 9.0 & 11.9 & 1.0 & 67.0 & \\
\hline & & TAA3 & 30 & 6.3 & 5.0 & 4.7 & 0 & 19.0 & \\
\hline & & TAA4 & 29 & 6.0 & 3.0 & 6.2 & 0 & 31.0 & \\
\hline & & TAA5 & 5 & 4.6 & 4.0 & 2.7 & 2.0 & 9.0 & \\
\hline & & TAA6 & 3 & 24.3 & 10.0 & 32.0 & 2.0 & 61.0 & \\
\hline
\end{tabular}

- $\quad$-valor obtido da comparação H0: a média das pacientes COM neutropenia é igual a média das pacientes SEM neutropenia, H1: são diferentes. Utilizou-se teste paramétrico adequado de acordo com o teste de igualdade de variâncias.

A redução da dose foi utilizada para uma (1,3\%) mulher ocorreu em decorrência da toxicidade hematológica na fase neoadjuvante e para 5 (7\%) mulheres na fase de adjuvância, conforme registro no prontuário.

A incidência de eventos neutropênicos, com predomínio dos atrasos entre os ciclos, tem impacto significante na condição da mulher em receber a dose do tratamento quimioterápico planejada, o que pode interferir na sobrevida de longo prazo. No estudo de Leonard et al. (2003), com protocolos que utilizaram antracíclicos, observou-se que um elevado número de pacientes não receberam $85 \%$ da dose planejada, o que para Bonadonna et al.(1995) compromete a resposta final do tratamento.

Leonard et al. (2003) realizaram projeção para estimar a dose total recebida pela mulher durante o tratamento quimioterápico, dependendo do número de dias de atraso entre os ciclo de quimioterapia (Tabela 20). Observa-se que a cada semana de atraso há uma redução de cerca de até cinco por cento da dose ideal, o que pode comprometer os resultados esperados, interferindo na sobrevida global e no tempo livre da doença. 
Tabela 20: Impacto do atraso entre os ciclos na dose total planejada de quimioterapia. FONTE: Leonard et al. (2003)

\begin{tabular}{cc}
\hline Dias de atraso & \% estimada da redução da dose total \\
\hline 0 & 100 \\
7 & 95 \\
14 & 90 \\
21 & 86 \\
28 & 82 \\
35 & 78 \\
42 & 75 \\
\hline
\end{tabular}

Hayes (2001) em seu estudo afirma que, muitas vezes, a redução de dose do quimioterápico e o aprazamento entre os ciclos, visam diminuir a agressividade dos efeitos adversos relacionados com a mielotoxicidade. Afirma, ainda, que esta prática pode reduzir as toxicidade de curta duração, porém também reduzem o potencial de cura, de sobrevida e podem vir a apresentar resistência ao tratamento no caso de recorrência ou metástase do câncer inicial.

\section{III. e. Análise de sobrevida}

\section{III. e.1. Tempo total de tratamento}

O tempo de tratamento médio foi estimado pelo método não-paramétrico de Kaplan-Meier (COLLET, 1994; COLOSIMO; GIOLO, 2006). Para o grupo de mulheres que não tiveram neutropenia, o tempo médio de tratamento estimado foi de 200 dias, e o tempo mediano foi de 189 dias (I.C. 95\% = $[175 ; 213]$ ).

Para as mulheres que apresentaram neutropenia, o tempo médio também foi de 200 dias e o tempo mediano foi de 186 dias (I.C. 95\% = $[182 ; 215]$ ). Assim, tem-se um indicativo de que, independentemente de ter tido neutropenia ou não, o tempo total de tratamento foi o mesmo para estas mulheres.

Uma forma inicial de verificar esta igualdade é pela análise gráfica, isto é, observar as curvas de sobrevivência (em relação ao tempo de tratamento) das mulheres dos dois grupos, que são apresentados na Figura 13 abaixo.

Foram consideradas duas pacientes como censura, pois não finalizaram o tratamento, por morte no início do regime de neoadjuvância.

A variável neufinal foi a variável de classificação dos dois grupos. As mulheres que não fizeram neutropenia foram classificadas como 0 (zero), e as que fizeram neutropenia foram classificadas como 1 (um). 


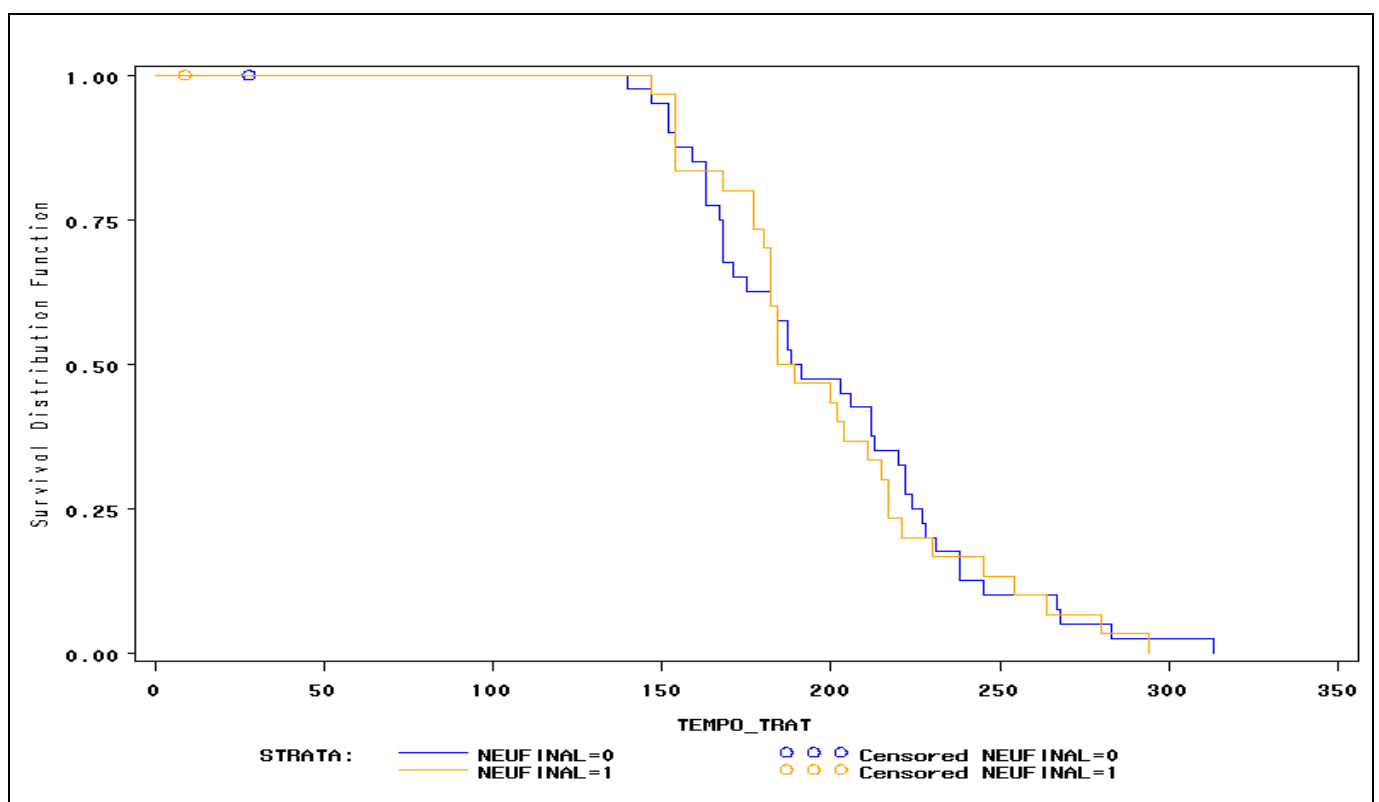

Figura 13: Tempo de tratamento das mulheres submetidas à quimioterapia para câncer de mama que apresentaram ou não neutropenia. Ribeirão Preto, 2008.

As curvas não apresentaram diferença do tempo de tratamento de um grupo para o outro. Outra forma de verificar a igualdade das curvas foi realizar um teste de igualdade dos estratos, em que se desejou testar as hipóteses:

$\mathrm{H}_{0}$ : As sobrevidas dos dois grupos são iguais.

$\mathrm{H}_{\mathrm{a}}$ : As sobrevidas dos dois grupos são diferentes

Realizado o teste do Log-Rank, a hipótese nula $\left(\mathrm{H}_{0}\right)$ foi aceita (qui-quadrado = 0,0450, p-valor $=0,8321)$, de maneira que conclui-se que as curvas do tempo de tratamento dos dois grupos são iguais.

\section{III. e.2. Análise de sobrevida das mulheres acometidas pelo câncer de mama}

Para análise da sobrevida, foi utilizado o método não-paramétrico de KaplanMeier (COLLET, 1994; COLOSIMO; GIOLO, 2006), estimando a sobrevida média pósdiagnóstico.

Para o grupo de mulheres que não apresentaram neutropenia, o tempo médio de vida estimado foi de 1233 dias, o tempo mediano não foi estimado, pois a última observação foi censurada.

Para as mulheres que apresentaram neutropenia, o tempo médio também foi de 1119 dias, e o tempo mediano também não foi estimado pelo fato de a última observação ser censurada. 
Com os tempos médios próximos, tem-se um indicativo de que, independentemente de ter apresentado ou não neutropenia, a sobrevivência foi a mesma para diferentes grupos de mulheres. É importante ressaltar que o tempo de vida médio está superestimado, em razão das ultimas observações serem censuradas (Figura 14).

Uma forma de se verificar esta igualdade é observar as curvas de sobrevida das mulheres dos dois grupos, que são apresentadas abaixo.

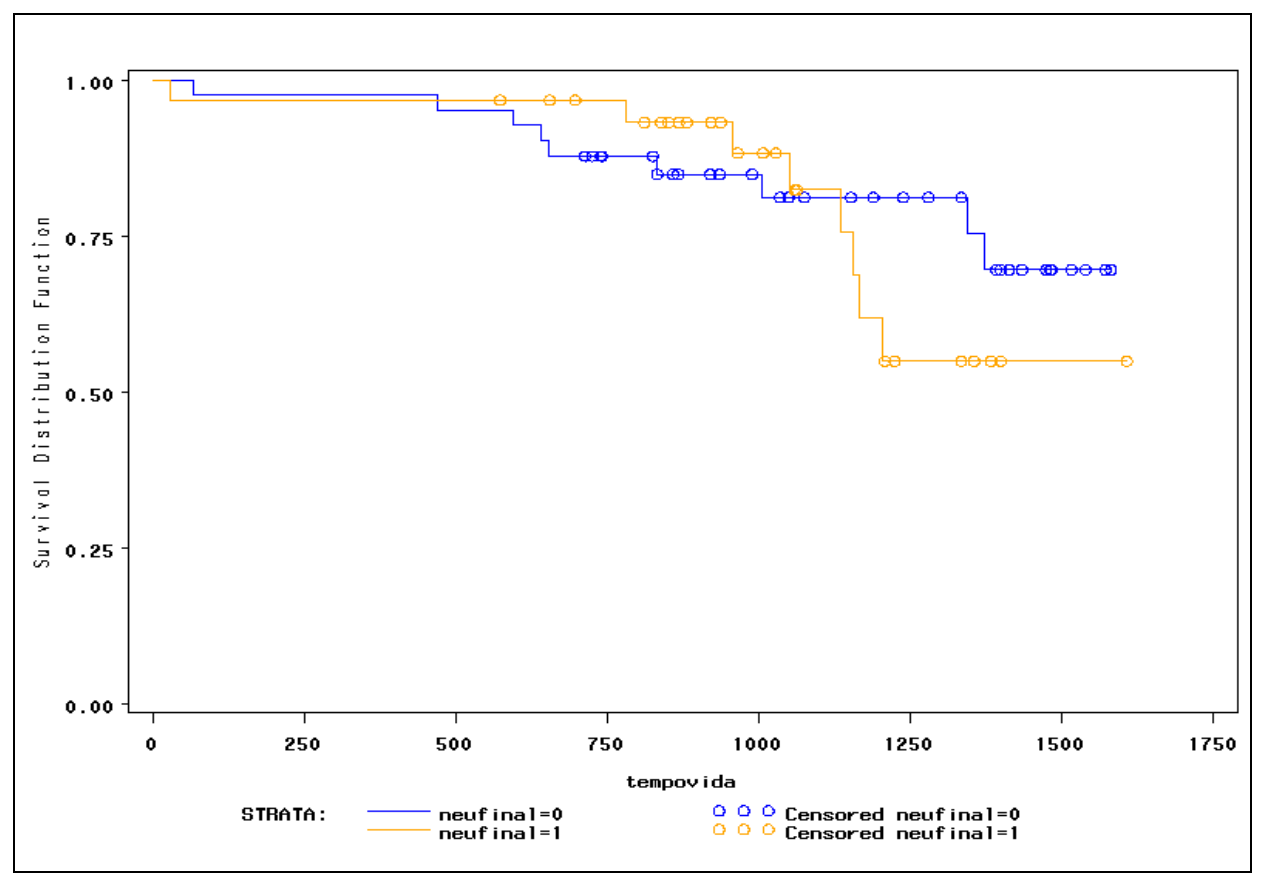

Figura 14: Tempo de sobrevida das mulheres submetidas à quimioterapia para câncer de mama que apresentaram ou não neutropenia. Ribeirão Preto, 2008.

As curvas não apresentam diferença do tempo de sobrevida de um grupo para o outro (o fato de se cruzarem algumas vezes é um indicativo isso). Outra forma de avaliar se os tempos foram iguais para os dois grupos, foi realizar um teste de igualdade dos estratos, em que se desejou verificar as hipóteses:

$\mathrm{H}_{0}$ : As sobrevidas dos dois grupos são iguais.

$\mathrm{H}_{\mathrm{a}}$ : As sobrevidas dos dois grupos são diferentes.

Realizado o teste do Log-Rank, a hipótese nula $\left(\mathrm{H}_{0}\right)$ foi aceita (qui-quadrado $=$ $0,3814, \mathrm{p}$-valor $=0,5369)$, de maneira que conclui-se que o tempo de sobrevida foi igual para os dois grupos de mulheres. 
Apesar de tempo de sobrevida não apresentarem diferenças nos grupos de mulheres que apresentaram ou não neutropenia, observa-se que as mulheres que não apresentaram neutropenia, a sobrevida passa de 81\% com 1006 dias para 70\% com 1372 dias, quando foi encerrada a coleta de dados do presente estudo.

Enquanto as mulheres que apresentaram neutropenia, a sobrevida diminui progressivamente a partir do dia 1051 (82\%) até o dia 1204 (54\%) período em que foi encerrada a coleta de dados para o presente estudo. $\mathrm{O}$ que pode indicar que estas mulheres podem vir apresentar complicações referentes à neutropenia a longo prazo. 


\section{CONCLUSÕES}

Este estudo teve o objetivo de analisar a ocorrência das toxicidades hematológicas e não hematológicas em mulheres submetidas ao tratamento neoadjuvante e adjuvante para o câncer de mama.

Foram analisados os prontuários de 72 mulheres com câncer de mama, em seguimento no Ambulatório de Mastologia do HCFMRP-USP, que iniciaram o tratamento do câncer com a quimioterapia, nos anos de 2003 a 2006. Os esquemas quimioterápicos estudados foram epirrubicina e docetaxel para a neoadjuvância e epirrubicina e ciclofosfamida para a adjuvância.

Na caracterização da amostra, observou que:

- estádio clínico do câncer mais freqüente foi o IIIa com $25(34,7 \%)$ mulheres;

- $59 \%$ (41) das mulheres foram submetidas à cirurgias conservadoras.

Um total de 558 ciclos de quimioterapia foram analisados. Observou-se que as mulheres apresentaram 152 registros de eventos adversos, sendo 109 de toxicidade não hematológica (59 durante a neoadjuvância e 50 na adjuvância) e 43 de toxicidade hematológica (18 durante a neoadjuvância e 31 na adjuvância)

Entre as toxicidades não-hematológicas registradas nos prontuários das participantes as mais freqüentes foram:

- Gastrointestinais: com 49,5\% (sendo 18,3\% de náusea, $10 \%$ de vômito e $3,6 \%$ de mucosite)

- Dermatológica com $34 \%$ das ocorrências, sendo $23,6 \%$ de extravasamento e a hiperpigmentação com 18,3\% (trajeto venoso escurecido).

As toxicidades hematológicas foram:

- $43 \%$ das mulheres apresentaram, pelo menos, um episódio de neutropenia durante o tratamento quimioterápico;

- $\quad 54,2 \%$ (39) apresentaram valores de HB $\geq 11,9 \mathrm{~g} / \mathrm{dl}$, e destas $22,2 \%$ (16) apresentaram anemia de grau II, não foi observado nenhuma participante com anemia de graus III ou IV. 
Decorrente dos eventos hematológicos houveram:

- 19 hospitalizações, sendo 15 foram por neutropenia febril (87\% (13) na neoadjuvância e 13,3\% (2) na adjuvância);

- 152 atrasos entre os ciclos, sendo que $24,3 \%$ (37) foram na neoadjuvância e 75,7\% (115) na adjuvância;

- Seis mulheres tiveram a dose do quimioterápico reduzida durante o tratamento.

$\mathrm{Na}$ análise dos grupo de mulheres que apresentaram ou não neutropenia durante o tratamento, observou-se que:

- Não foi encontrado relação entre a idade e a ocorrência de neutropenia;

- Os valores dos GB entre os grupos foram menores de acordo com a progressão do tratamento, tanto na neoadjuvância quanto na adjuvância;

- As análises estatísticas não apontaram relação entre a ocorrência de anemia com a neutropenia.

Em relação à sobrevida das mulheres seguidas neste estudo não houve diferenças entre as que apresentaram neutropenia e as que não apresentam. Observou-se que após os 1000 dias de seguimento, o comportamento entre os grupos diferiu, ocorrendo mais mortes entre aquelas que apresentam neutropenia. Com estes resultados, sugere-se que outros estudos, realizem um acompanhamento destas mulheres a longo prazo, para observar possíveis alterações tardias decorrentes de neutropenia.

Os resultados acima apontam para questões relacionadas à prática de enfermagem ressaltando-se:

- A mulher e seus familiares têm necessidade de informações acerca do tratamento quimioterápico, incluindo: retornos médicos, coleta de exames, e seguimento do tratamento;

- A mulher e seus familiares devem ser orientados sobre a ocorrência de efeitos adversos da quimioterapia, como a alopecia, náuseas e vômitos, perda de apetite, mucosite e febre e o manejo dos mesmos no domicílio;

- A enfermagem deve definir protocolos de avaliação e seguimento, incluindo os efeitos colaterais e os graus de comprometimento, bem como manejo dos mesmos. 
A enfermeira que trabalha com as mulheres com câncer de mama e seus familiares não deve medir esforços na educação destes, salientando a importância da adesão ao tratamento e ao manejo dos seus efeitos adversos. Deve, também, enfatizar quanto a transitoriedade dos efeitos adversos e estimulando à mulher e sua família a questionar quanto a dúvidas e queixas apresentadas.

A enfermeira deve também programar atividades de educação em serviço, para que toda a equipe de enfermagem tenha condutas uniformes, quanto ao manejo dos efeitos adversos, orientações para o paciente e a família, e registrar ocorrência dos eventos adversos observados e relatados por estes.

Estas atitudes da equipe podem facilitar à mulher em tratamento quimioterápico, para que esta tenha conhecimento prévio dos possíveis efeitos adversos e do manejo adequado destes que são necessários para melhorar os resultados a longo prazo. Ou seja, para diminuir a ocorrência de reduções na dosagem e aprazamento entre os ciclos.

A importância dos protocolos se dá devido a um controle mais ágil e eficiente na identificação dos eventos adversos e no manejo destes, para que a mulher possa ter uma recuperação mais rápida. Podendo ser evitados atrasos entre os ciclos e eventuais reduções de dose, que podem comprometer a resposta ao tratamento, e em caso de recidiva da doença ou metásteses, a resistência tumoral aos quimioterápicos utilizados.

Deste modo, os resultados deste estudo apontam a necessidade de que estudos futuros acompanhem estas mulheres a longo prazo, para que seja possível avaliar as toxicidades tardias do tratamento quimioterápico.

Apontam também para a importância da elaboração e implementação de protocolos e cuidados de enfermagem para mulheres com câncer de mama com a finalidade de avaliação dos eventos adversos e manejo mais adequado dos mesmos. 


\section{REFERÊNCIAS BIBLIOGRÁFICAS}

ALMEIDA, A.M. Vivendo com a incerteza da doença: a experiência de mulheres com câncer de mama. 1997. 153 f. Tese (Doutorado), Escola de Enfermagem de Ribeirão Preto, Universidade de São Paulo, Ribeirão Preto, 1997.

ALMEIDA, J.R.C. Farmacêuticos em oncologia: uma nova realidade. São Paulo: Editora Atheneu, 2004. p. 358.

AMAT, S. et al. Neoadjuvant docetaxel for operable breast cancer induces a high pathological response and breast-conservation rate. British Journal of Cancer, v. 88, p. 1339-1345, 2005.

AMORIM, G.; WISINTAINER, F. Câncer de mama: quimioterapia e hormoniterapia adjuvante. In: BOFF, A., WISINTAINER, F. Mastologia Moderna: abordagem multidisciplinar. $1^{\text {a }}$ ed. Caxias do Sul: Editora Mesa Redonda, p.205-218, 2006.

ARDAVANIS, A. et al. Sequential epirubicin (E) and docetaxel (D) followew by surgery and postoperative chemotherapy for locally advanced breast cancer (LABC). Proc Am Soc Clin Oncol 20, abstract 1779, 2001.

BARBOSA, H.F. et al. Fatores de risco para infecção de sítio cirúrgico em pacientes operadas por câncer de mama. Revista Brasileira de Ginecologia e Obstetrícia. v. 26, n.3, p. 227-232, 2004.

BARLETTA, D.V. Radioterapia no câncer de mama. In: BOFF, R.A.; WISINTAINER, F. Mastologia moderna: abordagem multidisciplinar. $1^{\text {a }}$ ed. Caxias do Sul: Editora Mesa Redonda, p.165-174, 2006.

BEAR, H.D. et al. The effect on tumor response of adding sequential preoperative docetaxel to preoperative doxorubicin and cyclophosphamide: preliminary results from National Surgical Adjuvant Breast and Bowel Project Protocol B-27. Journal of Clinical Oncology, v. 21, n. 22, p. 4165-4174, 2003.

BERESFORD, M.J. et al. Pre-treatment haemoglobin levels and prediction of response to neoadjuvant chemotherapy in breast cancer. Clinical Oncology, v. 18, p. 453-458, 2006. 
BOFF, R.A.; RURARO, S.; SCHUH, F. Abordagem diagnóstica das massas palpáveis da mama. In: BOFF, A., WISINTAINER, F. Mastologia Moderna: abordagem multidisciplinar. Cap. 3, Editora Mesa Redonda, Caxias do Sul, 2006.

BOMAN, L.; LINDGREN, A.; SANDELIN, K. Women's perceptions of seroma and their drainage following mastectomy and axillary lymph node dissection. European Journal of Oncology Nursing, v. 6, n. 4, p. 213-219, 2002.

BONADONNA, G.B. et al. Adjuvant cyclophosphamide, methotrexate, and fluoracil in node positive breast cancer. The results of 20 years of follow-up. The New England Journal of Medicine, v. 332, n. 14, p. 901-906, 1995.

BONADONNA, G.B. et al. 30 year's follow up of randomised studies of adjuvant CMF in operable breast cancer: cohort study. BMJ, doi:10.1136/bmj.38314.622095.8F (publicado on line, em 13 de janeiro de 2005) Acessado em abril de 2008.

BONASSA, E. M. A. Enfermagem em terapêutica oncológica. $3^{\circ}$ ed.- São Paulo: Atheneu, 2005. 538 p.

BONNETTERRE, J. et al. Epirubicin long-term, survival in adjuvant chemotherapy of patients with poor-prognosis, node-positive, early breast cancer: 10-years follow-up results of a French Adjuvant Study Group 05 Randomized Trials. Journal of Clinical Oncology, v. 23, n. 12, p. 2686-2693, 2005.

BORREGA, P. et al. A phase II study of high-dose epirubicin plus docetaxel in locally advanced breast cancer. Proc Am Soc Clin Oncol 20, abstract 1878, 2001.

BOUGHEY, J.C. et al. Impact of preoperative versus postoperative chemotherapy on the extent and number of surgical procedures in patient treated in randomized clinical trials of breast cancer. Annals of Surgery, v. 244, p. 464-470, 2006.

BRASIL. Ministério da Saúde, Secretaria de Atenção à Saúde, Instituto Nacional do Câncer. Controle do câncer de mama: documento de consenso. Rio de Janeiro: INCA, 2004a. 39p. 
BRASIL. Ministério da Saúde, Secretaria de Atenção à Saúde, Instituto Nacional do Câncer. TMN: Classificação de tumores malignos. Tradução Ana Lúcia Amaral Eisenberg. $6^{\text {a }}$ ed. Rio de Janeiro: INCA, 2004b. 254p.

BRASIL. Ministério da Saúde, Secretaria de Atenção à Saúde, Instituto Nacional do Câncer. Coordenação de Prevenção e Vigilância de Câncer. Estimativa 2008: incidência de câncer no Brasil. INCA, 2007. 94 p.

BRENNA, S.M.; SYRJANEN, K.L. Regulation of cell cycles is of key importance in human papilomavirus (HPV) - associated cervical carcinogenesis. São Paulo Medicin Journal, v. 121, p. 128-132, 2003.

BUDZAR, A.U. et al. Significantly higher pathologic complete remission rate after neoadjuvat therapy with trastuzumab, paclitaxel and epirubicin chemotherapy: results of a randomized trial in human epidermal grow factor receptor to positive operable breast cancer. Journal of Clinical Oncology, v. 23, n. 16, p. 367-385, 2005.

BURDETTE-RADOUX, S. et al. Phase I/II trial of adjuvant dose-dense docetaxel/epirubicin/cyclophosphamide (TEC) in stage II and III breast cancer. The Brest Journal. v. 13, n. 3, p 274-280, 2007.

CAMERON, D.; AAPRO, M. Appropriate chemotherapy, optimal results. A teaching course under the auspices of EORTC 10-11 november 2006, Nice, France. European Journal of Cancer Suplplements 6, p. 1-3, 2008.

CARMICHAEL, J. UKCCCR trial of epirubicin and cyclophosphamide (EC) vs. epirubicin and Taxol® (ET) in the first line treatment of women with metastatic breast cancer (MBC). Proc Am Soc Clin Oncol. 20: 2001 (abstr 84).

CARVALHO, M.V.B. O cuidar no processo de morrer na percepção das mulheres com câncer de mama: uma atitude fenomenológica. 2003. Tese (Doutorado) Escola de Enfermagem, Universidade de São Paulo, São Paulo, 2003.

CHEN, Y.C.; HUNTER, D.J. Molecular epidemiology of cancer. Cancer Journal of Clinic, v. 55, p. 45-54, 2005. 
CITRON, M.L. et al. Randomized trial of dose-dense versus conventionally scheduled and sequential versus concurrent combination chemotherapy as postoperative adjuvant treatment of node-positive primary breast cancer: first report of Intergroup Trial C9741/Cancer and Leukemia Group B Trial 9741. Journal of Clinical Oncology, v. 21, n. 8, p. 1431-1439, 2003.

COELHO, C.P.; COELHO, G.P. Anatomia patológica e citopatológica. In: BOFF, R.A.; WISINTAINER, F. Mastologia moderna: abordagem multidisciplinar. $1^{\mathrm{a}}$ ed. Caxias do Sul: Editora Mesa Redonda, p.81-90, 2006.

COLLET, D. Modelling survival data in medical research. Editora Chapman \& Hall, 1994. $347 \mathrm{p}$.

COLOSIMO, E. A.; GIOLO, S. R. Análise de Sobrevivência Aplicada. 1a Edição, São Paulo: Edgard Blucher 2006.

COUTINHO, V.; COUTINHO, M.A. Leucocitose e leucopenias. Alterações morfológicas e funcionais dos leucócitos. In: ZAGO, M.A.; FALCÃO, R.P.; PASQUINI, R. Hematologia: fundamentos e práticas. $1^{\mathrm{a}}$ ed. São Paulo: Editora Atheneu, p.87-95, 2004.

DALBERG, $\mathrm{K}$, et al. A randomized study of axillary drainage and pectoral fascia preservation after mastectomy for breast cancer. EJSO. v. 30, p. 602-609, 2004.

DANCEY, J. et al. Quality of life scores: an independent prognostic variable in general population of cancer patients receiving chemotherapy. Quality of life research, v. 6, p151-158, 1997.

DAWOOD, S. et al. Prognostic value of initial clinical disease stage after achieving pathological complete response. The Oncologist, v. 13, p. 6-15, 2008.

DE CARLI, A.C. Diagnóstico por imagem em doenças da mama. In: BOFF, R.A.; WISINTAINER, F. Mastologia moderna: abordagem multidisciplinar. $1^{\mathrm{a}}$ ed. Caxias do Sul: Editora Mesa Redonda, p.53-80, 2006.

DEBLED, M. et al. Does chemotherapy-induced neutropaenia result in a postponement of adjuvant or neoadjuvante regimens in breast cancer patients? Results of a retrospective analysis. British Journal of Cancer, v. 97, p. 1642-1647, 2007. 
DRANITSARIS, G. et al. Chemotherapy-induced anaemia during adjuvant treatment for breast cancer: development of a prediction model. Lancet Oncology, v.6, p.856$863,2005$.

EBCTCG Early Breast Cancer Trialists' Collaborative Group. Effects of chemotherapy and hormonal therapy for early breast cancer on recurrence and 15-year survival: an overview of the randomised trials. Lancet, v. 365, p. 1687-1717, 2005.

ESPINOSA, E. et al. Docetaxel and high-dose epirubicin as neoadjuvant chemotherapy in locally advanced breast cancer. Cancer Chemotherapy Pharmacology. v. 54, p. 546-552, 2004.

FISHER, B.; MAMOUNAS, E. Preoperative chemotherapy: a model for studying the biology and therapy of primary breast cancer. Journal of Clinical Oncology, v. 13, p. 537-540, 1995.

FISHER, B. et al. Effect of preoperative chemotherapy on local-regional disease in women with operable breast cancer: finding from National Surgical Adjuvant Breast and Bowel Project B-18. Journal of Clinical Oncology, v. 15, p. 2483-2493, 1997.

FORTNER, B.V. et al. Experiencing neutropenia: quality of life interviews with adult cancer patients. BMC Nursing, v.4, n. 4, 2005. Disponível em: www.biomedicentral.com/1472-6955/4/4, acesso em maio de 2007.

FRENCH ADJUVANT STUDY GROUP. Benefit of a high-dose epirubicin regimen in adjuvant chemotherapy for node positive breast cancer patients with poor prognostic factors: 5 year follow-up results of French Adjuvant Study Group 05 Randomized Trial. Journal of Clinical Oncology, v. 19, n.3, p. 602-611, 2001.

FRITH, H.; HARCOURT, D.; FUSSELL, A. anticipating an altered appearance: women undergoing chemotherapy treatment for breast cancer. European Journal of Oncology Nursing. v. 11, p. 385-391, 2007.

GIANNI, L. et al. Anemia during adjuvant non-taxane chemotherapy for early breast cancer: Incidence and risk factors from two trials of International Breast Cancer Study Group. Support Care Cancer, v.16, p. 67-74, 2008. 
GILLESPIE, T.W. Chemotherapy dose and dose intensity: analyzing data to guide therapeutic decision. Oncology Nursing Forum, V. 28, n. 2 (sup), p. 5-10, 2001.

GOGAS, H.; FOUNTZILAS, G. The role of taxanes as a component of neoadjuvante chemotherapy for breast cancer. Annals of Oncology, v.14, p. 667-674, 2003.

GOZZO, T.O. Movimentação precoce do braço no controle do seroma póslinfadenectomia axilar. 2005. 76 f. Dissertação (Mestrado), Escola de Enfermagem de Ribeirão Preto, Universidade de São Paulo, Ribeirão Preto, 2005.

HAYES, N.A. Analyzing current practice patterns: lessons from Amgens's Project ChemoInsight@. Oncology Nursing Forum, V. 28, n. 2 (sup), p. 11-16, 2001.

HASSET, M.J. et al. Frequency and cost chemotherapy-related serius adverse effects in a population sample of women with breast cancer. Journal National Cancer, v. 98, p. 1108-1117, 2006.

HEGG, R. Câncer de mama. Revista Brasileira de Medicina. v. 57, n. 5, p. 463-473, 2000 .

HENDERSON, I.C. et al. Improved outcomes from adding sequential paclitaxel but not from escalating doxorubicin dose in an adjuvant chemotherapy regimen for patient with node positive primary breast cancer. Journal of Clinical Oncology, v. 21, p. 976-983, 2003.

HIRANO, A. et al. The combination of epirubicin plus docetaxel as neoadjuvant chemotherapy in locally advanced breast cancer. Anticancer Res. v. 26 (1B), p. 581-4, 2006.

HUTCHEON, A.W. et al. Neoadjuvant docetaxel in locally advanced breast cancer. Breast Cancer Research and Treatment. v. 7 supl 1, p. 19-24, 2003.

JONES, S. E. et al. Phase III trial comparing doxorubicin plus cyclophosphamide with docetaxel plus cyclophosphamide as adjuvant therapy for operable breast cancer. Journal of Clinical Oncology, v. 24, n. 34, p. 5381-5387, 2006. 
KAUFMANN, M. et al. International expert panel on the use of primary (preoperative) systemi treatment of operable breast cancer: review and recommendations. Journal of Clinical Oncology, v. 21, n.13, p. 2600-2608, 2003.

KAUFMANN, M. et al. Recommendations from International Expert Panel on the use of neoadjuvant (primary) systemic treatment of operable breast cancer: an update. Journal of Clinical Oncology, v. 24, n.12, p. 1940-1949, 2006.

KHAN, S. et al. Impact of neutropenia on delivering planned chemotherapy for solid tumour. European Journal of Cancer Care, v. 17, p. 19-25, 2008.

KURBET, S.; BARROS, A.C.S.D.; PINOTTI, J.A. The safe association of intraoperative evaluation of surgical margins and neoadjuvant chemotherapy in breast cancer larger than 3 centimeters. Tumori, v.92, p. 21-25, 2006.

LEONARD, R.C. F. et al. impact of neutropenia on delivering planned adjuvant chemotherapy: UK audit of primary breast cancer patients. British Journal of Cancer, v. 89, p. 2062-2068, 2003.

LINDEN, H. M. et al. Sequenced compared with simultaneous anthracycline and cyclophosphamide in high-risk stage I and II breast cancer: final analysis from int-0137 (s9313). Journal of Clinical Oncology, v. 25, n. 6, p. 656-661, 2007.

LYMAN, G.H., et al. Risck models for predicting chemotherapy-induced neutropenia. The Oncologist, n. 10, p. 427-437, 2005.

LUCK, H. et al. Epirubicin/paclitaxel (ET) vs epirubicin/cyclophosphamide (EC). A study of the Ago Breast Cancer Group. Proc Am Soc Clin Oncol. 19: 2000 (abstr 280).

MAMOUNAS, E. P. et al. Paclitaxel after doxorubicin plus cyclophosphamide as adjuvant chemotherapy for node-positive breast cancer: results from NSABP B-28. Journal of Clinical Oncology, v. 23, n. 16, p. 3686-3696, 2005.

MARWANE, B. et al. Reduction of tumor size using neoadjuvant wiyh docetaxel and epirubicin in primary operable breat cancer. Proc Am Soc Clin Oncol 20, abstract 1814, 2001. 
MENKE, C.H. et al. Diagnóstico clínico do câncer de mama. In: BASEGIO, D.L. Câncer de mama. Rio de Janeiro, Revinter Editora, 1999. 371 p.

MENKE, C. H. et al. Tratamento cirúrgico do câncer de mama. In: BOFF, R.A.; WISINTAINER, F. Mastologia moderna: abordagem multidisciplinar. $1^{\mathrm{a}}$ ed. Caxias do Sul: Editora Mesa Redonda, p.139-154, 2006.

MICHELONI, A.P.C. Qualidade de vida de adultos com câncer colorretal, com e sem ostomia. 2002. 116 p. Dissertação (Mestrado), Escola de Enfermagem, Universidade de São Paulo, São Paulo, 2002.

MIEOG, J.S.D.; VAN DER HAGE, J.A.; VAN DER VELDE, C.J.H. Quimioterapia preoperatoria para mujeres con cáncer de mama operable (Cochrane Review). In: La Biblioteca Cochrane Plus, Issue 4, 2007.

MOTTA, N.W.; OBST, F.M.; MOTTA, E.R. Radioterapia no câncer de mama: equipamentos e técnicas. IN: BOFF, R.A.; WISINTAINER, F. Mastologia moderna: abordagem multidisciplinar. $1^{\mathrm{a}}$ ed. Caxias do Sul: Editora Mesa Redonda, p.155-164, 2006.

MULLER, O. Hemograma - série vermelha. In: MULLER, O. O laboratório para o clínico. $8^{\text {ed }}$, Editora Athneu, São Paulo, 199.

NATIONAL CANCER INSTITUTE. Common Toxicity Criteria, Version 2.0. de 1999, Acessado em junho de 2007, disponível http://safetyprofilerctep.nci.nih.gov/CTC/CTC.aspx.

NATOLI, C. et al. A phase II study of dose-dense epirubicin plus cyclophosphamide followed by docetaxel plus capecitabine and pegfilgrastim support as preoperative therapy for patients with stage II, IIIA breast cancer. Annals of Oncology. v.18, p. 1015-1020, 2007. 
PEREZ-MESA, C. M. Gross and microscopic pathology. In: DONEGAN, W.L.; SPRATT, J.S. Cancer of the breast. $4^{\circ}$ ed. EUA, W.B. Saunders Company, p. 240-278, 1995.

PESSOA, E.C. et al. Avaliação da resposta à quimioterapia primária em amostra de mulheres brasileiras com tumores de mama localmente avançados. Revista Brasileira de Ginecologia e Obstetrícia. v. 29, n. 1, p. 18-26, 2007.

PICCART, M. J. et al. Phase III trial comparing two dose levels os epirubicin combined with cyclophosphamide, cyclophosphamide, methotrexate, and fluoracil in nodepositive breast cancer. Journal of Clinical Oncology, v. 19, n. 12 (June 15), 2001: p 3103-3110.

PIEDBOIS, P. et al. Dose-dense adjuvant chemotherapy in node-positive breast cancer: docetaxel followed by epirubicin/ciclophosphamide (T/EC), the reverse sequence (EC/T), every 2 weeks, versus docetaxel, epirubicin and cyclophosphamide (TEC) evey 3 weeks. AERO B03 randomized phase II study. Annals of Oncology, v.18, p. 52-57, 2007.

PINOTTI, J.A.; BRENELLI, H. B. Anatomia cirúrgica da mama. In: PINOTTI, J.A., Compêndio de mastologia. São Paulo, Ed. Manole, p. 01-10, 1991.

PINOTTI, J.A. Câncer de mama: tratamento conservador. In: HALBE, H.W. Tratado de ginecologia. $3^{\text {a }}$ ed. São Paulo: Roca, p.2055-2064. 2000.

PEINTINGER, F. et al. The safety of breast-conserving surgery in patients who achieve a complete pathologic response after neoadjuvante chemotherapy. Cancer. v. 107, n. 16, p.1248-1254, 2006.

POGSON, C.J.; ADWANI, A.; EBBS, S.R. Seroma following breast cancer surgery. EJSO. n. 29, p. 711-717, 2003.

POLIT,D.F.; BECK,C.T.; HUNGLER,B.P. Fundamentos de pesquisa em enfermagem: métodos, avaliação e utilização. $5^{\text {a }}$ edição. Artmed, 2004. 
RAMASWAMY, B. et al. Phase II trial of neoadjuvante chemotherapy with docetaxel followed by epirubicin in stage II/III breast cancer. Breast Cancer Research and Treatment, v. 93, p. 67-74, 2005.

RICCI, et al. Influência da preservação de pele em cirurgia conservadora por câncer de mama sobre as taxas de recorrência local e a distância. Revista Brasileira de Ginecologia e Obstetrícia, v. 25, n. 6, p. 403-409, 2003.

RILKE, F.; DI PALMA, S. Pathology. In: BONADONNA, G.; HORTOBAGYI, G.N.; GIANNI, A.M. Textbook of breast cancer- a clinical guide to therapy. Martin Dunitz, p. 17-33, 1998.

RASTOGI, P. et al. Preoperative chemotherapy: updates of National Surgical Adjuvant Breast and Bowel Projects Protocols B-18 and B-27. Journal of Clinical Oncology, v.26, n. 5, p. 778-785, 2008.

RIVERA, E. et al. First-cycle absolute neutrophil count can be used to improve chemotherapy-dose delivery and reduce the risk of febrile neutropenia in patients receiving adjuvant therapy: a validation study. Breast Cancer Research, v.5, n. 5, p.114-120, 2003.

RIVOIRE, W.A. et al. Biologia molecular do câncer cervical. Revista Brasileira de Saúde Materno Infantil. v. 6, n. 4, p. 447-451, 2006.

ROCHÉ, H. et al. Sequential adjuvant epirubicin-based and docetaxel chemotherapy for node positive breast cancer patients: the FNCLCC PACS 01 Trial. Journal of Clinical Oncology, v. 24, n. 36, p. 5664-5671, 2006.

SAVVIDES, P. et al. Development and validation of a patient-specific predictive instrument for the need for dose reduction in chemotherapy for breast cancer: a potential decision aid for the use of myeloid growth factors. Support Care Cancer, v. 11, p. 313-320, 2003.

SCHAFER, S.L. Noções gerais de quimioterapia. In: Manual de enfermagem oncológica. São Paulo: Fundação Oncocentro de São Paulo, p. 11-22.1996. 
SCHULMEISTER, L. Extravasation management. Seminars in Oncology Nursing, v.23, n. 3, p. 184-190, 2007.

SHAPIRO, C.L.; RECHT, A. Drug Therapy: side effects of adjuvant treatment of breast cancer. Breast Cancer Research and Treatment, v.62, n. 2, p. 141-150, 2000.

SIPSAS, N.V.; BODEY, G.P.; KONTOYIANNIS, D.P. Perspectives for the management of frebrile neutropenic patient with cancer in $21^{\text {st }}$ century. Cancer, v.103, p. 1103-1113, 2005.

SOUZA, A.Z.; AGUIAR, L.F.; HEGG, R. Câncer da mama: tratamento radical e prognóstico. In: HALBE, H.W. Tratado de ginecologia. $3^{\mathrm{a}}$ ed. São Paulo: Roca, p. 2065-2067, 2000.

SOUZA, I.V.; SHIOZAWA, M.B.; BRUSA, M.G.S. Patologia do câncer ginecológico. In: SILVEIRA, L.A. (Organizador). Câncer ginecológico: diagnóstico e tratamento. $1^{\mathrm{a}}$ ed. Florianópolis: Editora da UFSC, p.71-120, 2005.

STEGER, G.G. et al. Pathologic complete response with six compared with three cycles of neoadjuvante epirubicin plus docetaxel and granulocyte colony-stimulating factor in operable breast cancer: results of ABCSG-14. Journal of Clinical Oncology, v. 25, n. 15, p. 2012-2018, 2007.

TCHEN, N. et al. Cognitive function, fatigue, and menopausal symptoms in women receiving adjuvant chemotherapy for breast cancer. Journal of Clinical Oncology, v. 21, n. 22, p. 4175-4183, 2001.

TESSARO, S.; BREZOLIN, R. Epidemiologia do câncer de mama. In: BOFF, A., WISINTAINER, F. Mastologia Moderna: abordagem multidisciplinar. $1^{\mathrm{a}}$ ed. Caxias do Sul: Editora Mesa Redonda, p., 2006.

TFAYLI, A. et al. Activity of combination chemotherapy, docetaxel and epirrubicin as neoadjuvant therapy for women with breast cancer. Anticancer Res. v. 26(6C), p. 4911-4916, 2006. 
THULER, L.C.S.; MENDONÇA, G.A. Estadiamento inicial dos casos de câncer de mama e colo do útero em mulheres brasileiras. Revista Brasileira de Ginecologia e Obstetrícia, v. 27, n. 11, p. 656-660, 2005.

TIEZZI, D.G. Cirurgia conservadora no câncer de mama. Revista Brasileira de Ginecologia e Obstetrícia, v. 25, n. 6, p. 428-434, 2007.

TOLEDANO, A. et al. Phase III Trial of concurrent or sequential adjuvant chemoradiotherapy after conservative surgery for early -stage breast cancer: final results of the ARCOEIN trial. Journal of Clinical Oncology, v. 25, n. 4, p. 405-410, 2007.

TRUDEAU, M; SINCLAIR, S. E.; CLEMONS, M. Breast Cancer Disease Site Group. Neoadjuvant taxanes in the treatment of non-metastatic breast cancer: a systematic review. Cancer Treatment Rev. v. 31, n. 4, p. 283-302, 2005.

VELIKOVA, G.; STARK, D.; SELBY, P. Quality of life instruments in oncology. European Journal of Cancer, v. 35, n. 11, p. 1571-1580, 1999.

WAGNER, L.I. et al. Measuring health-related quality of life and neutropenia-specific concerns among older adults undergoing chemotherapy: validation of the Functional Assessment of Cancer Therapy-Neutropenia (FACT-N). Support Care Cancer, v.16,p. 47-56, 2008. 


\section{ANEXO A}

\section{TMN Classificação Clínica}

\begin{tabular}{ll}
\hline Classificação & \\
\hline Tx & Tumor primário não pode ser avaliado \\
T0 & Não há evidencia de tumor primário \\
Tis & Carcimona in situ intraductal ou lobular, ou Doença de Paget \\
T1 & Tumor de 2 cm ou menos em sua maior dimensão \\
T1 mic & Microinvasão de $0,1 \mathrm{~cm}$ ou menos em sua maior dimensão \\
T1a & Tumor de até $0,5 \mathrm{~cm}$ \\
T1b & Tumor de 0,6 a 1,0 cm \\
T1c & Tumor de 1,1 a 2,0 cm \\
T2 & Tumor com mais de 2 cm e menos de 5 cm na sua maior dimensão \\
T3 & Tumor maior do que 5 cm \\
T4 & Tumor de qualquer dimensão, com extensão direta à parede torácica \\
T4a & Extensão à parede torácica \\
T4b & Edema ou ulceração da pele mamária, ou nódulos satélites cutâneos \\
T4c & T4a+ T4b \\
T4d & Carcinoma inflamatório \\
Nx & Não é possível avaliar os linfonodos regionais \\
N0 & Ausência de metástase em linfonodos regionais \\
N1 & Metástases em linfonodo(s) axilar(es) homolaterais móveis \\
N2 & Metástases em linfonodo(s) axilar(es) homolaterais fixos ou \\
& linfonodos de cadeia mamária interna clinicamente suspeitos \\
N2a & Metástases em linfonodo(s) axilar(es) homolaterais fixos ou outras \\
& estruturas \\
N2b & Metástases em linfonodo de cadeia mamária interna \\
N3 & Metástases em linfonodo(s) supraclevicular(es) com ou sem \\
& Penvolvimento de linfonodo(s) axilar(es) \\
N3a & Metástases em linfonodo(s) infraclavicular(es) \\
N3b & Metástases em linfonodo de cadeia mamária interna e linfonodo(s) \\
& axilar(es) \\
N3c & Metástase à distância \\
M0 & \\
M1 &
\end{tabular}

Fonte: INCA, 2004. 
ANEXO B

Grupamento por Estádios

\begin{tabular}{|cccc|}
\hline Estádio 0 & Tis & N0 & M0 \\
\hline Estádio I & T1 & N0 & M0 \\
Estádio IIa & T0 & N1 & M0 \\
& T1 & N1 & M0 \\
& T2 & N0 & M0 \\
Estádio IIb & T2 & N1 & M0 \\
& T3 & N2 & M0 \\
Estádio IIIa & T0 & N2 & M0 \\
& T2 & N2 & M0 \\
Estádio IIIb & T3 & Qualquer N & M0 \\
& T4 & N3 & M0 \\
Estádio IV & Qualquer T & Qualquer N & M1 \\
\hline
\end{tabular}

Fonte: INCA, 2004. 


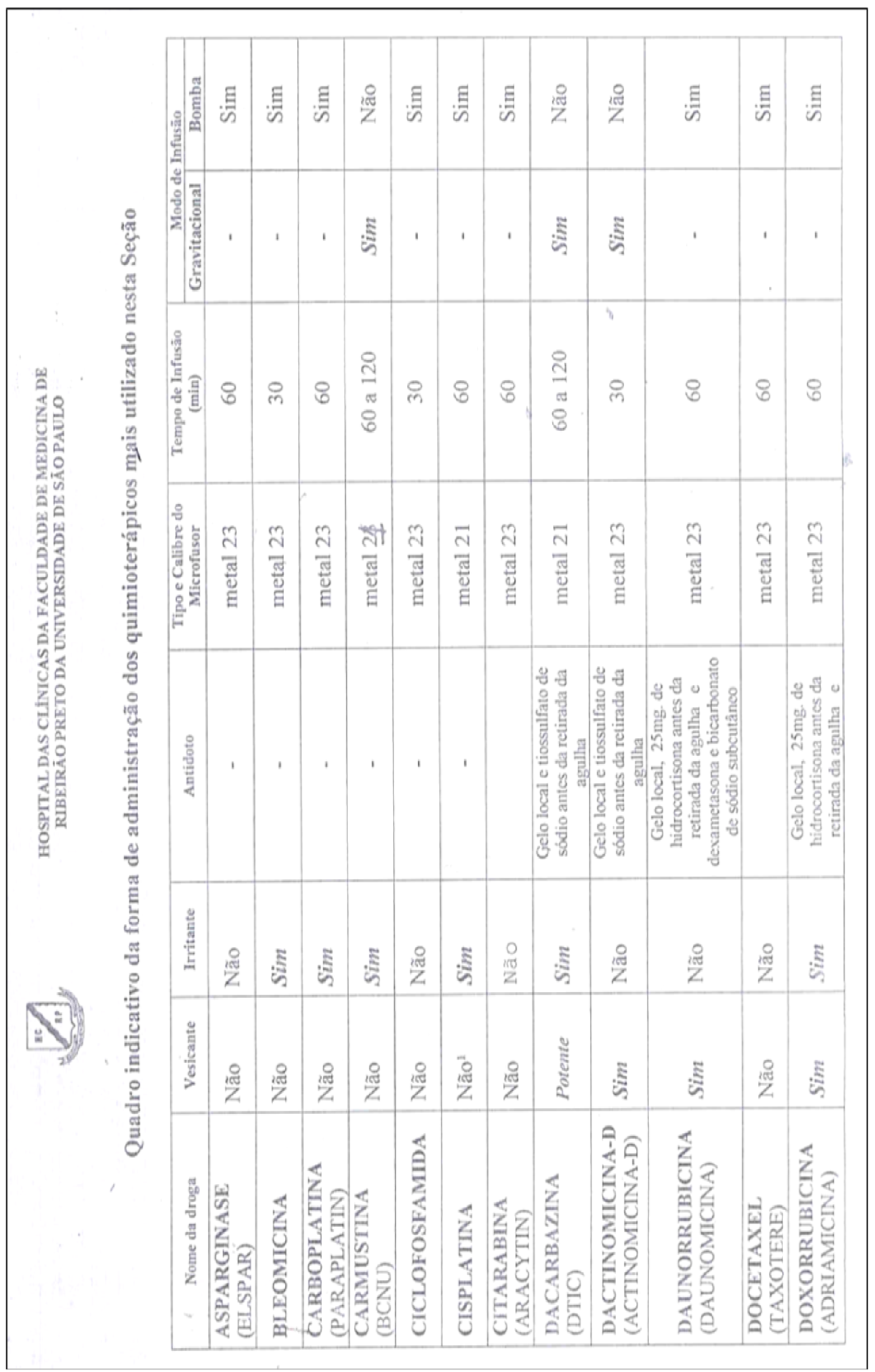




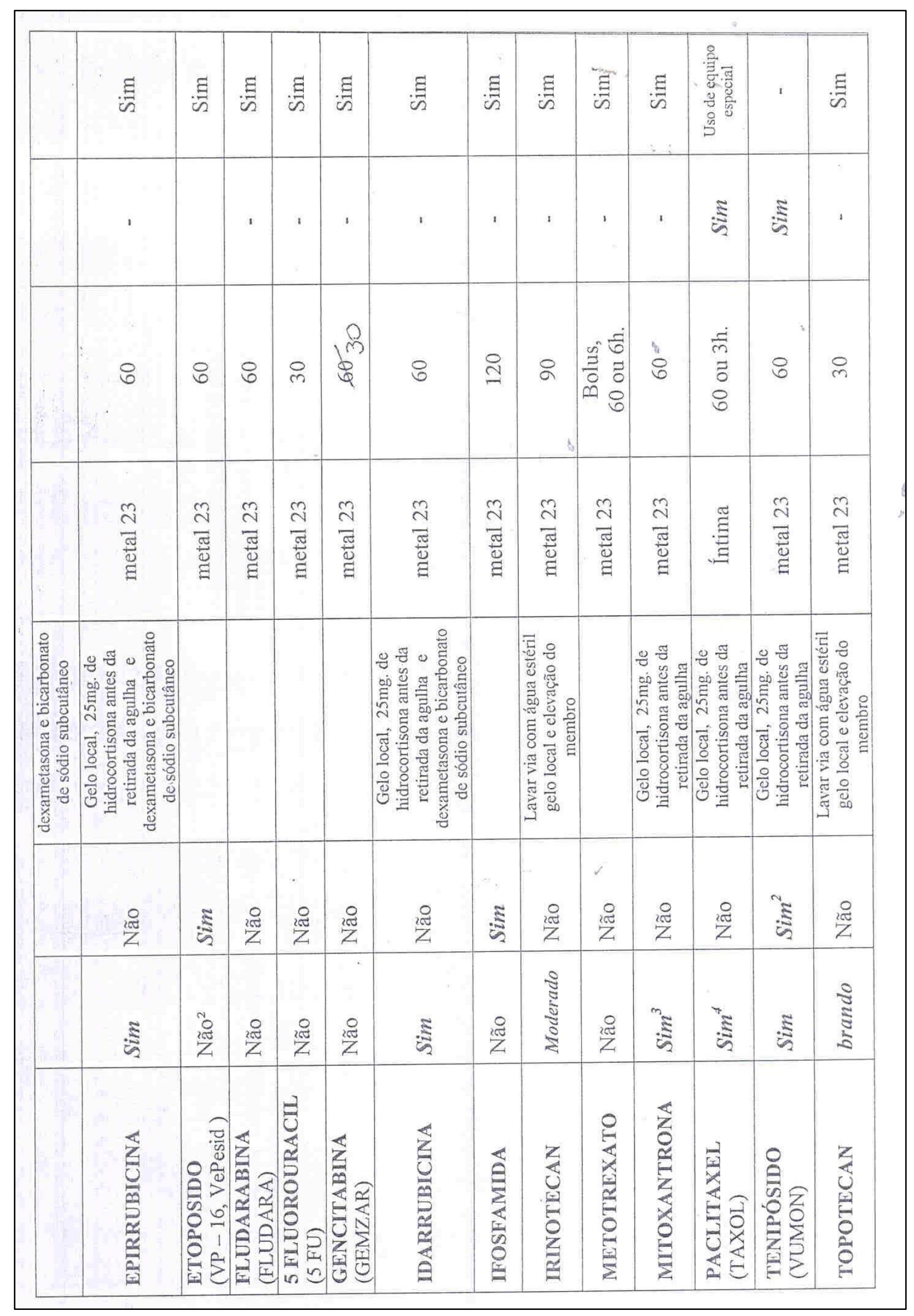




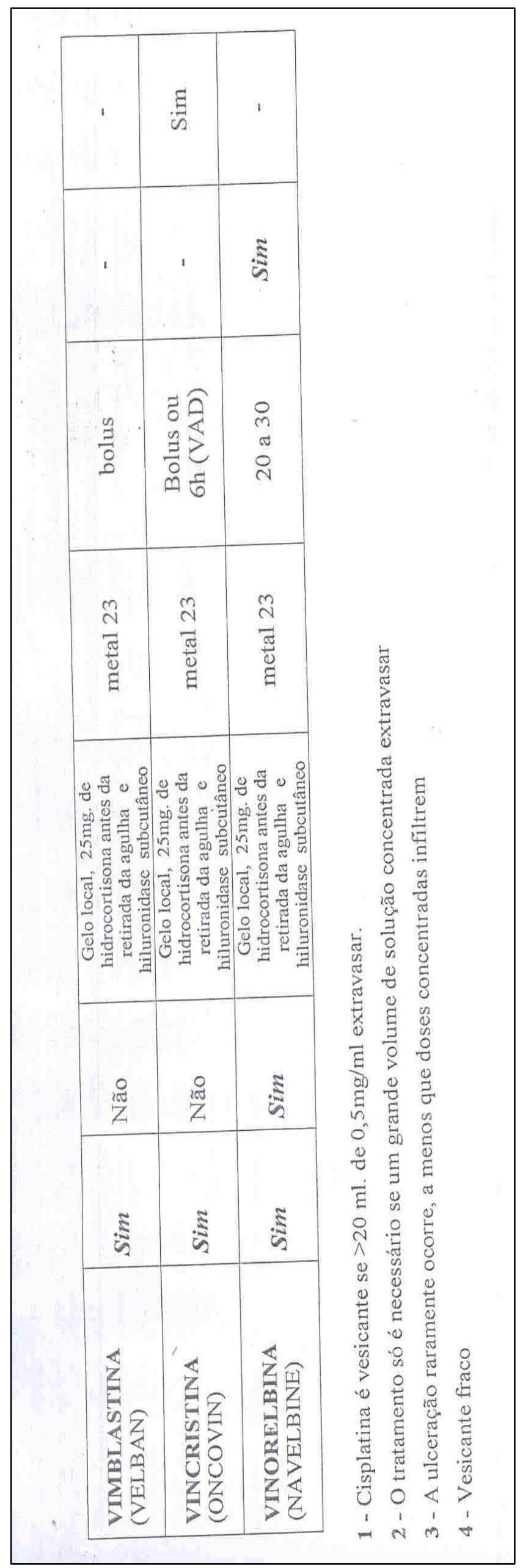


ANEXO D

HOSPITAL DAS CLINICAS DA FACULDADE DE MEDICINA DE RIBEIR 10 PRETO DA UNIVERSIDADE DE SAO PAULO

wwwherp.fmrp.usp.br

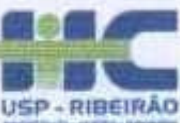

Ribeirão Preto, 12 de setembro de 2007

Oficio $n^{\circ} 3149 / 2007$

CEP/EGS

Prezada Senhora,

O trabalho intitulado "TOXICIDADES EM MULHERES COM CÂNCER DE MAMA SUBMETIDAS AO TRATAMENTO QUIMIOTERÁPICO", foi analisado pelo Comitê de Ética em Pesquisa, em sua $254^{\text {" }}$ Reuniâo Ordinária realizada em 10/09/2007, e enquadrado na categoria: APROVADO, de acordo com o Processo HCRP n ${ }^{\circ} 8602 / 2007$.

Lembramos que devem ser encaminhados a este CEP relatórios semestrais e relatório final da pesquisa.

Atenciosamente.

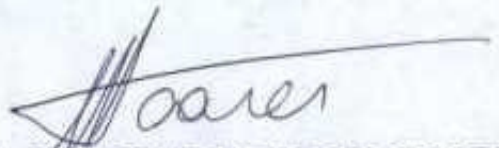

PROF. DR. EDSON GARCIA SOARES Membro Titular do Comitê de Ética em Pesquisa do HCRP e da FMRP-USP

llustrissima Senhora

THAIS DE OLIVEIRA GOZZO

PROF", DRa. ANA MARIA DE ALMEIDA(Orientadora)

Escola de Enfermagem de Ribeirão Preto-USP

Comite de Etica em Pesquisa HC e FMRP-USP. Campus Universitarlo FWA-00002733; IRP-00002186

Fone (16) 3602-2228 - E-mail : cep(ahcrp finrp. usp br

Monte Alegre 14048-900 Ribeirdo Preto SP 


\section{ANEXO E}

Tabela: Graus de toxicidade hematológica e não-hematológica para o tratamento quimioterápico. Fonte: Bonassa (2005), National Cancer Institute (1999).

\begin{tabular}{lllll}
\hline Toxicidade & Grau 1 & Grau 2 & Grau 3 & Grau 4
\end{tabular}

\begin{tabular}{|c|c|c|c|c|}
\hline Hematológi & & & & \\
\hline Hemoglobina & 10,0 - LIN & $8,0-9,9$ & $6,5-7,9$ & $<6,5 \mathrm{~g} / \mathrm{dl}$ \\
\hline Plaquetas & 75.000 - LIN & $50.000-74.000$ & $25.000-49.000$ & $<25.000 / \mu \mathrm{L}$ \\
\hline Leucócitos & 3.000 - LIN & $2.000-3.000$ & $1.000-2.000$ & $<1.000 / \mu \mathrm{L}$ \\
\hline Neutrófilos & 1.500 - LIN & $1.000-1.500$ & $500-1.000$ & $<500 / \mu \mathrm{L}$ \\
\hline Linfócitos & $1.500-2.000$ & $1.000-1.500$ & $500-1.000$ & $<500 / \mu \mathrm{L}$ \\
\hline
\end{tabular}

\begin{tabular}{l|c|c|c|c} 
Constitucional & - & $10-19,9 \%$ & $>20 \%$ peso basal & - \\
\hline Perda de peso & Leve & $\begin{array}{c}\text { Moderada, causa } \\
\text { alguma dificuldade } \\
\text { no desempenho de } \\
\text { atividades diárias }\end{array}$ & $\begin{array}{c}\text { Severa, causa } \\
\text { dificuldade no } \\
\text { desempenho de } \\
\text { atividades diárias }\end{array}$ & $\begin{array}{c}\text { Incapacitante, } \\
\text { impede o } \\
\text { desempenho de } \\
\text { atividades diárias }\end{array}$ \\
\hline $\begin{array}{l}\text { Febre sem } \\
\text { neutropenia }\end{array}$ & Febre $\leq 38^{\circ} \mathrm{C}$ & $39,1^{\circ}$ a $40^{\circ} \mathrm{C}$ & $>40^{\circ} \mathrm{C}$ por $\leq 24 \mathrm{~h}$ & $>40^{\circ} \mathrm{C}$ por $>24 \mathrm{~h}$ \\
\hline Neutropenia febril & $38^{\circ}$ a $39^{\circ} \mathrm{C}$ & - & Presente & Com risco de vida \\
\hline Reações alérgicas & $\begin{array}{c}\text { Rush ou rubor } \\
\text { transitório }\end{array}$ & $\begin{array}{c}\text { Rush, urticária, } \\
\text { dispnéia, febre } \geq \\
38^{\circ} \mathrm{C}\end{array}$ & $\begin{array}{c}\text { Broncoespasmo- } \\
\text { requer medicação } \\
\text { parenteral }\end{array}$ & Anafilaxia \\
\hline
\end{tabular}

\begin{tabular}{|c|c|c|c|c|}
\hline \multicolumn{5}{|c|}{ Gastrointestinal } \\
\hline Náusea & $\begin{array}{l}\text { Ingestão oral } \\
\text { reduzida, porém } \\
\text { razoável }\end{array}$ & $\begin{array}{c}\text { Ingestão } \\
\text { significativamente } \\
\text { reduzida, porém } \\
\text { pode comer }\end{array}$ & $\begin{array}{l}\text { Necessidade de } \\
\text { hidratação ou } \\
\text { alimentação } \\
\text { parenteral } \geq 24 \text { h }\end{array}$ & Com risco de vida \\
\hline Vômito & $\begin{array}{c}1 \text { episódio em } 24 \\
\mathrm{~h}\end{array}$ & $\begin{array}{l}\text { 2- } 5 \text { episódios em } \\
24 \mathrm{~h}, \text { hidratação } \\
\text { parenteral }<24 \mathrm{~h}\end{array}$ & $\begin{array}{c}6 \text { ou mais } \\
\text { episódios em } 24 \mathrm{~h} \text {, } \\
\text { hidratação } \\
\text { parenteral } \geq 24 \mathrm{~h}\end{array}$ & Com risco de vida \\
\hline Estomatite & $\begin{array}{c}\text { Sintomas } \\
\text { mínimos que não } \\
\text { interferem com a } \\
\text { ingestão } \\
\text { alimentar }\end{array}$ & $\begin{array}{c}\text { Pode comer e } \\
\text { engolir dieta } \\
\text { modificada }\end{array}$ & $\begin{array}{l}\text { Não pode ingerir } \\
\text { alimentos e } \\
\text { líquidos por via } \\
\text { oral, sintomas } \\
\text { interferem no } \\
\text { desempenho de } \\
\text { atividades diárias }\end{array}$ & Com risco de vida \\
\hline Diarréia & $\begin{array}{c}\text { Acréscimo de } 3 \\
\text { episódios/dia ao } \\
\text { basal }\end{array}$ & $\begin{array}{c}\text { Acréscimo de } 4 \text { a } \\
6 \text { episódios/dia ao } \\
\text { basal, hidratação } \\
\text { parenteral }<24 \mathrm{~h} \text {, } \\
\text { sem interferência } \\
\text { nas atividades } \\
\text { diárias }\end{array}$ & $\begin{array}{c}\text { Acréscimo de } 7 \\
\text { episódios/dia ao } \\
\text { basal ou } \\
\text { incontinência, } \\
\text { hospitalização, } \\
\text { com interferência } \\
\text { nas atividades } \\
\text { diárias } \\
\end{array}$ & Com risco de vida \\
\hline
\end{tabular}


Continuação Tabela.

\begin{tabular}{|c|c|c|c|c|}
\hline Toxicidade & Grau 1 & Grau 2 & Grau 3 & Grau 4 \\
\hline \multicolumn{5}{|l|}{ Dermatológica } \\
\hline Alopecia & $\begin{array}{c}\text { Mínima- perda }< \\
25 \%\end{array}$ & $\begin{array}{l}\text { Moderada- perda } \\
\text { de } 25 \% \text { a } 50 \%\end{array}$ & $\begin{array}{c}\text { Severa-perda }> \\
50 \% \\
\end{array}$ & $\mathrm{X}$ \\
\hline $\begin{array}{l}\text { Reação no local da } \\
\text { punção }\end{array}$ & $\begin{array}{l}\text { Dor, prurido e } \\
\text { eritema }\end{array}$ & $\begin{array}{c}\text { Dor ou edema com } \\
\text { inflamação ou } \\
\text { flebite }\end{array}$ & $\begin{array}{c}\text { Ulceração ou } \\
\text { necrose que requer } \\
\text { cirurgia }\end{array}$ & $\mathrm{X}$ \\
\hline Síndrome mão e pé & $\begin{array}{c}\text { Alterações } \\
\text { cutâneas mínimas } \\
\text { ou dermatite sem } \\
\text { dor }\end{array}$ & $\begin{array}{c}\text { Alterações } \\
\text { cutâneas } \\
\text { moderadas ou dor } \\
\text { sem interferência } \\
\text { nas atividades } \\
\text { diárias } \\
\end{array}$ & $\begin{array}{c}\text { Ulceração ou dor } \\
\text { com interferência } \\
\text { nas atividades } \\
\text { diárias }\end{array}$ & \\
\hline \multicolumn{5}{|l|}{ Hepática } \\
\hline Aspectos clínicos & $X$ & Icterícia & Asterixe & Coma hepático \\
\hline Bilirrubina & $\mathrm{LSN}-1,5 \times \mathrm{LSN}$ & $1,6-3,0 \times \mathrm{LSN}$ & $3,1-6,0 \times \mathrm{LSN}$ & $>6,0 \times \mathrm{LSN}$ \\
\hline Fosfatase alcalina & $\leq 2,5 \times \mathrm{LSN}$ & $2,6-5,0 \times \mathrm{LSN}$ & $5,1-20,0 \times \mathrm{LSN}$ & $>20,0 \times \mathrm{LSN}$ \\
\hline
\end{tabular}




\begin{tabular}{|c|c}
\multicolumn{2}{c}{ ANEXO F } \\
\hline HEMOGRAMA Valores normais & $\begin{array}{c}\text { Homem }=4.500 .000 \text { a } 5.500 .000 / \mathrm{mm}^{3} \\
\text { Mulher }=4.000 .000 \text { a } 5.000 .000 / \mathrm{mm}^{3}\end{array}$ \\
Hemácias & 4.000 a $11.000 / \mathrm{mm}^{3}$ \\
Leucócitos & Homem $=13,5$ a $17,5 \mathrm{~g} \%$ \\
Hemoglobina & Mulher $=12,0$ a $15,5 \mathrm{~g} \%$ \\
& \\
Contagem Específica & \\
Bastonetes & 3 a $5 \%$ \\
Eosinófilo & 1 a $3 \%$ \\
Basófilo & 0,0 a $0,75 \%$ \\
Linfócito & 25,0 a $33,0 \%$ \\
Monócitos & 3,0 a $7,0 \%$ \\
Segmentados & 54 a $62 \%$ \\
\hline
\end{tabular}

Fonte: Procedimentos técnicos dos Laboratórios do Hospital das Clínicas de Ribeirão Preto, 2006. 
ANEXO G

Cálculo da Superfície corporal

Uma linha reta de conexão entre os valores de pro (coluna à direita) e altura (coluna á esquerda) cruza a coluna central exatamente no ponto correspondentes ao valor da superfície corporal.

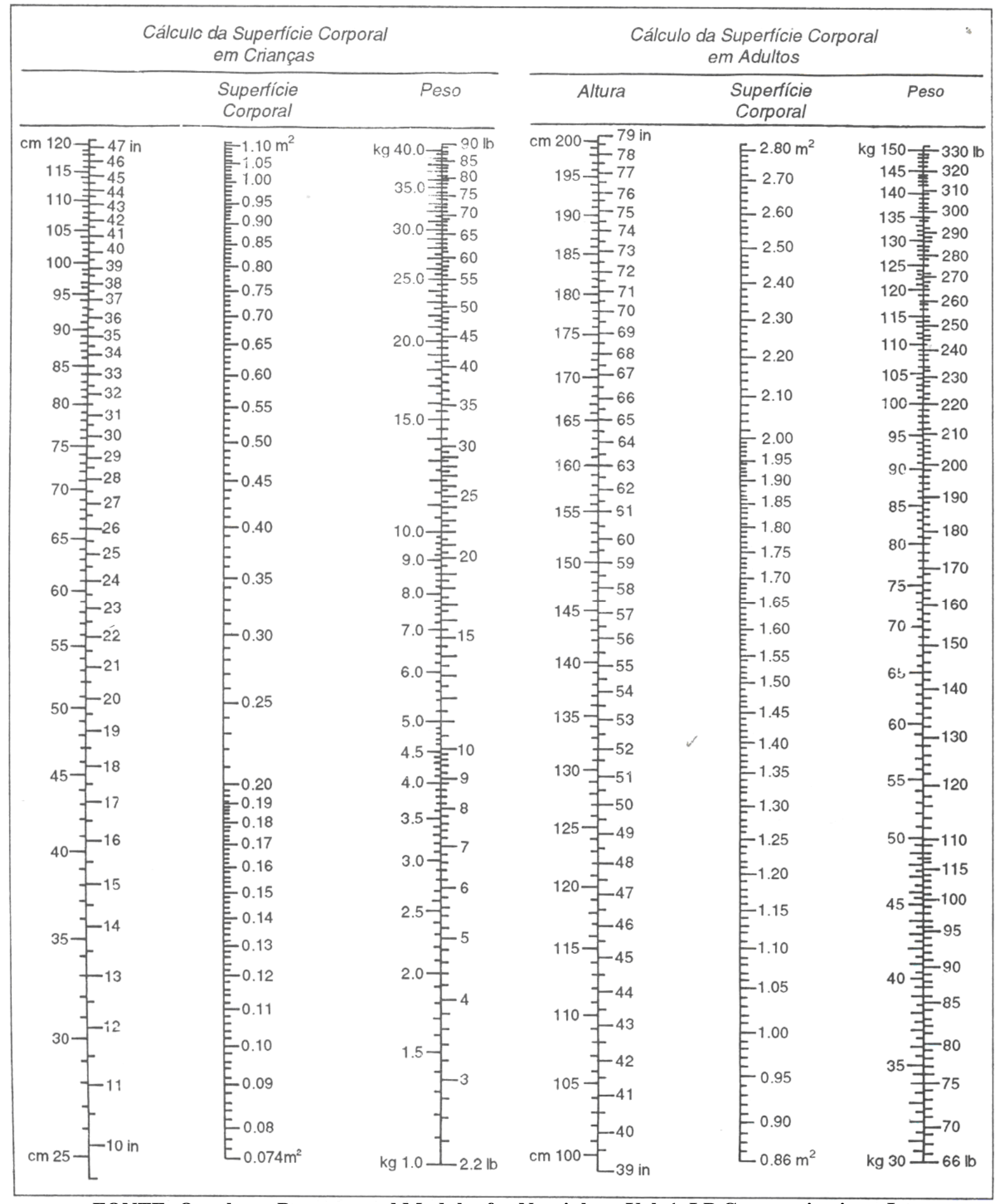

FONTE: Oncology: Programmed Modules for Nursinhg - Vol. 1. LP Communications. Inc. Pubishers, 1998. 


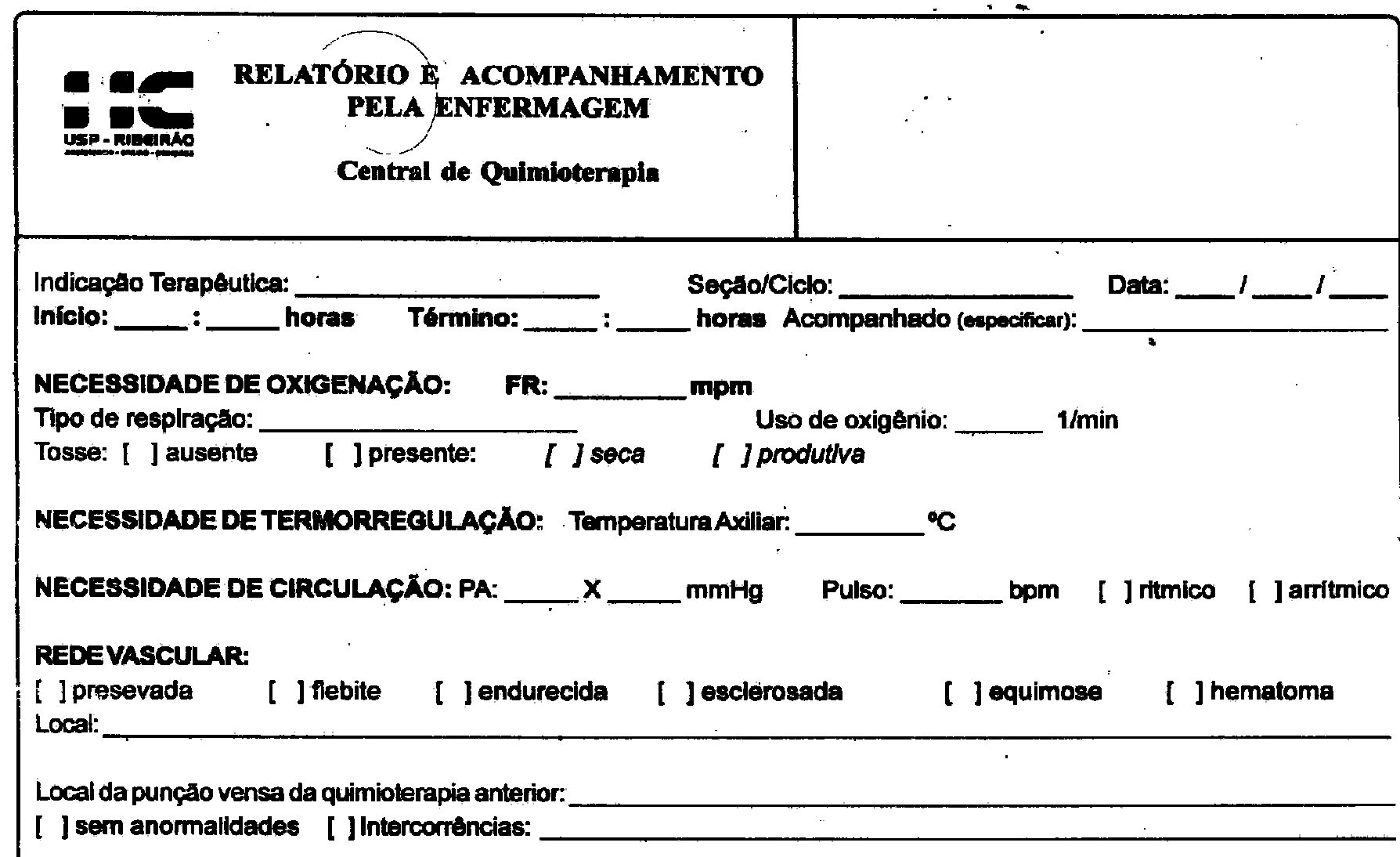

\section{ACESSO VENOSO:}

[ ] periférico, [ ] reservatório do C.V.C. (esainalar no dosonho com caneta tinta axul)

[ ] Material utilizado (especificar o calibre): [ ] microfusor n1

[] microfusor com agulha hubber $\mathrm{n1}$ _ i ] cateter teflon $\mathrm{n}^{\circ}$

[ ] cateter intima n1

Antissepsia local: [ ] álcool 70\% [ ] P.V.P.I. alcóolico Intercorrências: [ ] nấo [ ] Sim

Se houve extravazamento (assinalar no desenho com caneta tinta vermelha)

Relato da Intercorréncia, da assistencia e da orientaço prestada:

NECESSIDADE DE PERCEPCAOO SENSORIAL:

[ J Consciento

Orientado: [ ] tempo [ ] espaço [ ] pessoa

Dor: [ ] relato verbal

Local:

Intensidade: 0

Observaça:

\section{NECESSIDADE DEINTECRIDADE TECIDUAL:}

Caracteristicas da pele: [ ] Integra

I . ] corada_+13+ [ ] letérica _ _ $+13+$
[ ] cianótica_ com lesoes Tamanho $+13+$
Local:

Observaça:

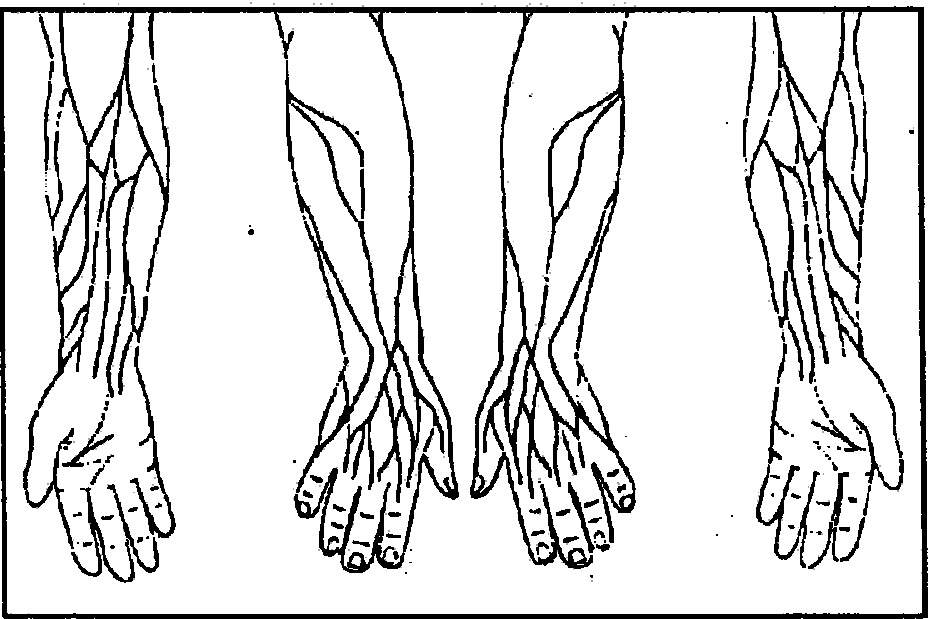


NECESSIDADE DE MOBILIDADE: [ ] Preservada [ ] Prejudicada

Grau de dependência: [ ] independente [ ] parcialmente dependente ${ }^{\cdots}$ [ [ ] totalmente dependente

MOBILIZAÇÃO:

[ ] Instabilidade postutal [ ] capacidade limitada para algumas atividades [ ] alteração de mancha

[ ] movimentos não coordenados [ ] dificuldade para virar-se [ ] dificuldade para sentar-se

Observações:

\section{NECESSIDADE DE ALIMENTAÇÃO/HIDRATAÇÃO:}

\section{Apetite: [ ]preservado [ ] diminuido}

Alterações: [ ] náuseas [ ] vômitos [ ] azia

Via de alimentação:

Paladar: [ ] preservado [ ] ausente [ ] dor à deglutição [ ] disfagia Observações:

\section{TERAPÊUTICA MEDICAMENTOSA:}

Medicamentos e Quimioterápicos e vias de administração:

[ ] via oral:

[ ] sub-cutânea:

[ ] intra-muscular:
[ ]endovenoso: local da aplicação: local da aplicação:

\begin{tabular}{|c|c|c|c|}
\hline SOLUÇĂO INFUNDIDA & VOLUME & HORA INÍCIO & HORA TÉRMINO \\
\hline Solução fisiológica & $20 \mathrm{ml}$ & & $\ldots$ \\
\hline & & & \\
\hline & & & \\
\hline & & & \\
\hline & & & \\
\hline & & & \\
\hline - & & & \\
\hline & & & \\
\hline & & $\checkmark$ & \\
\hline & & & \\
\hline
\end{tabular}

HEPARINIZAÇÃO DO C.V.C.: $\mathrm{ml}(10 \mathrm{Ul} / \mathrm{ml})$ $\mathrm{ml}(250 \mathrm{Ul} / \mathrm{ml})$

[. ] Uso de medicamento tópico, hirudoid, no local da punção Orientaçōes de Enfermagem realizadas:

[ ] ] retorno para quimiotekapia em

[ ] ] data da próxima heparinização do catater:

[ ] restrição alimentar [ ] necessidade de hidratação [ ] efeitos colaterais dos quimioterápicos

[ ] ] restrição à exposição solar [ ] higiene corporal, bucal, intima

[ ] prevenção de doenças sexualmente transmissiveis

Relato de procedimentos realizados e observaçōes do enfermeiro:

Enfermeiro: COREN: 


\section{APÊNDICE A \\ Instrumento de coleta de dados}

$\mathrm{N}^{\circ}$ de ordem:

Registro no hospital:

Nome: (iniciais)

Idade:

Peso: Kg Estatura: m Superfície corporal:

Co-morbidades: DM ( ) HAC ( ) Cardiopatia ( ) Anemia ( ) Outras ( )

( ) Pré-menopausa

( ) Menopausa há anos

Diagnóstico médico:

Data do diagnóstico:

Biópsia: Sim ( ) Não ( ) tipo:

Estádio da doença:

Esquema quimioterápico proposto: Epirrubicina $\mathrm{mg}$

Docetaxel $\mathrm{mg}$

Início da quimioterapia neoadjuvante:

1

Hemograma pré-quimioterapia:

$\mathrm{Hb}$ :

GB:

Linfócitos:

Gv:

Neutrófilos:

Eosinófilos:

Plaquetas:

Basófilos:

Monócitos:

Atraso para iniciar novo ciclo? Sim ( ) Não ( ) Número de dias:

Ciclo II

Data_

Hemograma pré-ciclo II:

$\mathrm{Hb}$ :

GB:

Linfócitos:

Gv:

Neutrófilos:

Eosinófilos:

Plaquetas:

Basófilos:

Monócitos:

Outros efeitos colaterais relatados no prontuário:

Atraso para iniciar novo ciclo? Sim ( ) Não ( ) Número de dias:

Ciclo III

Data

Hemograma pré- ciclo III:

$\mathrm{Hb}$ :

GB:

Linfócitos:

Gv:

Neutrófilos:

Eosinófilos: 
Plaquetas:

Basófilos:

Monócitos:

Outros efeitos colaterais relatados no prontuário:

Atraso para iniciar novo ciclo? Sim ( ) Não ( ) Número de dias:

Ciclo IV Data__ /

Hemograma pré- ciclo IV

$\mathrm{Hb}$ :

GB:

Linfócitos:

Gv:

Neutrófilos:

Eosinófilos:

Plaquetas:

Basófilos:

Monócitos:

Outros efeitos colaterais relatados no prontuário:

Atraso para iniciar novo ciclo? Sim ( ) Não ( ) Número de dias:

Ciclo V

Data

Hemograma pré- ciclo V:

$\mathrm{Hb}$ :

GB:

Linfócitos:

Gv:

Neutrófilos:

Eosinófilos:

Plaquetas:

Basófilos:

Monócitos:

Outros efeitos colaterais relatados no prontuário

Paciente tem cateter totalmente implantado? ( ) sim

( )não

Existe relato de extravasamento de quimioterapia relatado no prontuário? ( ) sim ( ) não

Se sim Qual :

Conduta:

Conseqüências:

Houve redução da dose em função de efeitos adversos?

Término da quimioterapia:

$1+1$

Hemograma pré-operatório:

$\mathrm{Hb}$ :

GB:

Linfócitos:

Gv:

Neutrófilos:

Eosinófilos:

Plaquetas:

Basófilos:

Monócitos:

Outros efeitos colaterais relatados no prontuário 
Intervalo entre quimioterapia neoadjuvante e cirurgia:

Cirurgia: Sim ( ) Não ( ) Qual :

Quando foi realizada?

Houve complicações da cirurgia? Sim ( ) Não ( ) Qual :

Intervalo entre a cirurgia e a Qtx adjuvante:

Esquema quimioterápico proposto: Epirrubicina $\mathrm{mg}$

Ciclofosfamida $\mathrm{mg}$

Houve atraso no início da quimioterapia adjuvante por complicações cirúrgicas?

Sim ( ) Não ( ) Quanto tempo:

Início da quimioterapia adjuvante:

Hemograma pré-quimioterapia:

1

$\mathrm{Hb}$ :

GB:

Gv:

Neutrófilos:

Linfócitos:

Plaquetas:

Basófilos:

Eosinófilos:

Ciclo II

Data

Hemograma pré-ciclo II:

$\mathrm{Hb}$ :

GB:

Linfócitos:

Gv:

Neutrófilos:

Eosinófilos:

Plaquetas:

Basófilos:

Monócitos:

Outros efeitos colaterais relatados no prontuário

Atraso para iniciar novo ciclo? Sim ( ) Não ( ) Número de dias:

Ciclo III

Data

Hemograma pré- ciclo III:

$\mathrm{Hb}$ :

GB:

Linfócitos:

Gv:

Neutrófilos:

Eosinófilos:

Plaquetas:

Basófilos:

Monócitos:

Outros efeitos colaterais relatados no prontuário

Atraso para iniciar novo ciclo? Sim ( ) Não ( ) Número de dias: 
Ciclo IV

Data

Hemograma pré- ciclo IV:

$\mathrm{Hb}$ :

GB:

Linfócitos:

Gv:

Neutrófilos:

Eosinófilos:

Plaquetas:

Basófilos:

Monócitos:

Outros efeitos colaterais relatados no prontuário

Atraso para iniciar novo ciclo? Sim ( ) Não ( ) Número de dias:

Ciclo V

Data

Hemograma pré- ciclo V:

$\mathrm{Hb}$ :

GB:

Linfócitos:

Gv:

Neutrófilos:

Eosinófilos:

Plaquetas:

Basófilos:

Monócitos:

Outros efeitos colaterais relatados no prontuário

Atraso para iniciar novo ciclo? Sim ( ) Não ( ) Número de dias:

Ciclo VI

Data

Hemograma pós-ciclo V:

$\mathrm{Hb}$ :

GB:

Linfócitos:

Gv:

Neutrófilos:

Eosinófilos:

Plaquetas:

Basófilos:

Monócitos:

Outros efeitos colaterais relatados no prontuário

Hemograma após ultimo ciclo de quimioterapia:

$\mathrm{Hb}$ :

GB:

Linfócitos:

Gv:

Neutrófilos:

Eosinófilos:

Plaquetas:

Basófilos:

Monócitos:

Outros efeitos colaterais relatados no prontuário

Foi implantado cateter totalmente implantado? ( ) sim （ )não

Existe relato de extravasamento de quimioterapia relatado no prontuário? ( ) sim ( ) não Se sim Qual:

Conduta: 
Conseqüências:

Houve redução da dose em função de efeitos adversos?

Término da quimioterapia: 1 


\section{APÊNDICE B}

Houve internação durante o tratamento? : neoadjuvante ( ) adjuvante ( )

Internação durante o tratamento quimioterápico? ( ) sim ( ) não Tempo de Internação:

Motivo da internação: ( ) neutropenia febril ( ) diarréia/vômito

( ) outros

Exames colhidos durante a internação:

Hemograma:

$\mathrm{Hb}$ :

GB:

Linfócitos:

Gv:

Neutrófilos:

Eosinófilos:

Plaquetas:

Basófilos:

Monócitos:

Hemocultura: amostras

Resultado:

Urocultura: amostras

Resultado:

Raio X de tórax: sim ( ) não ( ) Resulatdo:

Infecção: $\operatorname{sim}($ ) não ( ) Sítio:

Uso de filgrastima: sim ( ) não ( ) Número de doses:

Antibióticos usados:

Transfusão de hemoderivados: sim ( ) não ( ) O qual:

Medicação prescrita para alta hospitalar: 